THYAGO ROBERTO RODRIGUES

\title{
ESTUDO DE ALCALOIDES HARMÂNICOS EM SEMENTES DE Passiflora edulis Sims f. flavicarpa Degener (MARACUJÁ AZEDO) POR SBSE/CLAE-Flu dual
}

Dissertação apresentada ao Instituto de Química de São Carlos da Universidade de São Paulo como parte dos requisitos para obtenção do título de mestre em ciências.

Área de concentração: Química Analítica

Orientadora:

Prof $^{\mathrm{a}} \mathrm{Dr}^{\mathrm{a}}$ Janete Harumi Yariwake

\section{Exemplar revisado}

O exemplar original encontra-se em acervo reservado na Biblioteca do IQSC-USP 
Dedico este trabalho ao meu pai e à minha mãe, não somente pelo apoio $e$ incentivos oferecidos durante esta etapa, mas por todas as conquistas da minha vida. 


\section{AGRADECIMENTOS}

A Deus, pela minha vida, por todas as oportunidades e pelas pessoas que colocou em meu caminho;

À Prof $^{\mathrm{a}}$ Dr ${ }^{\mathrm{a}}$ Janete Harumi Yariwake, pela credibilidade, ensinamentos, direcionamento e eficiente orientação em todas as etapas deste trabalho;

Aos meus familiares, em especial meu pai Sidney Gilberto Rodrigues e minha mãe Vera Lúcia Rodrigues, que mesmo distantes nunca deixaram de acreditar em minhas escolhas, sempre estiveram presentes e solícitos, vibraram as minhas alegrias e temeram as minhas tristezas;

Ao meu grande amigo e companheiro em todas as horas, Msc Guilherme Araujo Vuitik, pelas histórias divididas e pelo apoio em tempos mais difíceis; e aos seus pais e irmãos por me acolher como parte da família;

Ao meu amigo Bene, pela amizade conquistada e pelas longas horas de convívio e troca de experiências, pelos ensinamentos práticos no laboratório e pelo acompanhamento em todas as etapas deste trabalho;

Aos queridos(as) amigos(as) de São Carlos, conquistados durante esses anos do mestrado;

Aos demais colegas do Instituto de Química de São Carlos e do Grupo de Análise Fitoquímica, em especial a Dra Cintia Pereira, pela atenção e pela inspiração para o desenvolvimento desta pesquisa;

À FAPESP pelo auxilio financeiro (Processo 2010/05711-4).

À todos aqueles que de uma forma ou de outra, contribuíram para a realização deste trabalho. 
..."as árvores produzirão novos frutos de mês a mês, porque sua água provém do santuário; seus frutos servirão de alimento e suas folhas de remédio "...

Apocalipse de São João (Apocalipse 22:2) 


\section{RESUMO}

RODRIGUES, T. R. Estudo de alcaloides harmânicos em sementes de Passiflora edulis Sims f. flavicarpa Degener (maracujá azedo) por SBSE/CLAE-Flu dual. 2013. Dissertação (Mestrado) Instituto de Química de São Carlos - Universidade de São Paulo, São Paulo, 2013.

Há muitos estudos sobre plantas medicinais brasileiras, porém a carência de pesquisas relacionadas à segurança alimentar de plantas brasileiras usadas como alimento ainda é consideravelmente grande. A maioria dos alcaloides são substâncias tóxicas que podem ser encontrados em uma grande variedade de plantas medicinais e alimentícias, inclusive em espécies de Passiflora chamadas popularmente no Brasil de "maracujá". As pesquisas sobre as diversas espécies de Passiflora, em grande parte estão relacionadas com as folhas e frutos e na maioria das vezes as sementes são consideradas como resíduo. As metodologias analíticas modernas para análises na área de alimentos, utilizando SBSE com fase extratora de PDMS, tem o objetivo de facilitar o preparo de amostras complexas e diminuir os resíduos orgânicos gerados na etapa de preparo da amostra. Para isso, este estudo teve como objetivo a análise de alcaloides harmânicos pelo método SBSE/CLAE-Flu dual, adaptado para a quantificação de harmana e de harmina em sementes de maracujá azedo. O método foi especifico e linear para os alcaloides estudados $\left(r^{2}=0,996\right.$ para harmana e $r^{2}=0,999$ para harmina). Os ensaios de repetibilidade $e$ de precisão intermediária confirmam a precisão do método. Os testes de recuperação (entre $92,34 \%$ a 105,90\% para a harmana e $83,61 \%$ a $117,76 \%$ para a harmina) indicam a exatidão do método. A amostra analisada continha $\left(3,094 \times 10^{-2} \pm 5,874 \times 10^{-5}\right) \mu \mathrm{g}$ de harmana por grama de sementes secas de maracujá azedo e $\left(8,108 \times 10^{-3} \pm 7,599 \times 10^{-4}\right) \mu \mathrm{g}$ de harmina por grama de sementes secas de maracujá azedo. A detecção por fluorescência foi um método sensível e seletivo para a detecção da harmana ( $L O D=30 \mathrm{ng} \mathrm{L}^{-1}$ e $\mathrm{LOQ}=200 \mathrm{ng} \mathrm{L}^{-1}$ ) e para a harmina $\left(\mathrm{LOD}=100 \mathrm{ng} \mathrm{L}^{-1}\right.$ e LOQ $\left.=400 \mathrm{ng} \mathrm{L}^{-1}\right)$. Conclui-se que o método SBSE/CLAE-Flu dual pode ser usado para a análise dos alcaloides harmânicos nas sementes de maracujá azedo.

Palavras-chave: Passiflora edulis Sims f. flavicarpa Degener, alcaloides harmânicos, maracujá azedo, SBSE/CLAE-Flu. 


\begin{abstract}
RODRIGUES, T. R. Study of harman alkaloids in seeds of Passiflora edulis Sims f. flavicarpa Degener (sour passion fruit) by dual SBSE/HPLC-Flu. 2013. (Master of Sciences) Instituto de Química de São Carlos - Universidade de São Paulo, São Paulo, 2013.
\end{abstract}

There are many studies of Brazilian medicinal plants, but the lack of research related to food safety of Brazilian plants used as food is still high. Most of the alkaloids are toxic chemicals found in a wide variety of medicinal plants and edible plants, including Passiflora species popularly known in Brazil as "maracujá". Researches about most of the Passiflora species are largely related about the leaves and the fruits and in most of the cases, the seeds are considered as waste. Modern analytical methodologies for food analysis, using SBSE with PDMS as the extraction phase, have the purpose of make easier the preparation of complex samples and to reduce the organic waste generated in the sample preparation step. For that, this study had the aim to analyze harman alkaloids by a dual SBSE/HPLC-Flu method, adapted to the quantification of harmane and harmine in sour passion fruit seeds. The method was specific and linear for the studied of the alkaloids $\left(r^{2}=0.996\right.$ for harmane and $r^{2}=0.999$ for harmine). The repeatability and accuracy intermediate assays confirm the precision of the method. The recovery assay (between $92.34 \%$ and $105.90 \%$ to harmane and between $83.61 \%$ and $117.76 \%$ to harmine) indicate the accuracy of the method. The sample analyzed contained $\left(3.094 \times 10^{-2} \pm 5.874 \times 10^{-5}\right) \mu \mathrm{g}$ of the harmane in $1.0 \mathrm{~g}$ of dried seeds of sour passion fruit and $\left(8.108 \times 10^{-3} \pm 7.599 \times 10^{-4}\right)$ $\mu \mathrm{g}$ of the harmine in $1.0 \mathrm{~g}$ of dried seeds of sour passion fruit. The fluorescence detection was a sensitive and selective method for detection of harmane $\left(\mathrm{LOD}=30 \mathrm{ng} \mathrm{L^{-1 }}\right.$ and $\left.\mathrm{LOQ}=200 \mathrm{ng} \mathrm{L^{-1 }}\right)$ and harmine $\left(\mathrm{LOD}=100 \mathrm{ng} \mathrm{L}^{-1}\right.$ and $L O Q=400 \mathrm{ng}^{-1}$ ). It was concluded that the dual SBSE/HPLC-Flu method can be used for the analysis of the harman alkaloids in dried seeds of sour passion fruit.

Keywords: Passiflora edulis Sims f. flavicarpa Degener, harman alkaloids, sour passion fruit, SBSE/HPLC-Flu. 


\section{LISTA DE FIGURAS}

Figura 1 - Flor, folha, frutos inteiros e frutos abertos mostrando a polpa com sementes de Passiflora edulis Sims f. flavicarpa Degener (maracujá azedo)

Figura 2 - Estrutura do anel piridínico (piridína) e do anel heterocíclico condensado (indol), presentes nos alcaloides harmânicos.

Figura 3 - Estrutura dos alcaloides harmana, harmina, harmol, harmalol e harmalina.

Figura 4 - Desenho da barra de agitação magnética para SBSE com fase extratora de PDMS.

Figura 5 - Estrutura química do polidimetilsiloxano (PDMS)

Figura 6 - Desenho esquemático de um equipamento para cromatografia líquida de alta eficiência (CLAE).

Figura 7 - Diagrama de níveis energéticos de moléculas fluorescentes. 29

Figura 8 - Diagrama de blocos de um detector de fluorescência. 30

Figura 9 - Esquema de uma célula de fluorescência de um detector de fluorescência.

Figura 10 - Esquema representativo do método de quarteamento de amostras vegetais sólidas.

Figura 11 - Forno com corrente de nitrogênio para o condicionamento térmico das barras de SBSE, desenvolvido no IQSC: sistema de controle de temperatura e fluxo da corrente de nitrogênio, forno para SBSE e câmara de vidro para o tratamento térmico da SBSE.

Figura 12 - Esquema do método SBSE/CLAE-Flu dual adaptado para a análise de alcaloides harmânicos em sementes de maracujá azedo.

Figura 13 - Sementes inteiras de maracujá azedo, parte externa e parte interna....46

Figura 14 - Etapas do preparo da amostra vegetal: processo de separação das sementes por peneiração e armazenagem da polpa em frascos plásticos $\left(-20^{\circ} \mathrm{C}\right)$

Figura 15 - Secagem e determinação da granulometria das sementes de maracujá azedo: sementes depositadas em uma forma metálica para secagem em estufa $35-40 \stackrel{\circ}{-}$ por 72 horas; peneiras para determinação da granulometria e sementes trituradas de maracujá azedo: material com granulometria entre 32 a 65 mesh; com granulometria entre 16 a 32 mesh; e com granulometria inferior a 16 mesh. 
Figura 16 - Fotos das CCD do padrão de harmana $20,0 \mathrm{mg} \mathrm{L}^{-1}\left(R_{\mathrm{F}}=0,56\right)$ e de extratos de sementes de maracujá por ELL. Visualização sob luz UV em $\lambda=366 \mathrm{~nm}$.

Figura 17 - Cromatograma do extrato de sementes de maracujá azedo obtido por SBSE/CLAE-Flu dual: detecção no comprimento de onda específico para harmana e detecção no comprimento de onda específico para harmina.

Figura 18 - Comparação dos cromatogramas do extrato de sementes de maracujá azedo com o padrão de harmana $10,0 \mu \mathrm{g} \mathrm{L}^{-1}$ e metanol e de harmina $10,0 \mu \mathrm{g} \mathrm{L}^{-1}$ e metanol obtidos por CLAE/Flu $\left(\lambda_{\text {excitação }}=254 \mathrm{~nm}\right.$ e $\lambda_{\text {emissão }} 425 \mathrm{~nm}$ para harmana e $\lambda_{\text {excitação }}=254 \mathrm{~nm}$ e $\lambda_{\text {emissão }}=410 \mathrm{~nm}$ para harmina).

Figura 19 - Comparação dos espectros de fluorescência dos picos da harmana e da harmina na amostra de sementes de maracujá azedo por SBSE/CLAE-Flu dual, referentess ao cromatograma da figura 18, com os obtidos de soluções padrão de harmana e de harmina $\left(10,0 \mu \mathrm{g} \mathrm{L}^{-1}\right)$ obtidos por CLAE/Flu ( $\lambda_{\text {excitação }}=254 \mathrm{~nm}$ e $\lambda_{\text {emissão }}=425 \mathrm{~nm}$ para a harmana e $\lambda_{\text {excitação }}=254 \mathrm{~nm}$ e $\lambda_{\text {emissão }}=410 \mathrm{~nm}$ para a harmina). 53

Figura 20 - Curvas analíticas obtidas pelo método SBSE/CLAE-Flu dual por adição de padrão para obtenção da concentração da harmana e da harmina nas sementes de maracujá azedo.

Figura 21 - Espectros de fluorescência em diferentes regiões do pico do padrão de harmana $\left(10,0 \mathrm{~g} \mathrm{~L} \mathrm{~L}^{-1}\right)$, do pico da harmana na amostra e cromatograma do extrato de sementes de maracujá obtido pelo método SBSE/CLAE-Flu dual.

Figura 22 - Espectros de fluorescência em diferentes regiões do pico do padrão de harmina $\left(10,0 \mu \mathrm{g} \mathrm{L}^{-1}\right)$, do pico da harmina na amostra e cromatograma do extrato de sementes de maracujá obtido pelo método SBSE/CLAE-Flu dual.

Figura 23 - Cromatograma e espectro de fluorescência de uma solução padrão de harmana $10,0 \mu \mathrm{g} \mathrm{L}^{-1}\left(\lambda_{\text {excitação }}=254 \mathrm{~nm}\right.$ e $\lambda_{\text {emissão }}=425 \mathrm{~nm}$ ) obtidos por CLAE-Flu.

Figura 24 - Cromatograma e espectro de fluorescência de uma solução padrão de harmina $10,0 \mu \mathrm{g} \mathrm{L}^{-1}\left(\lambda_{\text {excitação }}=254 \mathrm{~nm}\right.$ e $\left.\lambda_{\text {emissão }}=410 \mathrm{~nm}\right)$ obtidos por CLAE-Flu.

Figura 25 - Equilíbrio de dissociação química dos alcaloides harmana e harmina. 


\section{LISTA DE TABELAS}

Tabela 1 - Condições cromatográficas estabelecidas para o método SBSE/CLAE-Flu dual na análise de alcaloides harmânicos em sementes de maracujá azedo.

Tabela 2 - Quantidades utilizadas dos reagentes e alíquotas de solução estoque (100 $\mu \mathrm{g} \mathrm{L}-1)$ de harmana e de harmina, para construção das curvas analíticas pelo método de adição de padrão

Tabela 3 - Reagentes utilizados para o estudo de alcaloides harmânicos em sementes de maracujá azedo pelo método SBSE/CLAE-Flu dual

Tabela 4 - Dados obtidos para a quantificação de harmana e harmina nas sementes secas de maracujá azedo por SBSE/CLAE-Flu dual.

Tabela 5 - Área média e DPR(\%), $r^{2}$ e equação da curva analítica dos alcaloides harmana e harmina presentes nas sementes de maracujá azedo.

Tabela 6 - Resultados para os ensaios de precisão para a amostra de sementes de maracujá azedo fortificadas com soluções padrão de harmana e harmina.

Tabela 7 - Valores obtidos para os ensaios de exatidão para a harmana e a harmina, em diferentes níveis de concentração, pelo método SBSE/CLAE-Flu dual.

Tabela 8 - Limites de detecção (LOD) e de quantificação (LOQ) estabelecidos para soluções padrão de harmana e de harmina. 


\section{SIGLAS E ABREVIATURAS}

$\mathrm{C}_{18}$ - $^{-} \quad$ octadecilsilano.

CCD - $\quad$ cromatografia em camada delgada.

CLAE - comatografia líquida de alta eficiência.

CPDMS - concentração do analíto no pilidimetilsiloxano.

$\mathrm{C}_{\mathrm{W}}$ - concentração do analíto na fase aquosa.

DPR $(\%)$ - desvio padrão relativo.

ELL - $\quad$ extração líquido-líquido.

GAF - G G G G Go de Análise Fitoquímica.

ha - hectare.

$\mathrm{ICH}$ - International Conference on Harmonization.

IQSC - USP - $\quad$ Instituto de Química de São Carlos - Universidade de São Paulo.

IV - Infra-vermelho.

Ko/W - $\quad$ constante de dissociação octanol/água.

K $\mathrm{KDMS}_{\mathrm{W}} \mathrm{w}$ - constante de dissociação entre 0 polidimetilsiloxano e a fase aquosa.

LOD - $\quad$ Limite de detecção.

LOQ - $\quad$ Limite de quantificação.

$\mathrm{n}$ - $\quad$ número de amostras.

$\mathrm{N}$ - número de pratos teóricos.

PDMS - polidimetilsiloxano.

pH - potencial hidrogeniônico.

$r^{2}$ - coeficiente de correlação linear.

$\mathrm{R}_{\mathrm{F}}$ - fator de retenção.

RMN - Ressonância Magnética Nuclear.

rpm - $\quad$ rotação por minuto.

$\mathrm{S}_{0}$ - $\quad$ estado energético fundamental.

$\mathrm{S}_{1}$ - $\quad$ estado energético excitado.

SBSE/CLAE-Flu - Extração Sortiva em Barra de Agitação acoplada a Cromatografia líquida de alta eficiência com detecção por fluorescência. 
SNC -

$t_{R}-$

UV -

$\mathrm{v} / \mathrm{v}-$

$\lambda_{\text {excitação }}$

$\lambda_{\text {emissão - }}$
Sistema Nervoso Central.

tempo de retenção.

Ultra-violeta.

relação volume/volume.

comprimento de onda de excitação.

comprimento de onde de emissão. 


\section{SUMÁRIO}

1 INTRODUÇÃO ...................................................................................15

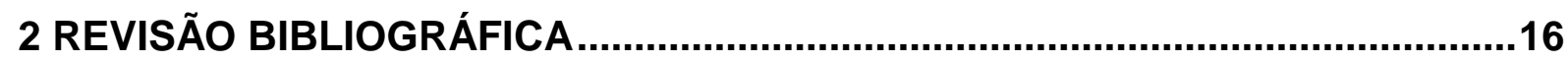

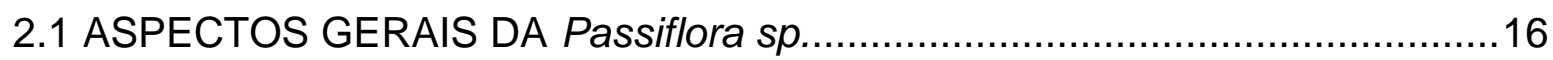

2.1.1 Passiflora edulis Sims f. flavicarpa Degener (maracujá azedo) ...................17

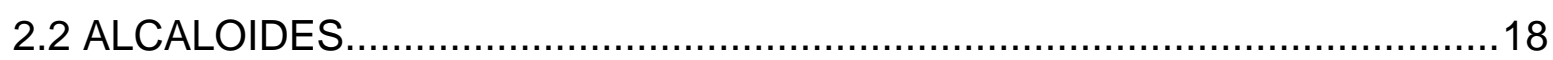

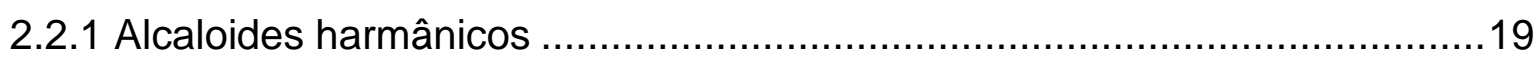

2.2.2 Quantificação de alcaloides harmânicos ...................................................21

2.3 EXTRAÇÃO SORTIVA EM BARRA DE AGITAÇÃO (SBSE) .........................22

2.4 CROMATOGRAFIA LÍQUIDA DE ALTA EFICIÊNCIA (CLAE) ......................26

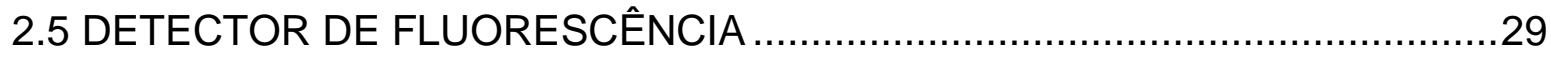

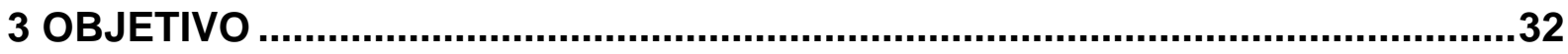

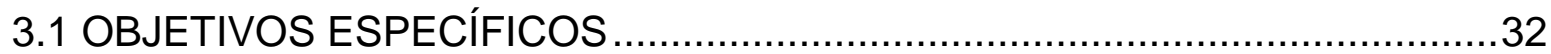

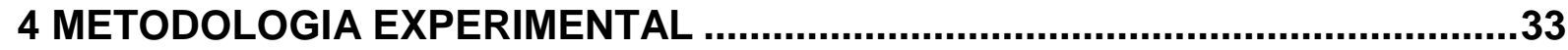

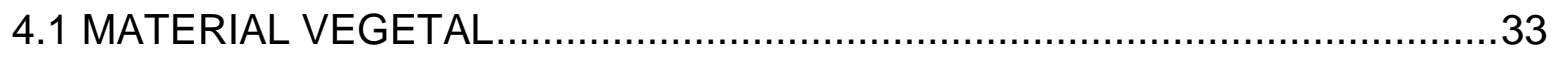

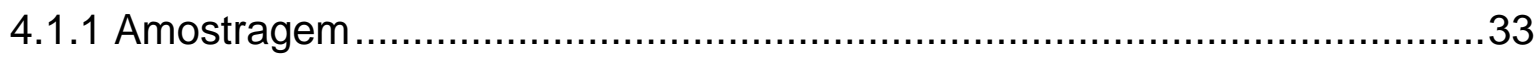

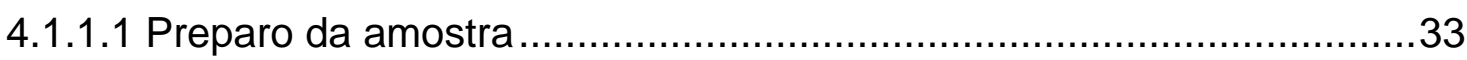

4.1.1.2 Quarteamento de amostras sólidas ..................................................34

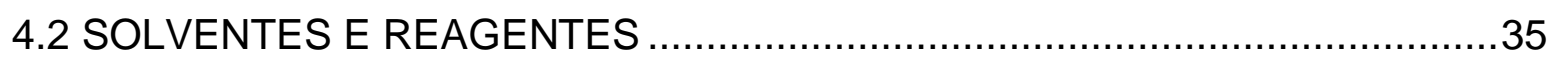

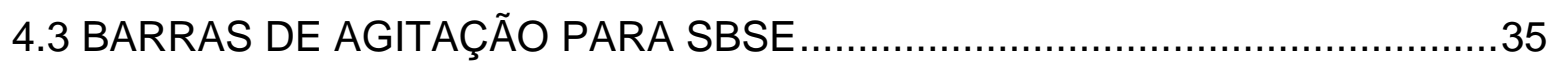

4.3.1 Ativação das barras de agitação para SBSE ..............................................35

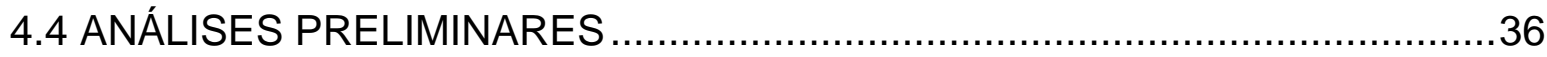

4.4.1 Cromatografia em camada delgada (CCD) ................................................37

4.4.2 Extração líquido-líquido (ELL) ………......................................................37

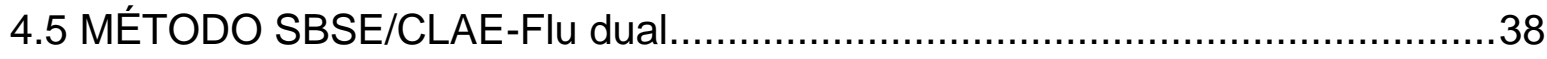

4.5.1 Análise das sementes pelo modo SBSE/CLAE-Flu dual..............................38 
4.5.2 Limpeza das barras após extração por SBSE......................................40

4.6 ANÁLISE CROMATOGRÁFICA POR CLAE-Flu.......................................40

4.7 ANÁLISE QUANTITATIVA DOS ALCALOIDES HARMÂNICOS.....................41

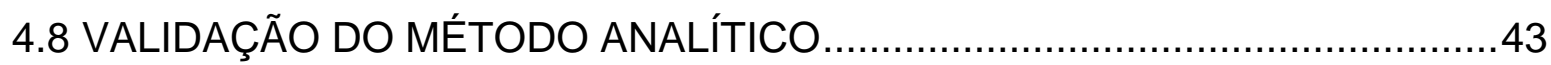

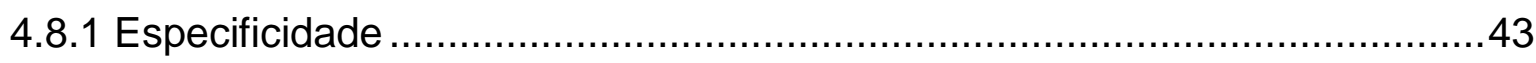

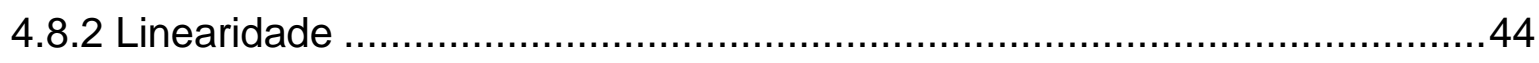

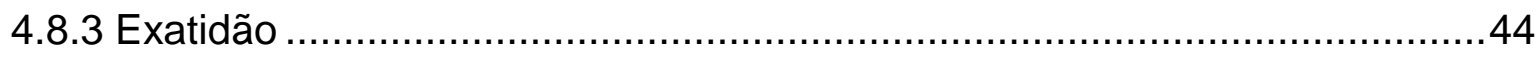

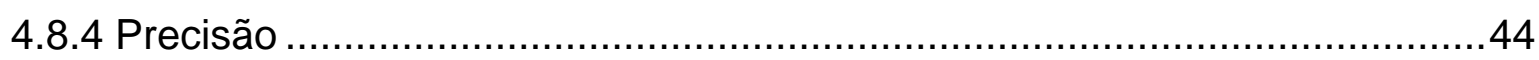

4.8.5 Limite de Detecção e Limite de Quantificação ....................................45

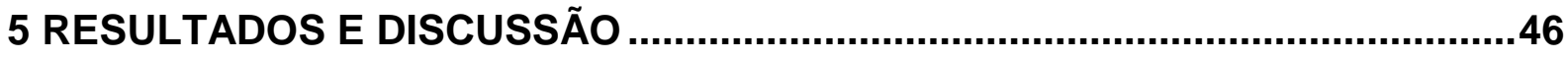

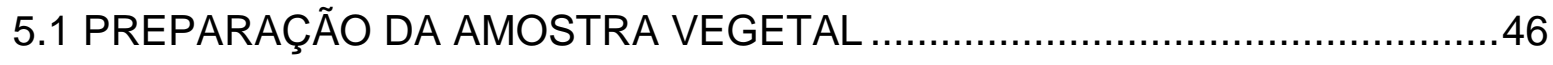

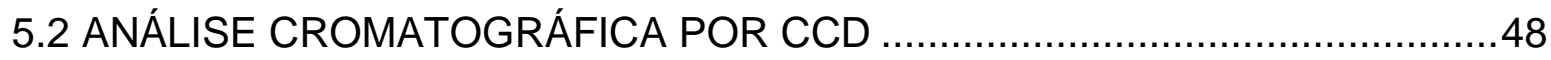

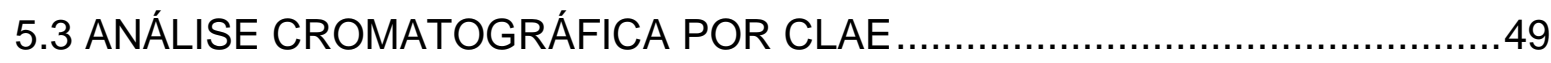

5.4 QUANTIFICAÇÃO DE HARMANA E HARMINA POR SBSE/CLAE-Flu dual ...53

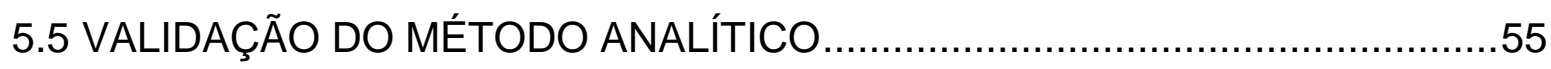

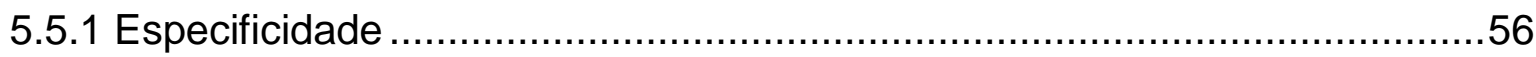

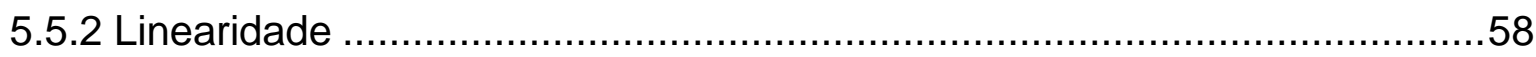

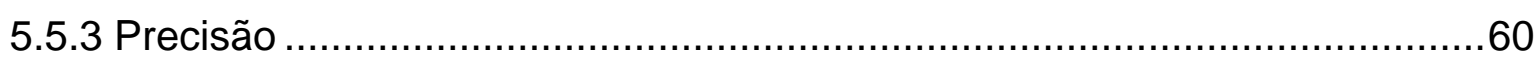

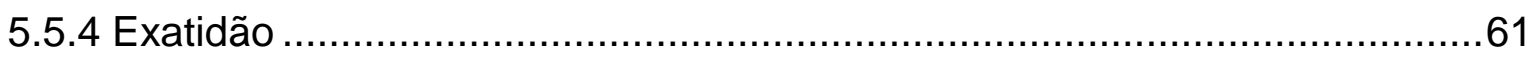

5.5.5 Limite de Detecção (LOD) e Limite de Quantificação (LOQ)......................63

6 CONCLUSÕES ............................................................................................67

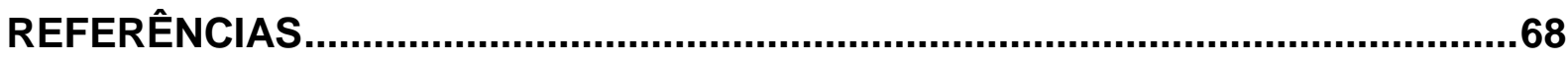




\section{INTRODUÇÃO}

O Brasil é caracterizado internacionalmente como possuidor da maior reserva florestal diversificada do planeta. A Passiflora edulis Sims f. flavicarpa Degener (maracujá azedo) é uma das espécies cultivadas no Brasil, e é estudada devido aos efeitos farmacológicos como sedativo e contra a ansiedade, podendo também ser uma fonte em potencial de alcaloides harmânicos (FRYE; HAUSTEIN, 2007; MACHADO et al., 2010).

Os estudos utilizando Extração Sortiva em Barra de Agitação (SBSE) têm aumentado nos últimos anos, com uma variedade de metodologias desenvolvidas e diversas aplicações em análise de alimentos, com inúmeras vantagens sob as formas clássicas de preparo de amostras (KAWAGUCHI et al., 2013).

As pesquisas desenvolvidas pelo Grupo de Análise Fitoquímica (GAF), do Instituto de Química de São Carlos - Universidade de São Paulo (IQSC-USP) têm como ênfase o estudo de substâncias naturais potencialmente tóxicas em Passiflora sp. por SBSE combinada com cromatografia líquida e SBSE combinada com cromatografia gasosa.

Em trabalhos realizados pelo GAF (PEREIRA; SANTOS; YARIWAKE, 2013), foram encontrados $36,75 \mu \mathrm{g} \mathrm{L}^{-1}$ de harmana e $8,72 \mu \mathrm{g} \mathrm{L}^{-1}$ de harmina na polpa e $69,80 \mu \mathrm{g} \mathrm{L}^{-1}$ de harmana e $14,55 \mu \mathrm{g} \mathrm{L}^{-1}$ de harmina na polpa com sementes do fruto de maracujá azedo. Com isso, sugerem que estes compostos também possam estar contidos nas sementes do fruto.

Nos estudos fitoquímicos sobre o maracujá azedo foram utilizadas as folhas, frutos e raízes (ZUCOLOTTO, 2005), mas há relatos sobre a necessidade de estudos sobre os constituintes químicos das diversas partes dos frutos do maracujá, incluindo as sementes (ZERAIK et al., 2010).

Este trabalho consiste na análise quantitativa de alcaloides harmânicos com potencial toxicológico em sementes de maracujá azedo e pretende contribuir para o aumento dos estudos utilizando SBSE para análises na área de alimentos visando à questão da segurança alimentar. 


\section{REVISÃO BIBLIOGRÁFICA}

\subsection{ASPECTOS GERAIS DA Passiflora sp.}

No Brasil, diversas espécies de Passiflora são designadas popularmente como maracujá. O Brasil é um dos maiores produtores de maracujá da América Latina, com destaque econônico para a Passiflora edulis Sims f. flavicarpa Degener, com uma área de 62.243 ha destinada ao cultivo deste fruto, com produção de 920.158 toneladas, destacando-se as regiões Nordeste e Sudeste com produção de 699.242 e 127.413 toneladas/ano respectivamente (IBGE, 2010).

A comparação dos dados do IBGE entre os anos de 2006 e 2010 mostra um aumento na produção de frutos de maracujá azedo durante esse período, sendo que em 2006 a produção foi de 615.196 toneladas de fruto com uma área de 45.327 ha destinados ao plantio (IBGE, 2006; 2010).

O maracujá é muito utilizado na cultura popular e é comercializado em feiras livres, mercados atacadistas e indústrias de sucos e polpas, podendo ser consumido in natura (com as sementes), em seu estado natural ou na forma de suco (MACHADO et al., 2010; ZERAIK et al., 2010).

Os flavonoides encontrados no maracujá foram relacionados com a atividade antioxidante, considerando várias espécies de maracujá como novas fontes em potencial de biomoléculas com atividade farmacológica (DHAWAN, K.; DHAWAN, S.; SHARMA, 2004).

A quantificação da isorientina em extratos da polpa e da casca do maracujá também indica uma correlação com a atividade antioxidante, atribuindo ao fruto características de alimento funcional e/ou possível fonte natural de flavonoides (ZERAIK et al., 2011) e sugere-se as cascas como possíveis fontes de flavonoides para a produção de fármacos (ZERAIK, 2010).

Pereira (2002), desenvolveu e validou uma metodologia para quantificação dos flavonoides presentes nas folhas de Passiflora edulis Sims $t$. flavicarpa Degener, Passiflora alata, Passiflora incarnata L. e Passiflora caerulea L. por cromatografia líquida de alta eficiência (CLAE) utilizando a rutina como padrão. 
Em um trabalho de revisão da literatura, Zeraik et al. (2010), relatam que as sementes de maracujá são ricas em ácidos graxos poliinsaturados (ácido linoleico, ácido oleico e ácido palmítico) essenciais aos seres humanos.

Os estudos feitos por Matsui et al. (2010) descrevem a presença de piacetamol, um polifenol que atua na inibição de células de melanomas e na síntese de fibroblastos, nas sementes de Passiflora edulis.

São encontrados na literatura alguns trabalhos relacionados com alcaloides utilizando as folhas e os frutos (casca e polpa) de Passiflora sp., porém, as sementes são pouco abordadas em estudos analíticos (ZERAlK et al., 2011; ZERAIK; YARIWAKE, 2010).

\subsubsection{Passiflora edulis Sims f. flavicarpa Degener (maracujá azedo)}

A espécie Passiflora edulis Sims $f$. flavicarpa Degener é conhecida popularmente como maracujá amarelo ou maracujá azedo. A ANVISA (2011) adota como nomenclatura oficial desta espécie de Passiflora como Passiflora edulis Sims, porém, muitos trabalhos científicos utilizam outras formas de nomenclatura (Passiflora edulis Sims f. flavicarpa Degener, Passiflora edulis (ZERAIK, 2010; MATSUI et al., 2010). Outras espécies de Passiflora também são conhecidas como maracujá, demonstrando a importância da diferenciação entre as espécies (BERALDO; KATO, 2010).

O maracujá azedo pode ser considerado como uma das principais espécies de Passiflora com importância econômica cultivada no Brasil, e é muito utilizada na medicina popular e principalmente no preparo de sucos pela indústria ou de forma caseira (FILHO et al., 2011).

A flor do maracujá azedo é hermafrodita e as folhas são simples, alternadas, trilobadas, inteiras ou bilobadas, de base cordada, ápice acuminado e margem serrilhada, nervura mediana biconvexa com saliência arredondada na face abaxial (BERALDO; KATO, 2010; SEAGRI, 2013). As folhas de várias espécies de maracujá promovem atividade ansiolítica, sedativa, antioxidante, anti-hipertensiva e promove a diminuição da taxa de glicose e do colesterol no sangue. No passado, enfatizava-se a ação conjunta de alcaloides e flavonoides como responsável pelos efeitos terapêuticos (MACHADO et al., 2010). 
Os frutos maduros do maracujá azedo tem formato ovoide, peso entre 70 - 130 gramas, com casca fina de cor amarelo-canário, polpa de acidez elevada, com aroma e sabor agradáveis, com rendimento de $30 \%$ em suco. A planta tem produção entre 12 - 15 toneladas/ha, mas com potencial para produção de até 30 - 35 toneladas/ha (SEAGRI, 2013). A Figura 1 mostra a flor, a folha, os frutos inteiros e os frutos abertos de maracujá azedo.
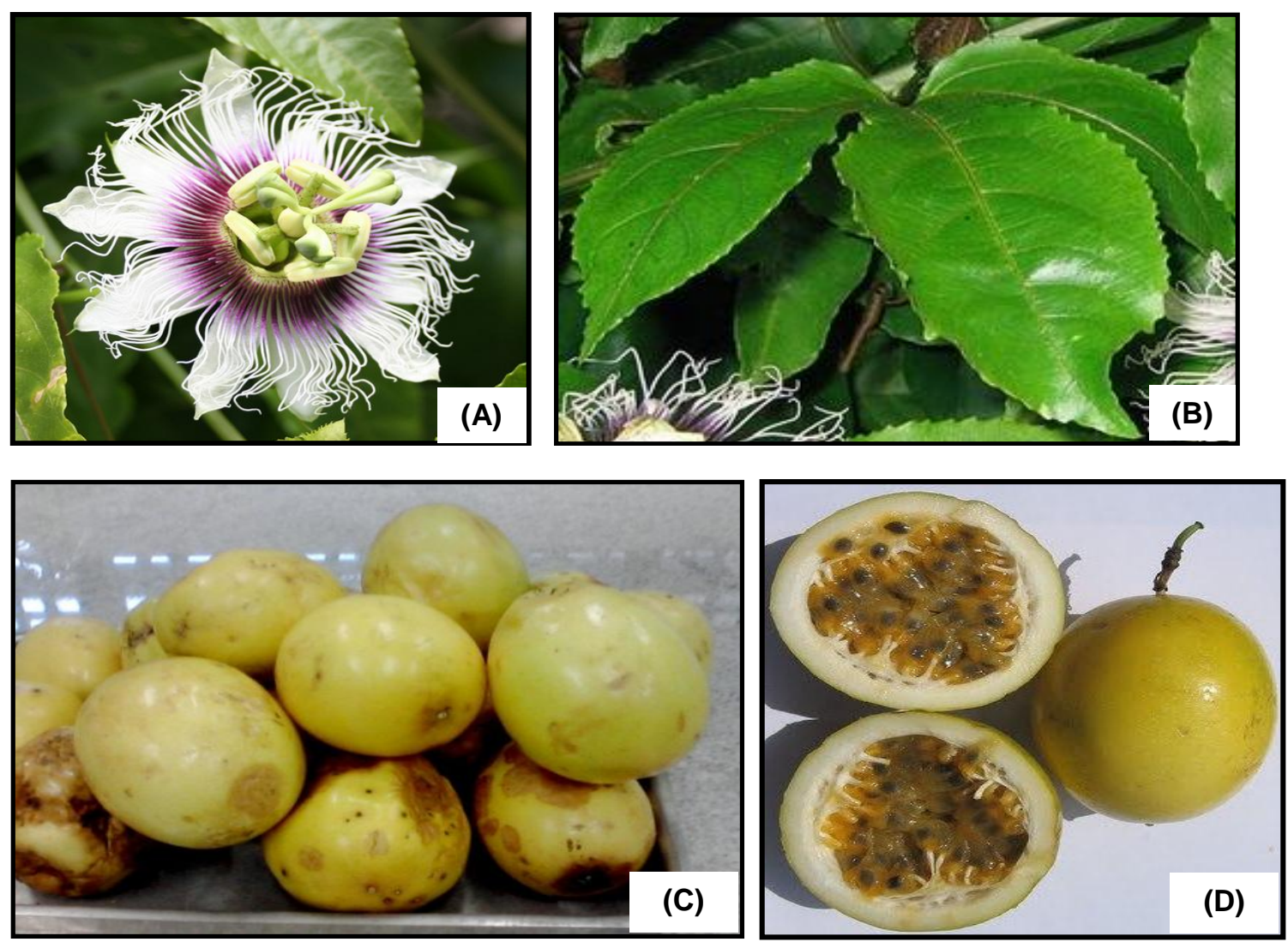

Figura 1 - Flor (A), folha (B), frutos inteiros (C) e frutos abertos mostrando a polpa com sementes (D) de Passiflora edulis Sims f. flavicarpa Degener (maracujá azedo)

\subsection{ALCALOIDES}

Os alcaloides são compostos de grande interesse para a comunidade científica devido aos efeitos tóxicos e medicinais. Suas funções na planta não são bem definidas, mas acredita-se que sirvam como reserva para síntese proteica e atuem na proteção contra a ação predadora de insetos e animais herbívoros (BARRACA, 1999).

Os alcaloides harmânicos fazem parte do grupo dos alcaloides $\beta$-carbolínicos e são encontrados em várias famílias de plantas. Este grupo de compostos 
nitrogenados de natureza básica contém em sua estrutura química um anel piridínico e um anel heterocíclico condensado com um átomo de nitrogênio amínico (Figura 2) (MOURA, 2006).

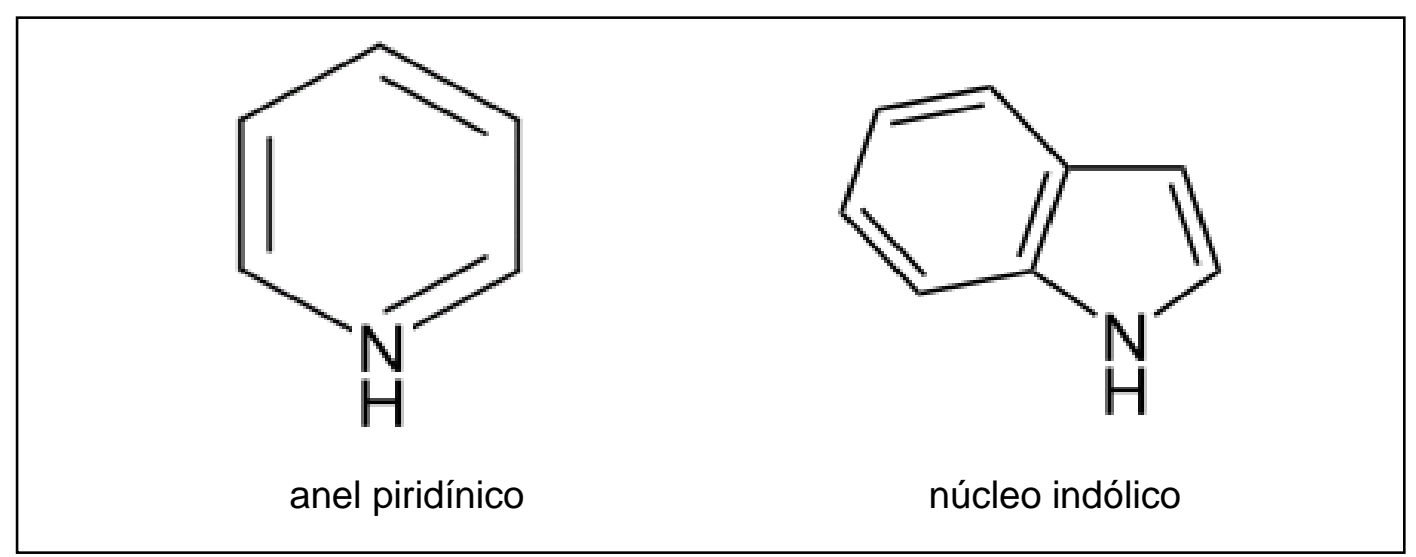

Figura 2 - Estrutura do anel piridínico (piridína) e do anel heterocíclico condensado (indol), presentes nos alcaloides harmânicos.

Fonte: Adaptado de (MOURA, 2006).

Os primeiros registros dos alcaloides harmânicos foram em sementes da Peganum harmala (harmina e harmalina), com relatos da ação alucinógena, toxicidade e atividade farmacológica no Sistema Nervoso Central, sendo estes alcaloides também encontrados no maracujá (ZERAIK et al., 2010; MONSEF-ESFAHANI et al., 2008; DE SOUZA, 2011).

A ação tóxica do extrato das sementes da Peganum harmala foi comprovada em ensaios de toxicidade para 0 uso desta planta como inseticida (SALARI et al., 2012).

Alguns estudos sobre alcaloides citam que harmana e harmalina estão presentes na Ayahuasca, uma bebida utilizada em rituais religiosos, com propriedades psicoativas e efeitos neurotóxicos (SÉRPICO; CAMURÇA, 2006; FIGUEROA, 2012).

\subsubsection{Alcaloides harmânicos}

Os alcaloides harmânicos, encontrados em quantidades significativas em muitas espécies de plantas, incluindo Passiflora sp., são descritos como responsáveis por efeitos farmacológicos e neurofarmacológicos (TSUCHIYA et al., 1999). 
A harmana, harmina, harmol, harmalol e harmalina (Figura 3), são compostos que pertencem à família dos alcaloides harmânicos (DHAWAN, K.; DHAWAN, S.; SHARM, 2004; FIGUEIREDO; GONÇALVES, 2007; MÜLLER, 2006).

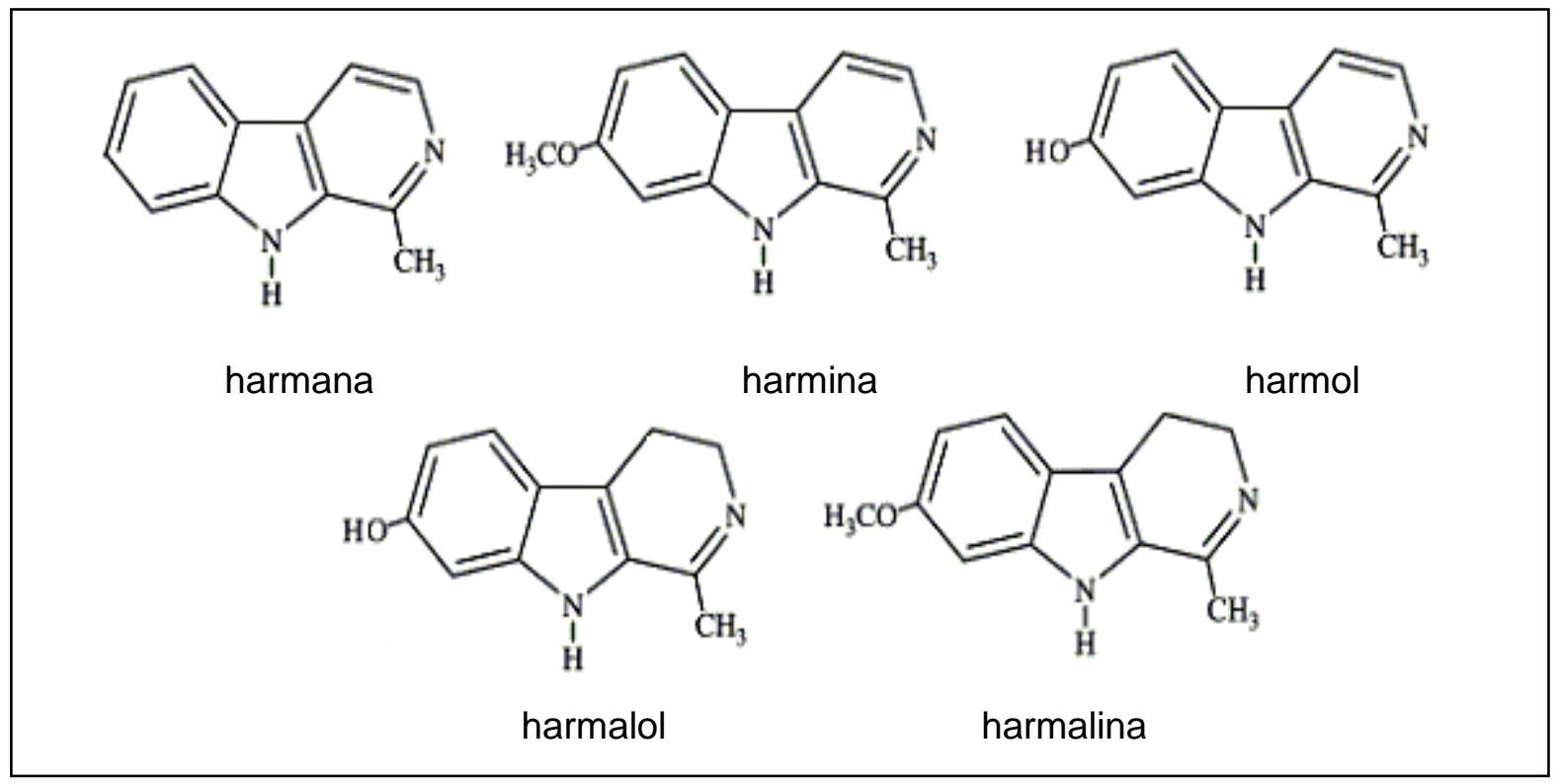

Figura 3 - Estrutura dos alcaloides harmana, harmina, harmol, harmalol e harmalina. Fonte: Adaptado de (MÜLLER, 2006).

Sobre os alcaloides harmânicos da Passiflora sp., Pereira e Vilegas (2000) relatam que são do tipo indólicos (com ação tranquilizante) e comparam o seu teor em diferentes órgãos vegetais de maracujá azedo, verificando que o maior teor ocorre nas folhas. Pereira, Santos e Yariwake (2013) também confirmam a presença destas substâncias na polpa do maracujá azedo e do maracujá doce.

Os alcaloides podem existir em solução aquosa como espécies neutras ou carregadas, dependendo de parâmetros como $\circ \mathrm{pH}$ e a temperatura da solução. $\mathrm{O}$ pH das amostras é uma variável importante na extração por SBSE e pode ser ajustado com a intenção de melhorar a eficiência do método mantendo o analito totalmente na forma não-iônica (PRIETO et al., 2010).

As estruturas da harmana e da harmina têm dois sítios de dissociação: o grupo $\mathrm{NH}$ do anel indol (fracamente ácido) e o átomo de nitrogênio do anel da piridina (básico). Assim, em pH mais elevado, estes alcaloides devem estar na forma neutra com pouca solubilidade em água, tornando-os muito adequados para a extração pela fase de PDMS por SBSE (WOLFBEIS; FURLINGER, 1982; WOLFBEIS; FURLINGER; WINTERSTEIGER, 1982; MOURA, 2006). 
2.2.2 Quantificação de alcaloides harmânicos

Os primeiros dados científicos relatando a presença de alcaloides harmânicos em maracujá amarelo datam de 1975 (LUTOMSKI, 1975), todavia com uma metodologia pouco apurada comparada com os tempos atuais. Na química analítica moderna, tem-se empregado a Cromatografia líquida de alta eficiência (CLAE) na pesquisa de compostos contidos em plantas medicinais, principalmente em amostras complexas com concentrações de compostos em escalas muito baixas (TSUCHIYA et al., 1999). Na análise qualitativa e quantitativa de Passiflora incarnata, utilizando CLAE com detecção por fluorescência, concluiu-se que os alcaloides harmânicos estavam presentes na faixa de concentração de $0,1 \mathrm{ng} \mathrm{L}^{-1}$ (REHWALD; STICHER; MEIER, 1995).

Em estudos do arilo de sementes de maracujá azedo realizados por Martins et al. (2010), com prospecção química e análise por Infra-vermelho (IV) e Ressonância Magnética Nuclear (RMN), a presença de alcaloides não foi detectada.

Estudos sobre o perfil de alcaloides em extratos de folhas de $P$. alata utilizando CLAE com detecção por UV (Ultra-violeta) não confirmaram a presença dos alcaloides harmânicos clássicos testados (harmana, harmina, harmol, harmalol e harmalina) (MÜLLER, 2006).

Frente à isso, torna-se evidente que alguns detectores não são seletivos para esse grupo de compostos, uma vez que análises quantitativas de alcaloides em Passiflora sp., utilizando CLAE com detecção por UV, concluiram que harmol e harmina estavam presentes em $P$. incarnata e harmina em $P$. caerulea $L$. (FRYE; HAUSTEIN, 2007).

Todavia, análises por CLAE de fase reversa com detecção de arranjo de diodos, sugerem que harmana pode ser encontrada em maracujá amarelo e harmalol, harmol, harmana, harmalina e harmina em diversas espécies de Passiflora sp. (ABOURASHED; VANDERPLANK; KHAN, 2003).

As metodologias anteriores comprovam a existencia de alcaloides harmânicos em maracujá, porém, entram em controversias em relação ao tipo de detector utilizado: Müller (2006), usando a detecção por UV não confirma a presença de alcaloides nas folhas de P. alata. Porém, Frye e Haustein (2007), também usando a deteç̧ão por UV, mostram que esses compostos estão presentes em Passiflora sp. 
e Abourashed; Vanderplank; Kham (2003) encontraram alcaloides harmânicos em Passiflora sp. com detecção por arranjo de diodos.

Sendo assim, é evidente a necessidade de metodologias analiticas modernas e validadas, que supram os pré-requisitos de rapidez e eficiência de um método para a qualificação e quantificação destes alcaloides em Passiflora sp.

Em recentes trabalhos, foi feita a otimização multivariada de condições de extração para alcaloides harmânicos utilizando SBSE/CLAE-Flu, Pereira, Santos e Yariwake (2013) apresentaram um método sensível e validado para a quantificação de harmana e harmina em polpa e em polpa com sementese de maracujá visando a questão da segurança alimentar.

Não existe uma metodologia específica para análise das sementes de maracujá, o que justifica a necessidade de uma metodologia moderna, prática e sensível para a qualificação e quantificação dos alcaloides harmânicos, ressaltando que as partes vegetais mais estudadas são as folhas e os frutos do maracujá.

\subsection{EXTRAÇÃO SORTIVA EM BARRA DE AGITAÇÃO (SBSE)}

A miniaturização dos sistemas analíticos tem sido uma tendência predominante na área de química analítica nos últimos tempos (CHAVES; QUEIROZ, 2008). Tem-se buscado metodologias com o emprego de instrumentação moderna para diversos tipos de amostras, que viabilize análises mais rápidas e com menor gasto de reagentes (KAWAGUCHI et al., 2013).

A Extração Sortiva por Barra de Agitação, do inglês: "Stir Bar Sorptive Extraction" (SBSE), têm ganhando espaço nas pesquisas analíticas. Essa técnica ganhou popularidade por minimizar a quantidade de solventes orgânicos utilizados na extração de substâncias e por isso é considerada como uma "técnica verde" de análise (IPARRAGUIRRE et al., 2011).

As barras de agitação (ou "twisters") usadas em SBSE apresentam três partes essenciais (Figura 4): a primeira delas e a mais interna é uma haste de aço inox (agitação magnética da amostra), a segunda parte é uma capa de vidro que recobre a haste de agitação e a terceira (mais externa) é a camada de polidimetilsiloxano (PDMS) (ALMEIDA et al., 2004; SILVA, 2007). 


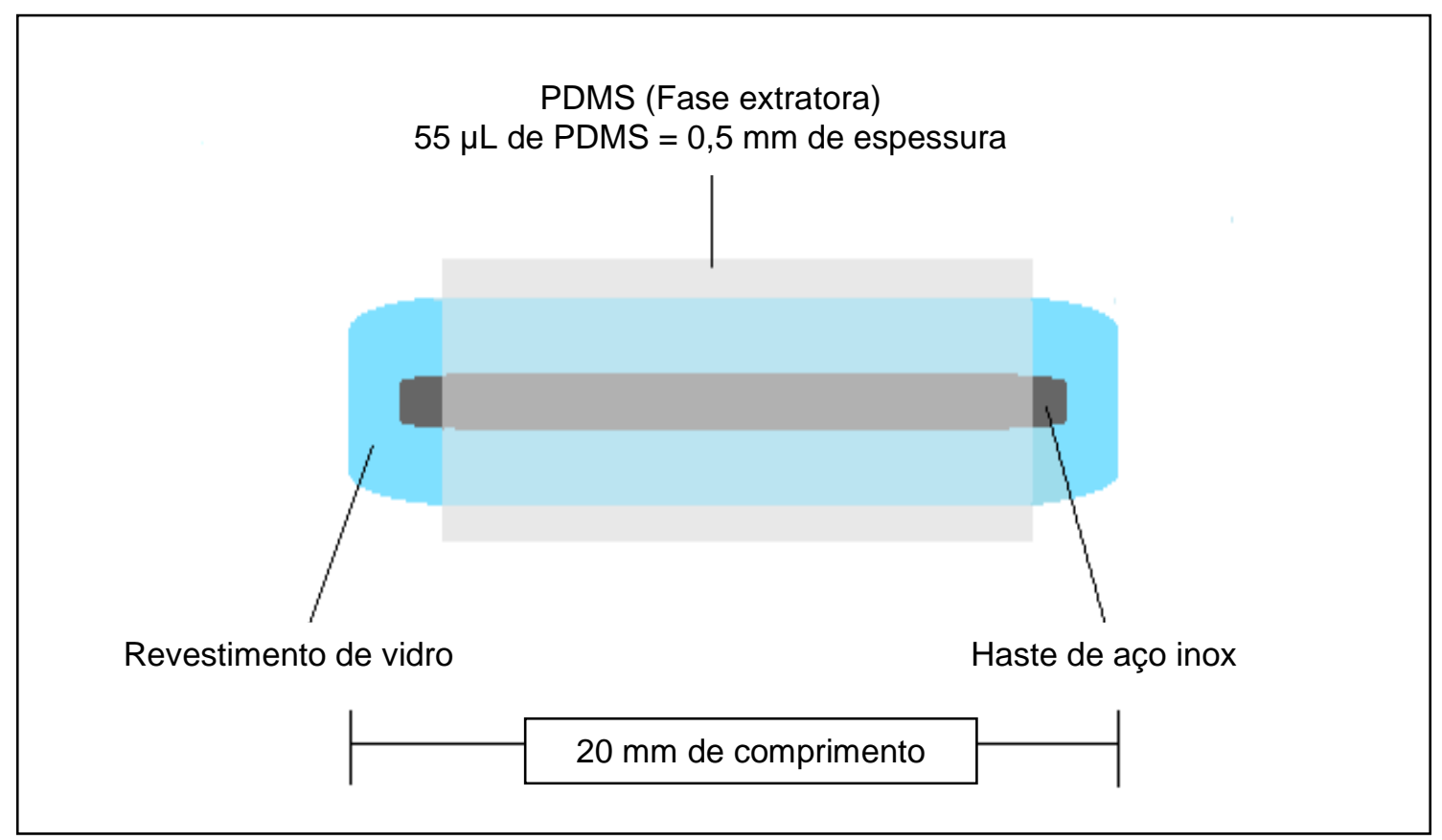

Figura 4 - Desenho da barra de agitação magnética para SBSE com fase extratora de PDMS. Fonte: Adaptado de (ALMEIDA et al., 2004; SEQUEIROS, 2009).

A SBSE apresenta uma série de vantagens em relação aos métodos de preparo de amostras convencionais. A SBSE não requer instrumentação analítica sofisticada, há menor exposição dos analistas aos solventes tóxicos, baixa geração de resíduos orgânicos, permite a reutilização das barras e ocorre mínima perda de analito durante o processo de extração (CHAVES; QUEIROZ, 2008).

Esta técnica pode ser descrita como uma microextração líquido-líquido devido à pré-concentração dos analitos da fase aquosa para a fase de PDMS; o princípio da técnica SBSE baseia-se no equilíbrio de partição (absorção) ou sorção, pois os analitos solubilizam-se na fase sorvente (PDMS), ocorrendo partição destes entre a fase extratora e a amostra (DAVID; SANDRA, 2007; IPARRAGUIRRE et al., 2011).

O coeficiente de partição octanol/água $(\mathrm{K} / \mathrm{w})$ permite avaliar 0 comportamento do analito entre duas fases distintas; no caso da SBSE, entre o

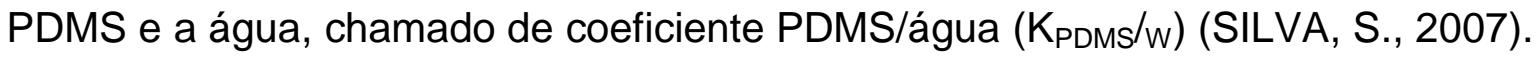

O Ko/w tem como importância a quantificação do caráter hidrofóbico de um analito, ajuda a estimar a sua solubilidade em fase aquosa e a previsão da partição em outras fases orgânicas não-polares (DAVID; SANDRA, 2007).

Considerando que o $\mathrm{K}_{\mathrm{PDMS}} / \mathrm{w}$ é proporcional ao $\mathrm{K}_{\mathrm{O}} / \mathrm{w}$, o $\mathrm{K}_{\mathrm{PDMS}} / \mathrm{w}$ é definido como a razão entre a concentração do analito na fase de PDMS ( $C_{\text {PDMS }}$ ) e na solução $\left(\mathrm{C}_{\mathrm{w}}\right)$ no equilíbrio. Assim, a distribuição dos analitos entre estas duas fases 
fornecerá a informação da eficiência de extração para cada soluto, determinada através da seguinte equação (Equação 1) (SILVA, S., 2007; SEQUEIROS, 2009):

$$
K_{O / W}=K_{P D M S} / W=\frac{C_{P D M S}}{C_{W}}=\left(\frac{m_{P D M S}}{m_{W}}\right) \times\left(\frac{V_{W}}{V_{P D M S}}\right)
$$

Onde:

$m_{P D M S}=$ massa do analito na fase de PDMS

$m_{W} \quad=$ massa do analito na fase aquosa

$V_{W} \quad=$ volume de fase aquosa

$V_{P D M S}=$ volume de PDMS

A recuperação por SBSE pode também estar associada com a relação entre a fase aquosa e a fase de PDMS, ou seja, quanto menor o volume da solução e maior o volume de PDMS, melhor será a recuperação do método (COSTA, 2012).

Em SBSE, as barras de extração são revestidas com uma camada de PDMS tipicamente com 0,5 - 1,0 mm de espessura, proporcionando alta eficiência na recuperação de analítos em pequenos volumes de fase aquosa (IPARRAGUIRRE et al., 2011).

O PDMS (Figura 5), em razão de suas propriedades de difusão e estabilidade térmica em ampla faixa de temperatura tem sido muito utilizado como fase de extração sortiva (CHAVES; QUEIROZ, 2008).

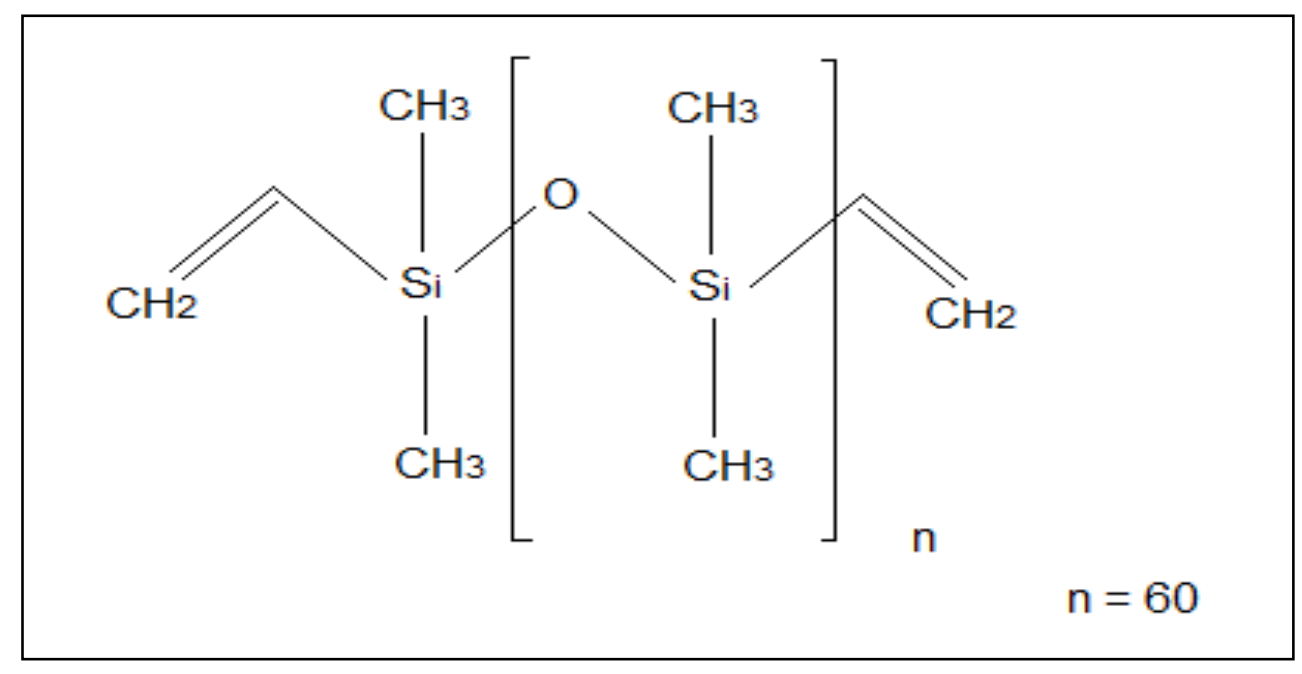

Figura 5 - Estrutura química do polidimetilsiloxano (PDMS). Fonte: Adaptado de (CHAVES; QUEIROZ, 2008) 
Este material convencional (PDMS) de revestimento para SBSE mostra a possibilidade da extração seletiva de compostos polares (KAWAGUCHI et al., 2013). $\mathrm{Na}$ extração seletiva dos analitos de interesse, é necessaria a otimização das principais variáveis do método, que são estudadas para atingir as condições ótimas de análise (LANÇAS et al., 2009). As variáveis incluem: o volume da amostra, o teor de solventes orgânicos (adição de $\mathrm{MeOH}$ ) ou de um sal inerte ( $\mathrm{NaCl}$ ), a temperatura, o pH, a velocidade de agitação, o tempo de extração e o solvente de dessorção (HUANG, X.; YUAN; HUANG, B., 2008; HUANG et al., 2009b; IPARRAGUIRRE et al., 2011).

Os efeitos do $\mathrm{pH}$ e as percentagens de $\mathrm{NaCl}$ e metanol foram fatores significativos na extração da harmana, obtida com pH $=13,0,50 \%$ de $\mathrm{NaCl}$ e $100 \%$ de metanol, que resultou numa recuperação de $(98,76 \pm 0,16) \%$; e na extração da harmina, obtida com $\mathrm{pH}=10,0,50 \%$ de $\mathrm{NaCl}$ e $100 \%$ de metanol, com recuperação de $(97,36 \pm 0,11) \%$ (PEREIRA; SANTOS; YARIWAKE, 2011).

Na SBSE, a recuperação dos analitos pela fase PDMS está associada com as constantes de dissociação, sendo que os analitos encontrados na forma neutra podem ser extraídos a partir de uma solução aquosa (BALON et al., 1987; DOUGLAS et al., 1983).

Considerando o valor de $\mathrm{K}_{\mathrm{PDMS}} / \mathrm{w}<3,5$ para os compostos polares, a extração de harmana e de harmina por SBSE pode ser favorecida, pois como os valores do K $\mathrm{PDMS} / \mathrm{w}$ para a harmana é 3,1 e para a harmina é 3,56, portanto, são considerados compostos polares. Devido à proximidade destes valores com o valor de $\mathrm{K}_{\mathrm{O} / \mathrm{W}}<3,5$, possivelmente estas substâncias tenham solubilidade em PDMS (ALMEIDA et al., 2004; SEQUEIROS, 2009; PEREIRA; SANTOS; YARIWAKE, 2011).

Para os compostos polares $\left(\mathrm{K}_{\mathrm{O} / \mathrm{w}}<3,5\right)$, tem-se o aumento da recuperação dos analitos com a adição de sais inertes, uma vez que o desempenho de extração da SBSE para os compostos polares depende fortemente da força iônica da matriz da amostra (GIORDANO et al., 2009; PRIETO et al., 2010).

O efeito de "salting-out", causado pela adição de sal, tem importante influência no processo de extração. As moléculas de água podem formar esferas de hidratação em torno das moléculas do sal iônico, diminuindo a concentração de água disponível para dissolver as moléculas do analito. Dessa forma, os analitos são conduzidos para a fase de extração (PDMS) (HUANG; QIU; YUAN, 2009a). 
Em contrapartida, o harmol apresenta $\mathrm{Ko} / \mathrm{w}=1,82$ demonstrando pouca ou nenhuma afinidade com o PDMS, necessitando outros tipos de fase estacionária para sua extração (PEREIRA; SANTOS; YARIWAKE, 2011).

A dessorção dos analitos adsorvidos pela fase estacionária (PDMS) pode ser feita em uma fase líquida com solventes adequados, geralmente utilizando um sistema de banho de ultra-som (SILVA, S., 2007).

Comercialmente existem apenas as barras revestidas com PDMS, evidenciando a necessidade do desenvolvimento de novos revestimentos absorventes para a extração de compostos com pouca ou nenhuma afinidade pelo PDMS (LANÇAS et al., 2009).

Para essa questão, diversos grupos de pesquisa vêm desenvolvendo diferentes tipos de revestimento mistos de PDMS e outros materiais (polipirrol e carvão ativado), para ampliar a seletividade da técnica, otimizar a extração, melhorar a recuperação e a dessorção dos analitos (NOGUEIRA, 2007; HUANG, X.; QIU; YUAN, 2008; SILVA, A.; PORTUGAL; NOGUEIRA et al., 2011; MELO et al., 2009; BARLETTA et al., 2011).

A técnica SBSE tem sido empregada combinada com a quantificação feita por CLAE com detecção por fluorescência para diversos tipos de amostras (VIÑAS et al., 2008). A detecção por fluorescência é utilizada para o desenvolvimento de metodologias mais sensíveis e seletivas para análise qualitativa e quantitativa para determinados compostos, como por exemplo os alcaloides harmânicos (TSUCHIYA et al., 1999; PEREIRA; SANTOS; YARIWAKE, 2013).

\subsection{CROMATOGRAFIA LÍQUIDA DE ALTA EFICIÊNCIA (CLAE)}

Entre os métodos modernos de análise, a CLAE merece destaque pela facilidade em separar, identificar e quantificar componentes químicos em diversas amostras (LIANG; XIEP; CHAN, 2004). A CLAE é uma das técnicas analíticas mais desenvolvidas e difundidas, sendo empregada em análises de diversos campos da ciência (COLLINS; BRAGA; BONATTO, 1995; MALDANER; JARDIM, 2009).

Os métodos de separação também são importantes em química analítica devido à necessidade de se isolar substâncias provenientes de uma mistura, purificação de uma amostra e/ou separação de interferentes (OKUMURA; SOARES; CARVALHO, 2002). 
O equipamento de CLAE (Figura 6) é constituído por um injetor de amostra, bomba de alta pressão, uma coluna cromatográfica, um detector e um sistema registrador dos dados. Esta técnica requer altas pressões, vazão entre 0,1 a $10 \mathrm{~mL} \mathrm{~min}^{-1} \mathrm{e}$ as peças necessitam ter resistência à corrosão devido à variedade de solventes utilizados (SKOOG; WEST; HOLLER, 1996; MÜHLEN; LANÇAS, 2004; VILA, 2006).

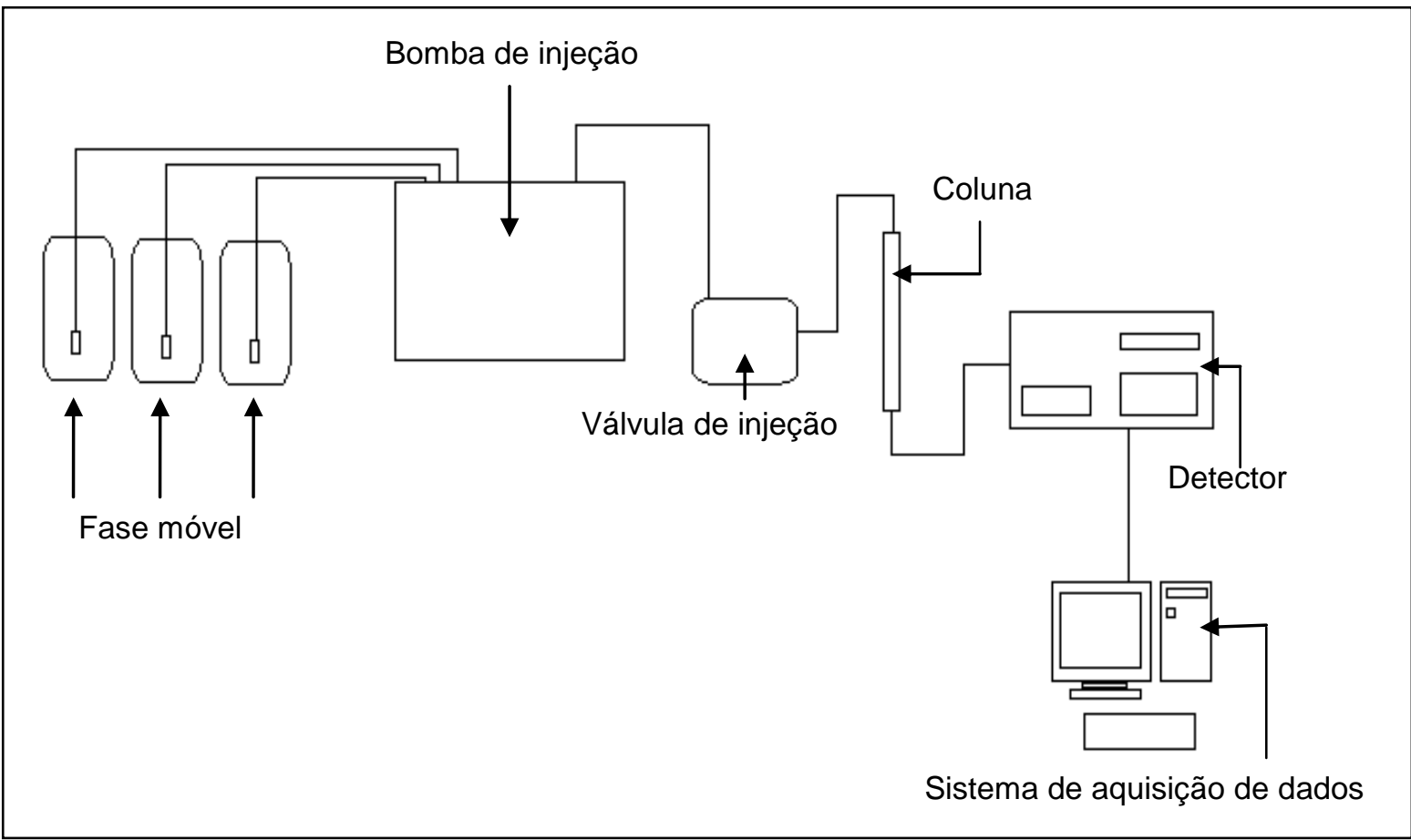

Figura 6 - Desenho esquemático de um equipamento para cromatografia líquida de alta eficiência (CLAE).

Fonte: Adaptado de (VILA, 2006).

A CLAE utiliza instrumentos sofisticados e emprega uma coluna fechada reaproveitável, podendo ser realizadas centenas de separações com a mesma coluna. Os avanços na instrumentação e nos materiais de enchimento das colunas possibilitam análises mais rápidas e separações mais eficientes (COLLINS; BRAGA; BONATTO, 1995; NETO, 2011).

A CLAE se destaca também devido à capacidade de possibilitar análises para fins qualitativos e quantitativos em diversos tipos de amostras (ambientais, farmacêuticas, biológicas e alimentos), tanto em misturas simples como nas complexas (RIBANI et al., 2004; NOGUEIRA et al., 2011).

Todavia, em fitoquímica, focalizam-se estudos qualitativos e quantitativos a partir de amostras vegetais complexas (elevado número de compostos e 
interferentes), e a CLAE tem papel fundamental na separação e isolamento destes compostos. Devido a essa complexidade, a utilização de uma coluna de guarda pode ajudar a estender a vida útil da coluna analítica (WATERS, 2013).

A CLAE é um método físico-químico de separação que consiste na distribuição dos compostos de uma mistura simples ou complexa, entre duas fases: a fase estacionária e a fase móvel. Cada composto é seletivamente retido pela fase estacionária, que resulta em migrações diferenciais destes compostos através da coluna (COLLINS; BRAGA; BONATTO, 1995; DEGANI; CASS; VIEIRA, 1998; JIM et al., 2008).

A coluna cromatográfica contém a fase estacionária. São usadas fases estacionárias de sílica, alumina e as fases quimicamente ligadas. A fase estacionária pode ser de fase normal (altamente polar), de fase reversa (não polar) ou as de fases quimicamente ligadas (polaridade variada de acordo com o grupo quimicamente ligado à sílica) (SKOOG; WEST; HOLLER, 1996; TONHI et al., 2002).

As fases reversas com grupos polares (quimicamente ligados) são úteis na separação de compostos básicos por minimizarem as interações indesejáveis com os grupos silanóis residuais (SILVA, C. et al., 2004).

A coluna $\mathrm{X}$-Terra ${ }^{\circledR} \mathrm{C}_{18}$ é um exemplo de coluna de fase quimicamente ligada. Nesta coluna, um em cada três grupamentos silanol ( $\mathrm{SiOH}$ ) é substituído por um grupo octadecil $\left(\mathrm{C}_{18}\right)$, e os grupos silanóis residuais (que permanecem ativos causando alargamento do pico) são minimizados através de uma ligação com um grupo metila $\left(\mathrm{CH}_{3}\right)$ (processo chamado de "endcapping"), resultando em uma partícula hibrida (inorgânica/orgânica) que pode ser operada em temperatura elevada e ampla faixa de $\mathrm{pH}$. A presença de 33\% menos grupos silanóis residuais, significa também que essas colunas são de alta eficiência para os picos de compostos básicos (WATERS, 2013; TONHI et al., 2002; MALDANER; COLLINS; JARDIM, 2010).

A fase móvel é composta pelos solventes utilizados na CLAE. A eluição da fase móvel pode ser feita no modo isocrático com a proporção constante das fases aquosa e orgânica, ou por gradiente de eluição, com dois ou mais sistemas de solventes com proporções alteradas, resultando em uma separação mais eficiente dos compostos (COLLINS; BRAGA; BONATTO, 1995; SKOOG; WEST; HOLLER, 1996; MÜHLEN; LANÇAS, 2004). 
Assim, os solutos eluem em ordem de coeficientes de distribuição (afinidade) pela fase estacionária, ou seja, os compostos com menor afinidade eluem com maior facilidade (menor tempo de retenção) em relação aos de maior afinidade (maior tempo de retenção) (SCOTT, 1994).

Para a detecção dos compostos separados pela CLAE, é necessária a utilização de uma técnica auxiliar, como por exemplo, o detector de fluorescência que é utilizado em análises de compostos fluorescentes (COLLINS; BRAGA; BONATTO, 1995; SILVA, C. G.; COLLINS, 2001).

\subsection{DETECTOR DE FLUORESCÊNCIA}

O detector de fluorescência é provavelmente o mais sensível de todos os detectores para CLAE (sensibilidade $1 \times 10^{-9} \mathrm{~g} \mathrm{~mL}^{-1}$ ). A detecção por fluorescência pode dispensar uma extensa preparação da amostra (etapa de "clean up") para eliminação de interferentes (PRESTES et al., 2007).

A separação por CLAE e detecção por fluorescência apresenta um alto grau de especificidade devido à seletividade da CLAE e à sensibilidade do detector que é utilizado em análises de compostos que emitem fluorescência mesmo que presentes em baixas concentrações (PRESTES et al., 2007; VALENZUELA et al., 2001).

A fluorescência é a emissão de uma luz resultante de um processo de excitação eletrônica (Figura 7), uma vez que, quando a fonte de energia excitante é desligada, a emissão de luz cessa (NERY; FERNANDES, 2004).

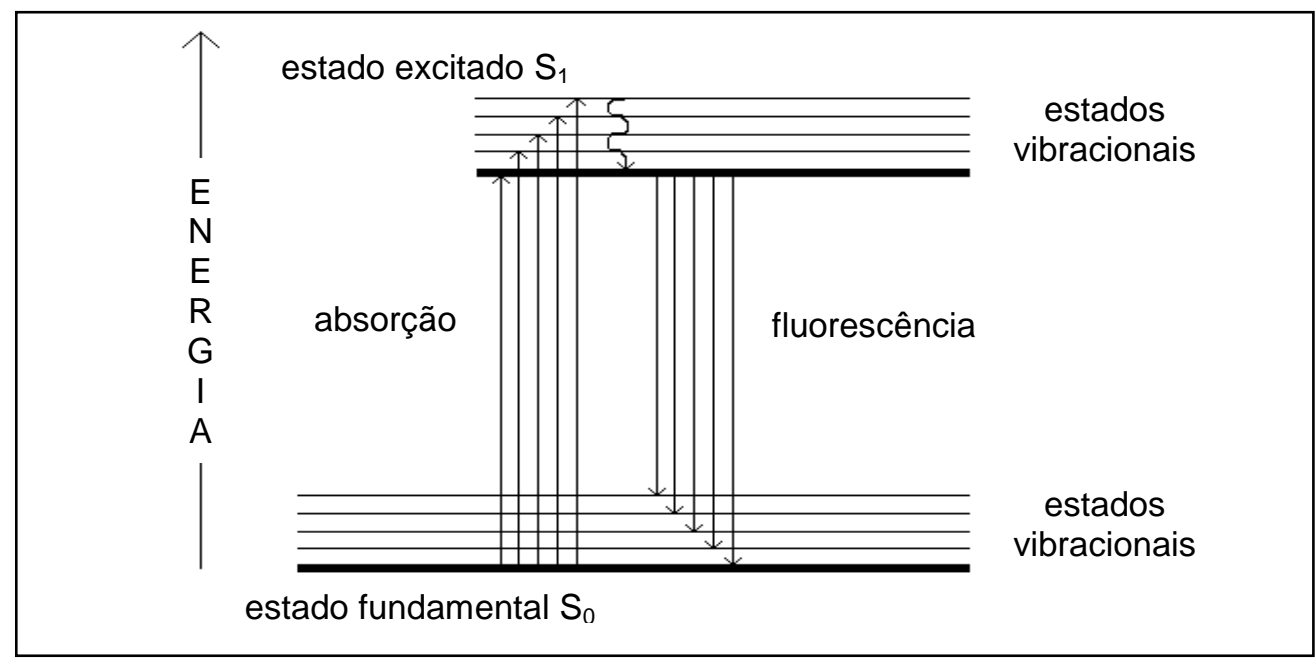

Figura 7 - Diagrama de níveis energéticos de moléculas fluorescentes. Fonte: Adaptado de (SCOTT, 1994). 
Isto ocorre quando os elétrons de uma molécula são excitados pela radiação eletromagnética, passando de um estado fundamental $\left(S_{0}\right)$ de menor energia para um estado excitado $\left(S_{1}\right)$ de maior energia. A liberação dessa energia absorvida é imediata devido a eliminação da radiação excitante (de $S_{1}$ para $\left.S_{0}\right)$, então é gerado o efeito chamado de fluorescência e é esse fenômeno utilizado no detector de fluorescência (SCOTT, 1994).

No detector de fluorescência (Figura 8) é medida a energia fluorescente de um composto que foi anteriormente excitado pela radiação ultravioleta (UV). As moléculas absorvem a radiação UV e fluorescem em diferentes frequências (NERY; FERNANDES, 2004).

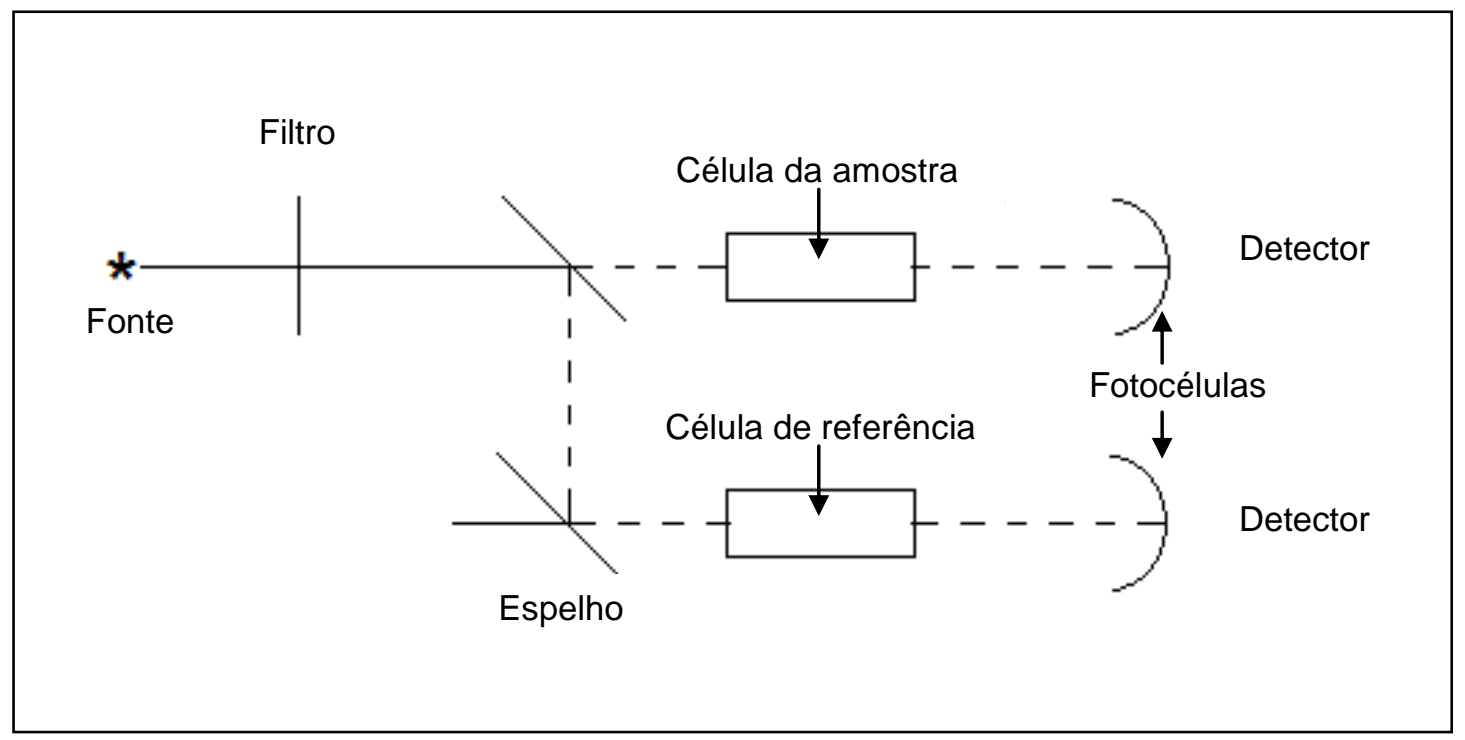

Figura 8 - Diagrama de blocos de um detector de fluorescência. Fonte: Adaptado de (SIMPSON, 1976).

A radiação UV é filtrada a partir da fonte e focalizada para duas células de detecção. Os filtros antes destas células filtram a radiação UV residual inicial e então a fotocélula detecta a radiação fluorescente, comparando com uma célula de referência permitindo que qualquer solvente fluorescente seja compensado (SIMPSON, 1976).

Na forma mais simples, a luz de uma lâmpada UV, de comprimento de onda fixo, passa através de uma célula (Figura 9) e a luz fluorescente emitida pelo composto é detectada por uma célula fotoelétrica, posicionada normalmente para a direção da luz UV excitante (SCOTT, 1994). 


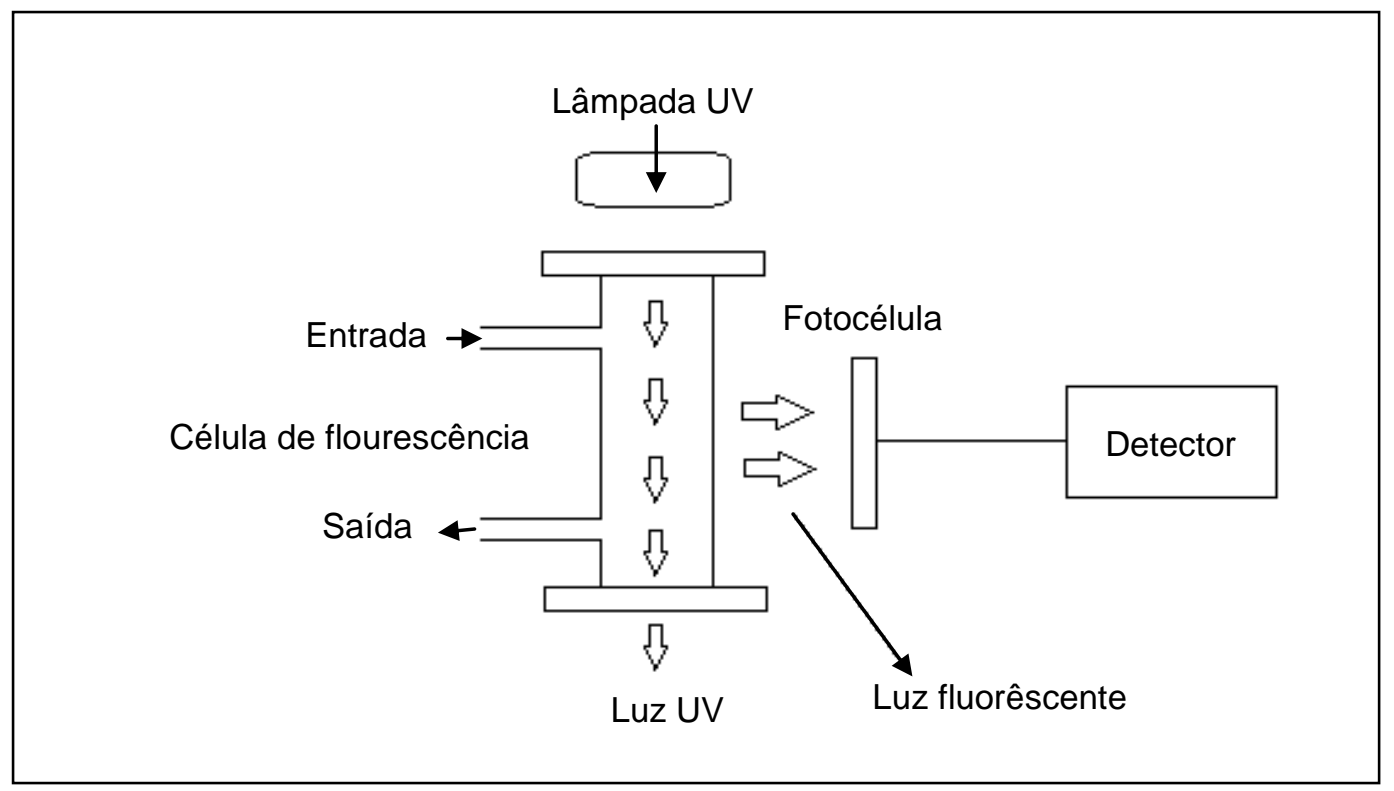

Figura 9 - Esquema de uma célula de fluorescência de um detector de fluorescência. Fonte: Adaptado de (SCOTT, 1994).

A detecção por fluorescência foi um método muito seletivo e sensível para a detecção de alcaloides harmana ( $\lambda_{\text {excitação }}=254 \mathrm{~nm}, \lambda_{\text {emissão }}=425 \mathrm{~nm}$ ) e harmina $\left(\lambda_{\text {excitação }}=254 \mathrm{~nm}, \lambda_{\text {emissão }}=410 \mathrm{~nm}\right.$ ) presentes em extratos de polpa e de polpa com sementes de maracujá azedo, com limite de detecção (LOD) de 30,3 ng $\mathrm{L}^{-1}$ e limite de quantificação (LOQ) de $0,1 \mu \mathrm{g} \mathrm{L}^{-1}$ (PEREIRA; SANTOS; YARIWAKE, 2013).

Outro método, desenvolvido por Unceta et al. (2010), mostrou-se sensível, seletivo e preciso, minimizando a preparação trabalhosa da amostra e evitando a presença de compostos interferentes com a utilização da técnida de extração por SBSE, e melhorando a seletividade com a separação por CLAE com detector de fluorescência.

Assim sendo, a separação por CLAE e detecção por fluorescência mostra-se uma técnica adequada para a qualificação e quantificação de alcaloides, e possivelmente pode ser aplicada para os estudos dos alcaloides em sementes de maracujá azedo. 


\section{OBJETIVO}

O desenvolvimento do trabalho teve como objetivo a análise de alcaloides em sementes de maracujá azedo, utilizando a Extração Sortiva em Barra de Agitação (SBSE) e identificação dos alcaloides por método cromatográfico CLAE-Flu (Cromatografia líquida de alta eficiência com detector de fluorescência).

\subsection{OBJETIVOS ESPECÍFICOS}

- Adaptação e aplicação de uma metodologia desenvolvida e validada por Pereira; Santos; Yariwake, (2013), para a pesquisa de alcaloides harmânicos em polpa e polpa com sementes, mantendo as condições ótimas de extração (para harmana e harmina) e as condições cromatográficas de análise, utilizando como amostra vegetal as sementes de maracujá azedo;

- Validar a metodologia adaptada, aplicada para a análise de alcaloides harmânicos em sementes de maracujá azedo;

- Quantificação de harmana e de harmina nas sementes de maracujá, por meio da curva de adição de padrão, por SBSE/CLAE-Flu dual. 


\section{METODOLOGIA EXPERIMENTAL}

\subsection{MATERIAL VEGETAL}

As sementes de maracujá utilizadas neste trabalho foram obtidas de frutos de Passiflora edulis Sims f. flavicarpa Degener (maracujá azedo), adquiridos no comércio local da cidade de São Carlos, São Paulo, Brasil, no mês de abril de 2013.

\subsubsection{Amostragem}

O preparo da amostra vegetal para o estudo de alcaloides harmânicos nas sementes de maracujá azedo por SBSE/CLAE-Flu dual foi realizado conforme as etapas descritas a seguir.

\subsubsection{Preparo da amostra}

Os frutos de maracujá azedo foram abertos com uma faca de serra e a polpa com sementes foi retirada com uma colher. Em seguida, as sementes foram separadas da polpa por peneiração, usando uma peneira comum com 1,4 mm de abertura.

Depois de separadas da polpa, as sementes foram colocadas em um recipiente metálico forrado com papel alumínio e deixadas em estufa a $40-45^{\circ} \mathrm{C}$ até secagem completa (por aproximadamente 72 horas).

Depois de secas, e atingido o equilíbrio térmico com o ambiente, as sementes foram trituradas em um liquidificador doméstico e todo o material vegetal foi passado em um jogo de peneiras para determinação da granulometria. Usou-se uma peneira tamis $16-32$ mesh ou ABNT $18=1,0 \mathrm{~mm}$ de abertura e outra peneira com 32 - 65 mesh ou ABNT $35=0,25$ a $0,59 \mathrm{~mm}$ de abertura. Cada amostra, de diferente granulometria, foi estocada separadamente em potes plásticos, ao abrigo da luz, da umidade e do calor. 


\subsubsection{Quarteamento de amostras sólidas}

Para obtenção das alíquotas de sementes utilizadas para extração por SBSE/CLAE-Flu dual, foi realizado o procedimento de quarteamento para amostras sólidas (Figura 10) conforme descrito pela Farmacopéia Brasileira (2010). Foram utilizadas sementes trituradas de maracujá azedo com granulometria entre 16 a 32 mesh.
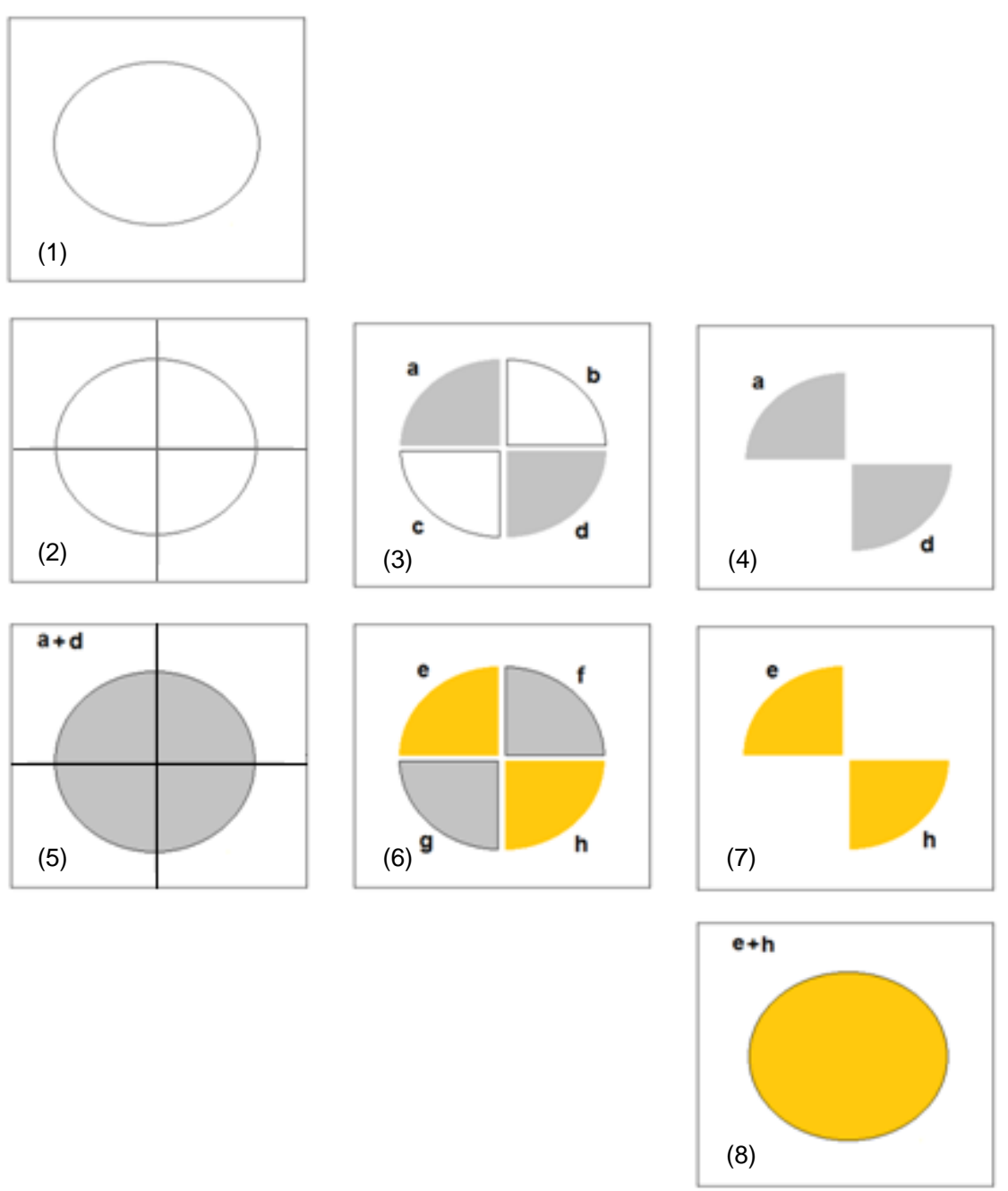

Figura 10 - Esquema representativo do método de quarteamento de amostras vegetais sólidas: (1) amostra depositada sobre uma folha de papel, (2) e dividida em quatro porções, (3) $\underline{a}$, $\underline{\mathrm{b}}, \underline{\mathrm{c}}$ e $\underline{\mathrm{d}}$, (4) selecionadas duas porções na diagonal - $\underline{\mathrm{a}}$ e $\underline{\mathrm{d}}$. (5). As porções selecionadas são novamente homogenizadas e divididas em quatro porções, (6) $\underline{e}, \underline{f}, \underline{g}$ e $\underline{h},(7)$ foram selecionadas duas partes na diagonal - $\underline{e}$ e $\underline{h}$. (8) As partes $\underline{e}$ e $\underline{h}$ são homogenizadas e utilizadas para análise.

Fonte: Adaptado de (FARMACOPÉIA BRASILEIRA, 2010). 
Inicialmente foi feita a homogeneização do material vegetal (sementes trituradas) e todo o conteúdo foi depositado sobre uma folha de papel manteiga de modo a formar um círculo.

Com o auxílio de uma espátula, o material foi dividido em quatro partes de proporções semelhantes. Posteriormente, foram selecionadas duas partes opostas em diagonal e as outras duas restantes foram reservadas.

As partes selecionadas foram novamente reunidas, homogeneizadas e divididas em quatro partes iguais; em seguida outras duas partes opostas em diagonal, foram selecionadas e homogeneizadas, sendo esta parte utilizada para a retirada das alíquotas para o processo analítico por SBSE/CLAE-Flu dual.

\subsection{SOLVENTES E REAGENTES}

Foram utilizados diclorometano, acetonitrila e metanol grau CLAE (Tedia ${ }^{\circledR}$ ), ácido fórmico grau p.a $\left(\right.$ Merck $\left.^{\circledR}\right)$, cloreto de sódio grau analítico (Spectrum ${ }^{\circledR}$ ), água purificada pelo sistema Milli-Q (Millipore ${ }^{\circledR}$ ) e padrões analíticos de harmana e harmina, ambos com $98 \%$ de pureza (Sigma-Aldrich ${ }^{\circledR}$ ).

\subsection{BARRAS DE AGITAÇÃO PARA SBSE}

As barras de agitação comerciais (Twister ${ }^{T M}$ ), para extração sortiva, foram obtidas da Gerstel ${ }^{\circledR}$. As barras utilizadas neste trabalho (Lote 0101071110) tinham $20 \mathrm{~mm}$ de comprimento com 0,5 mm de filme de PDMS (com volume de $55 \mu \mathrm{L}$ de PDMS).

\subsubsection{Ativação das barras de agitação para SBSE}

Antes da primeira utilização das barras de SBSE utilizadas no estudo dos alcaloides harmânicos, estas foram submetidas a uma etapa de tratamento térmico e condicionamento. Para o tratamento térmico foi usado um equipamento construído no IQSC (Figura 11). Este equipamento, que possibilita o tratamento térmico das barras de SBSE, foi desenvolvido e construído no IQSC como uma alternativa de menor custo aos equipamentos comerciais com a mesma finalidade (PEREIRA; YARIWAKE, 2012). 


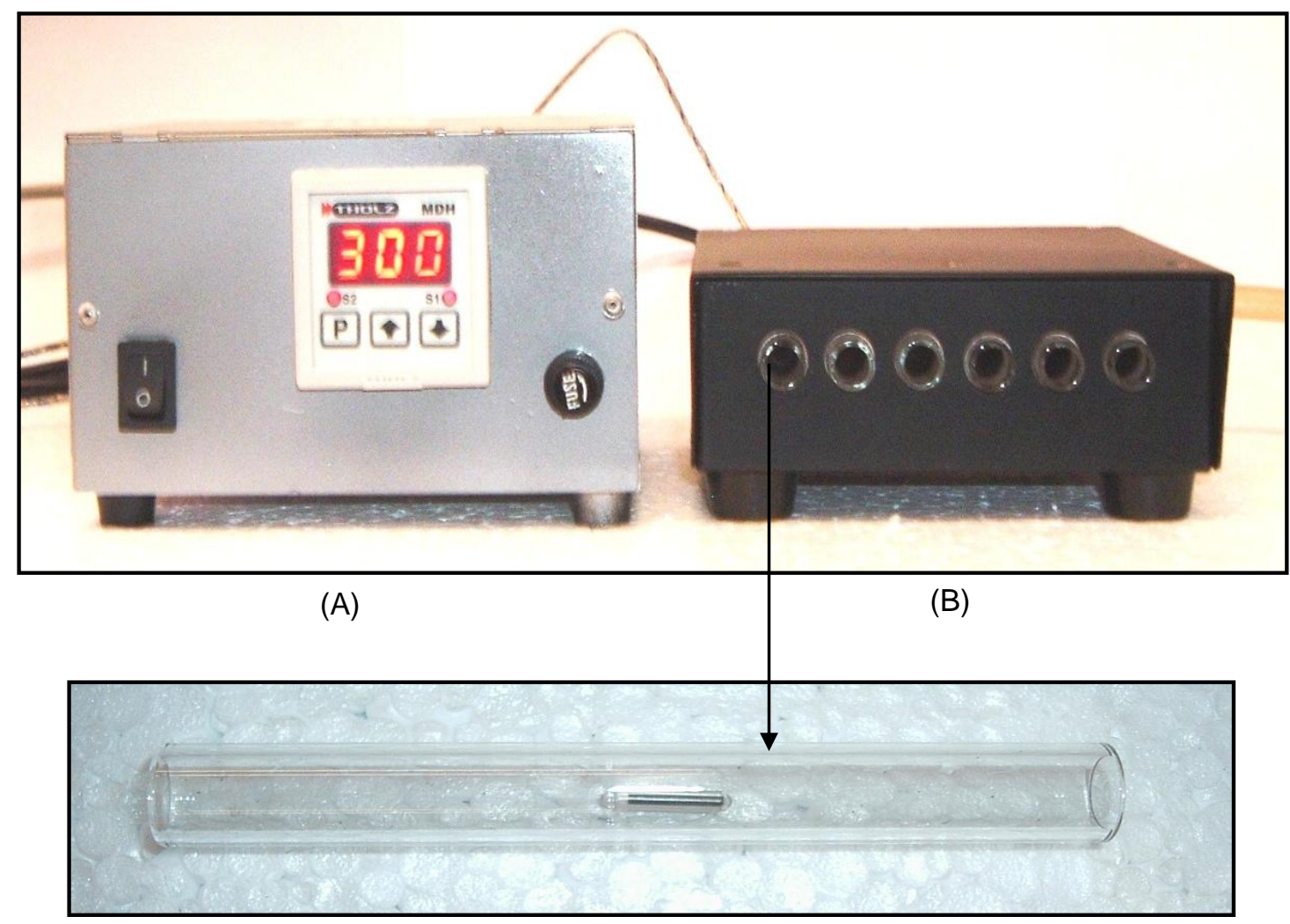

(C)

Figura 11 - Forno com corrente de nitrogênio para o condicionamento térmico das barras de SBSE, desenvolvido no IQSC: sistema de controle de temperatura e fluxo da corrente de nitrogênio (A), forno para SBSE (B) e câmara de vidro para o tratamento térmico da SBSE $(C)$.

Para o condicionamento, as barras foram agitadas por 72 horas, em $30,0 \mathrm{~mL}$ de uma solução metanol:diclorometano (50:50 v/v), trocada de 12 em 12 horas (totalizando seis trocas de solvente durante os três dias).

Depois de condicionadas, as barras foram secas em temperatura ambiente em um dessecador de vidro (com sílica), e em seguida foram submetidas a um tratamento térmico por 2 horas a $300^{\circ} \mathrm{C}$, sob corrente de nitrogênio.

\subsection{ANÁLISES PRELIMINARES}

As análises preliminares por cromatografia em camada delgada (CCD) e por Extração líquido-líquido (ELL) foram realizadas para verificar a possível presença de alcaloides harmânicos em amostras de sementes de maracujá azedo. 


\subsubsection{Cromatografia em camada delgada (CCD)}

As placas para CCD utilizadas nos testes preliminares foram preparadas manualmente, utilizando lâminas de vidro recobertas com sílica gel e ativadas em estufa à temperatura de $110^{\circ} \mathrm{C}$ por uma hora. Posteriormente passou-se a utilizar placas comerciais $\left(\right.$ Whatman $\left.^{\circledR}\right)$ com base de alumínio $(20 \times 20 \mathrm{~cm}$ ), revestida com uma camada de sílica gel (fase estacionária) com partículas de $250 \mu \mathrm{m}$. Para a análise dos extratos de sementes por $\mathrm{CCD}$ e para os cálculos dos $\mathrm{R}_{\mathrm{F}}$ dos compostos retidos, as placas foram cortadas no tamanho de $7,5 \mathrm{~cm} \times 2,5 \mathrm{~cm}$.

Uma solução padrão de harmana $20,0 \mu \mathrm{g} \mathrm{L}^{-1} \mathrm{em}$ metanol foi utilizada para comparação do $R_{F}$ e as características das manchas cromatográficas (emissão de fluorescência) obtidas por CCD, com os compostos presentes no extrato das sementes de maracujá azedo obtidos pelo método clássico de ELL.

Para as análises por CCD, 3,0 $\mu \mathrm{L}$ do extrato das sementes foram aplicados com capilar graduado sobre a placa cromatográfica. A eluição foi feita em cuba cromatográfica de vidro, usando como fase móvel uma mistura de diclorometano/metanol na proporção 9:1. Após a eluição, as placas foram secas ao ar livre e visualizadas sob luz UV em $\lambda 366 \mathrm{~nm}$.

As manchas cromatográficas do extrato foram comparadas com o padrão de harmana por meio da visualização da emissão de fluorescência e do fator de retenção $\left(R_{F}\right)$, calculado com a Equação 2 .

$$
R_{F}=\frac{\text { distância }(\mathrm{cm}) \text { percorrida pela substância }}{\text { distância }(\mathrm{cm}) \text { percorrida pelo eluente }}
$$

\subsubsection{Extração líquido-líquido (ELL)}

Para o preparo dos extratos por ELL foi preparada uma solução utilizando 1,0 grama de sementes, adicionando-se $30,0 \mathrm{~mL}$ de uma mistura de solventes metanol/água $70 \%$ e extraiu-se por 10 minutos em banho de ultrassom. Depois deste tempo, a solução resultante foi submetida à centrifugação a 5000 rpm durante 20 minutos e o sobrenadante foi retirado com o auxílio de uma pipeta de Pasteur e em seguida foi filtrado em papel de filtro. 
$\mathrm{O} \mathrm{pH}$ deste filtrado foi corrigido para o $\mathrm{pH}=10,0$ com adição de 2,0 $\mathrm{mL}$ de hidróxido de amônio 0,1 M. Ajustado o pH, a solução foi transferida para um funil de separação, extraindo-se 3 vezes com 30,0 mL de diclorometano, a temperatura ambiente.

A fase de diclorometano (mais densa) foi separada da fase aquosa e submetida à evaporação do solvente em rotaevaporador até secura total, e então resuspensa em metanol com o volume ajustado em um balão volumétrico para 2,0 mL, obtendo-se o extrato metanólico das sementes.

\subsection{MÉTODO SBSE/CLAE-Flu dual}

O método SBSE/CLAE-Flu dual utilizado neste trabalho, foi anteriormente desenvolvido e validado somente para a detecção de alcaloides harmânicos em polpa e polpa com sementes de maracujá, pelo Grupo de Análise Fitoquímica do Instituto de Química de São Carlos - Universidade de São Paulo (PEREIRA; SANTOS; YARIWAKE, 2013).

Neste método, para a extração da harmana, uma alíquota de 1,0 mL de polpa ou de polpa com sementes de maracujá é colocada em um béquer com 5,0 gramas de $\mathrm{NaCl}, 2,0 \mathrm{~mL}$ de $\mathrm{NaOH}$ 1,0 $\mathrm{mol} \mathrm{L}^{-1}$ (para extração em $\mathrm{pH}=13,0$ ) e 7,0 $\mathrm{mL}$ de água Milli-Q, com volume final de $10,0 \mathrm{~mL}$.

Para extração da harmina, uma segunda alíquota de polpa ou de polpa com sementes de maracujá é colocada em outro béquer de 50,0 mL com 5,0 gramas de $\mathrm{NaCl}, 1,0 \mathrm{~mL}$ de $\mathrm{NH}_{4} \mathrm{OH} 0,1 \mathrm{~mol} \mathrm{~L}^{-1}$ (para extração em $\mathrm{pH}=10,0$ ) e 8,0 mL de água Milli-Q, com volume final de 10,0 mL. Utiliza-se uma barra de SBSE em cada béquer, submete-se a agitação por 120 minutos e dessorção líquida por ultrassom, em $150 \mu \mathrm{L}$ de metanol, durante 60 minutos cada uma das barras.

\subsubsection{Análise das sementes pelo modo SBSE/CLAE-Flu dual}

O método SBSE/CLAE-Flu dual foi aplicado e validado neste trabalho para a detecção de harmana e harmina em sementes de maracujá azedo.

As condições ( $\mathrm{pH}, \% \mathrm{NaCl}$, tempo de extração, tempo de dessorção e solvente de dessorção) estabelecidas e validadas em trabalho anterior (PEREIRA; SANTOS; YARIWAKE, 2013) para a extração dos alcaloides da polpa e da polpa com 
sementes de maracujá azedo, foram mantidas para a extração dos alcaloides das sementes.

Para a análise simultânea por SBSE/CLAE-Flu dual das sementes de maracujá azedo, foram utilizadas duas alíquotas de 1,0 grama de uma mesma amostra de sementes. Uma alíquota foi submetida às condições de extração para harmana e a outra para as condições de extração da harmina, utilizando uma barra de SBSE para cada alíquota (Figura 12).

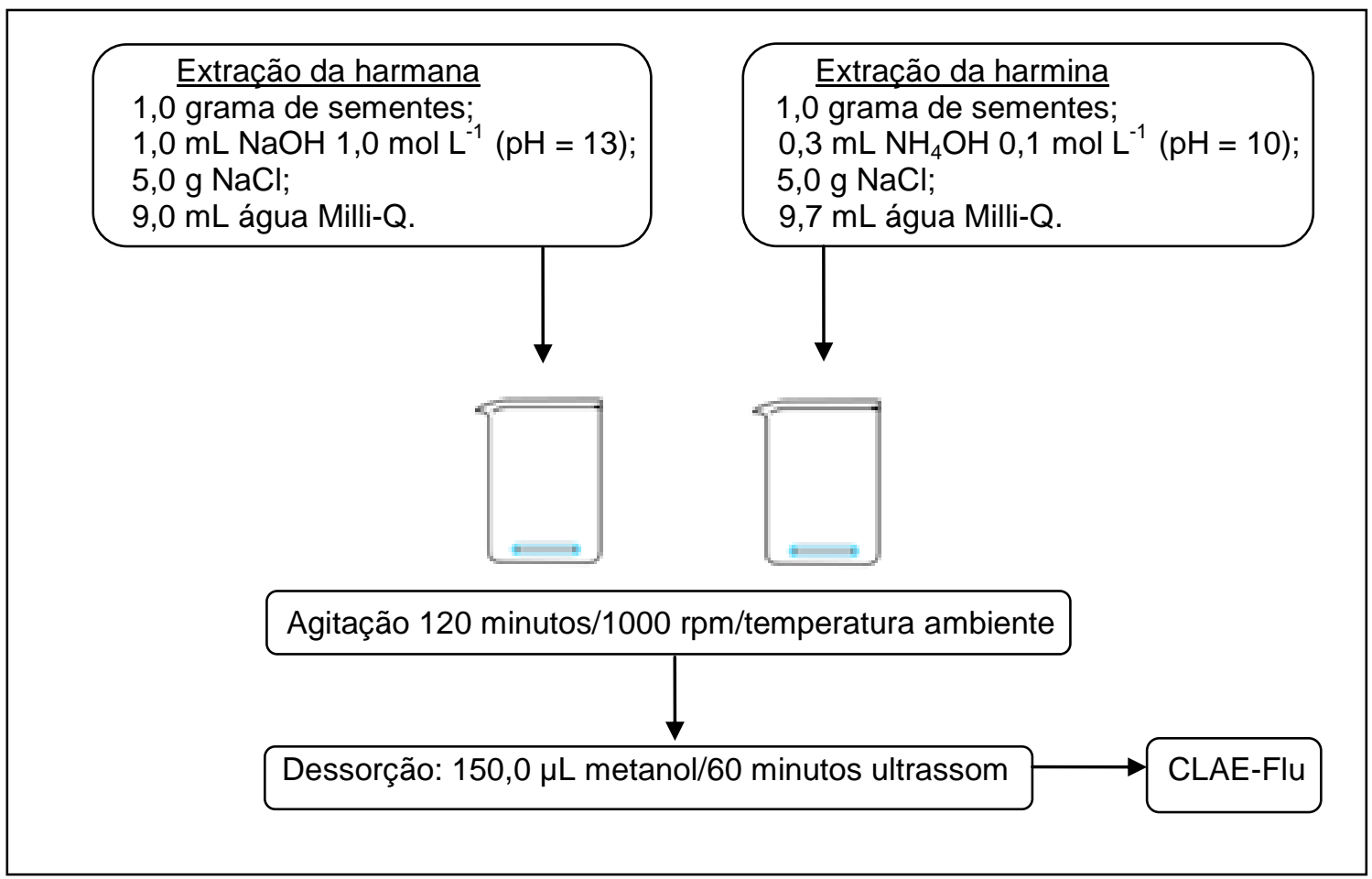

Figura 12 - Esquema do método SBSE/CLAE-Flu dual adaptado para a análise de alcaloides harmânicos em sementes de maracujá azedo.

As análises para a harmana e a harmina foram conduzidas simultaneamente, em paralelo, usando alíquotas de uma mesma amostra. Para a extração da harmana, uma alíquota de 1,0 grama de sementes foi colocada em um béquer de $50,0 \mathrm{~mL}$ com 5,0 gramas de $\mathrm{NaCl}, 1,0 \mathrm{~mL}$ de $\mathrm{NaOH} 1,0 \mathrm{~mol} \mathrm{~L}^{-1}$ (para o $\left.\mathrm{pH}=13,0\right) \mathrm{e}$ 9,0 mL de água Milli-Q, com volume final de 10,0 mL. Para a extração da harmina, uma segunda alíquota foi colocada em outro béquer de $50,0 \mathrm{~mL}$ com 5,0 gramas de $\mathrm{NaCl}, 0,3 \mathrm{~mL}_{\text {de }} \mathrm{NH}_{4} \mathrm{OH} 0,1 \mathrm{~mol} \mathrm{~L}^{-1}$ (para o $\mathrm{pH}=10,0$ ) e 9,5 mL de água Milli-Q, com volume final de $10,0 \mathrm{~mL}$. 
Em cada béquer foi adicionada uma barra de SBSE (Twister Gerstel ${ }^{\circledR}$ ), deixada em agitação magnética por 120 minutos em temperatura ambiente. Depois de atingido o tempo de agitação as barras foram removidas, limpas com água Milli-Q e secas com lenço de papel e dessorvidas com solvente.

Para a dessorção líquida, as barras foram colocadas (uma por vez) em um mesmo vial cônico contendo 150,0 $\mu \mathrm{L}$ de metanol, e cada barra deixada durante 60 minutos em banho de ultrassom. Após a dessorção líquida, as barras foram removidas do vial e a solução metanólica foi injetada diretamente para a análise por CLAE-Flu, sob as condições cromatográficas especificas para 0 método SBSE/CLAE-Flu dual (seção 4.6).

\subsubsection{Limpeza das barras após extração por SBSE}

Após o processo extrativo pelo método SBSE/CLAE-Flu dual e a dessorção líquida, as barras foram submetidas a um processo de limpeza entre uma extração e outra, para assegurar a remoção dos analitos restantes na fase de PDMS e evitar a interferência destes (mesmo que em quantidades muito baixas), que poderia comprometer a eficiência do método nas análises seguintes.

Conforme a recomendação do fabricante $\left(\right.$ Gerstel $\left.^{\circledR}\right)$ para o manuseio das barras, a limpeza foi feita utilizando uma mistura de metanol e diclorometano (50:50 v/v) como solução de limpeza. As barras foram colocadas sob agitação durante 3 horas, em temperatura ambiente, com 30,0 mL desta solução.

Após este procedimento, a confirmação da limpeza das barras sem a evidência de interferentes foi comprovada através de análises em branco por CLAE-Flu.

\subsection{ANÁLISE CROMATOGRÁFICA POR CLAE-Flu}

As análises por CLAE-Flu foram feitas usando um Cromatógrafo Waters Alliance 2695, acoplado a um detector de fluorescência Waters 2475, controlados por computador com o software Empower Waters ${ }^{\circledR}$.

As condições cromatográficas do método SBSE/CLAE-Flu dual utilizadas no estudo de alcaloides na polpa e polpa com sementes foram mantidas (Tabela 1) (PEREIRA; SANTOS; YARIWAKE, 2013). 
A identificação dos alcaloides nos extratos das sementes foi feita pela comparação direta do cromatograma da amostra com o tempo de retenção $\left(t_{R}\right)$ e com os espectros de fluorescência de padrões analíticos de harmana e de harmina, com $98 \%$ de pureza.

Tabela 1 - Condições cromatográficas estabelecidas para o método SBSE/CLAE-Flu dual na análise de alcaloides harmânicos em sementes de maracujá azedo.

Condições Cromatográficas

Especificações

Equipamento Waters Alliance 2695.

Fase estacionária: $\quad$ Coluna de guarda $\quad$ X-Terra ${ }^{\circledR} \mathrm{C}_{18}(20 \mathrm{~mm} \times 4,6 \mathrm{~mm}$ i.d., $5 \mu \mathrm{m})-$ Waters;

Coluna $\quad X$-Terra ${ }^{\circledR} \mathrm{C}_{18}(250 \mathrm{~mm} \times 4,6 \mathrm{~mm}$ i.d.; $5 \mu \mathrm{m})$-Waters;

Temperatura $\quad 25^{\circ} \mathrm{C}$.

Fase móvel: $\quad$ Solventes acetonitrila (solvente A) e água Milli-Q (solvente B), ambas acidificadas com $0,5 \%$ de ácido fórmico;

Eluição Modo gradiente:

- $20 \%$ até $34 \%$ de $A$ em 10 minutos;

- $34 \%$ até $20 \%$ de $A$ em 8 minutos;

Fluxo $\quad 1,0 \mathrm{~mL} \mathrm{~min}^{-1}$;

Volume de injeção $\quad 10,0 \mu \mathrm{L}$.

da amostra

Detecção:

Detector de fluorescência Waters 2475;

Comprimento de

onda $(\lambda)$
Faixa de varredura: $\lambda_{\text {emissão }}=390 \mathrm{~nm}-490 \mathrm{~nm}$.

$\lambda_{\text {excitação }}=254 \mathrm{~nm}$ e $\lambda_{\text {emissão }}=425 \mathrm{~nm}$ para a harmana.

$\lambda_{\text {excitacão }}=254 \mathrm{~nm}$ e $\lambda_{\text {emissão }}=410 \mathrm{~nm}$ para a harmina.

Aquisição de dados:

Software Empower Waters

Fonte: Adaptado de (PEREIRA; SANTOS; YARIWAKE, 2013).

\subsection{ANÁLISE QUANTITATIVA DOS ALCALOIDES HARMÂNICOS}

Devido à complexidade da amostra e a possibilidade de interferência da matriz, a quantificação dos alcaloides das sementes de maracujá azedo foi feita pelo método de adição de padrão (RIBANI et al., 2004), utilizando curvas analíticas construídas em triplicata, pelo método SBSE/CLAE-Flu dual com amostras de sementes fortificadas com alíquotas de soluções padrão de harmana e de harmina 
(100,0 $\mu \mathrm{g} \mathrm{L}^{-1}$ em metanol). A adição do volume de solução estoque $\left(100,0 \mu \mathrm{g} \mathrm{L}^{-1}\right)$ de modo a obter cinco concentrações diferentes $\left(0,1 ; 5,0 ; 10,0 ; 15,0\right.$ e 20,0 $\left.\mathrm{g} \mathrm{L} \mathrm{L}^{-1}\right)$ foi feita depois da adição do volume de água Milli-Q (necessário para completar $10 \mathrm{~mL}$ ) na amostra de sementes, e antes da correção do $\mathrm{pH}$ da amostra ( $\mathrm{NaOH}$ para extração da harmana e $\mathrm{NH}_{4} \mathrm{OH}$ para extração da harmina). Após a correção do pH $(\mathrm{pH}=13$ para a harmana e $\mathrm{pH}=10$ para a harmina) foi colocada uma barra de SBSE com fase extratora de PDMS para extração destes compostos. A Tabela 2 apresenta as quantidades dos reagentes utilizados para a extração destes alcaloides.

Tabela 2 - Quantidades utilizadas dos reagentes e alíquotas de solução estoque $\left(100 \mu \mathrm{g} \mathrm{L}^{-1}\right)$ de harmana e de harmina, para construção das curvas analíticas pele método de adição de padrão.

\begin{tabular}{|c|c|c|c|c|c|c|c|}
\hline $\begin{array}{l}\text { Solução } \\
\text { estoque } \\
100 \mu \mathrm{L}^{-1}\end{array}$ & $\begin{array}{c}\text { Concentração* } \\
\left(\mu \mathrm{L}^{-1}\right)\end{array}$ & $\begin{array}{c}\text { Volume de } \\
\text { solução } \\
\text { estoque } \\
100 \mu \mathrm{L} \mathrm{L}^{-1} \\
(\mathrm{~mL})\end{array}$ & $\begin{array}{l}\text { Massa de } \\
\text { sementes } \\
\text { (g) }\end{array}$ & $\begin{array}{c}\mathrm{NaCl} \\
(\mathrm{g})\end{array}$ & $\begin{array}{c}\mathrm{NaOH} \\
\mathrm{pH} 13 \\
(\mathrm{~mL})\end{array}$ & $\begin{array}{c}\mathrm{NH}_{4} \mathrm{OH} \\
\mathrm{pH} 10 \\
(\mathrm{~mL})\end{array}$ & $\begin{array}{c}\mathrm{H}_{2} \mathrm{O} \\
\text { Milli-Q } \mathrm{Q} \\
(\mathrm{mL})\end{array}$ \\
\hline harmana & $\begin{array}{c}0,1 \\
5,0 \\
10,0 \\
15,0 \\
20,0\end{array}$ & $\begin{array}{l}0,01 \\
0,05 \\
0,10 \\
0,15 \\
0,20\end{array}$ & $\begin{array}{l}1,00 \\
1,00 \\
1,00 \\
1,00 \\
1,00\end{array}$ & $\begin{array}{l}5,00 \\
5,00 \\
5,00 \\
5,00 \\
5,00\end{array}$ & $\begin{array}{l}1,00 \\
1,00 \\
1,00 \\
1,00 \\
1,00\end{array}$ & $\begin{array}{l}- \\
- \\
- \\
- \\
-\end{array}$ & $\begin{array}{l}8,99 \\
8,95 \\
8,90 \\
8,85 \\
8,80\end{array}$ \\
\hline harmina & $\begin{array}{c}0,1 \\
5,0 \\
10,0 \\
15,0 \\
20,0\end{array}$ & $\begin{array}{l}0,01 \\
0,05 \\
0,10 \\
0,15 \\
0,20\end{array}$ & $\begin{array}{l}1,00 \\
1,00 \\
1,00 \\
1,00 \\
1,00\end{array}$ & $\begin{array}{l}5,00 \\
5,00 \\
5,00 \\
5,00 \\
5,00\end{array}$ & $\begin{array}{l}- \\
- \\
- \\
-\end{array}$ & $\begin{array}{l}0,30 \\
0,30 \\
0,30 \\
0,30 \\
0,30\end{array}$ & $\begin{array}{l}9,69 \\
9,65 \\
9,60 \\
9,55 \\
9,50\end{array}$ \\
\hline
\end{tabular}

* valores nominais. Para o cálculo da curva analítica utilizou-se os valores corrigidos considerando 0 grau de pureza dos padrões (98\%).

A concentração de harmana e de harmina na amostra foi calculada utilizando o programa Microsoft Office Excel 2007, pela extrapolação da curva analítica cortando o eixo das abcissas, relacionando para cada ponto da curva a concentração conhecida da solução padrão adicionada, com base na área do pico referente à harmana e à harmina.

Os dados foram expressos como (média $\pm \mathrm{DP}$ ). Os resultados foram expressos em $\mu \mathrm{g}$ de alcaloides contidos em 1,0 grama de sementes $\left(\mu \mathrm{g} \mathrm{g}^{-1}\right)$. 


\subsection{VALIDAÇÃO DO MÉTODO ANALÍTICO}

Conforme a definição da ANVISA (2003), a validação deve garantir que o método atenda às exigencias das aplicações analíticas, assegurando a confiabilidade dos resultados.

A validação foi realizada de acordo com as diretrizes do protocolo da International Conference Harmonization (ICH), que diz respeito aos requisitos técnicos para o registro de medicamentos de uso humano, que considera e estabelece a avaliação dos parâmetros de especificidade, linearidade, exatidão, precisão (repetibilidade e precisão intermediária), limite de detecção (LOD) e limite de quantificação (LOQ) (ICH, 2010).

Para os ensaios de linearidade, exatidão e precisão do método SBSE/CLAE-Flu dual com amostras de sementes de maracujá azedo, as amostras foram fortificadas, para obtenção dos diferentes níveis de concentração, antes do processo de extração com as barras de SBSE, conforme descrito na Tabela 2. A faixa de concentração foi estabelecida, após ensaios preliminares, entre $0,1-20,0 \mu \mathrm{g} \mathrm{L}{ }^{-1}$.

\subsubsection{Especificidade}

Para determinar a especificidade, foram realizados testes de pureza dos picos de harmana e de harmina pela sobreposição dos espectros de fluorescência em diferentes pontos dos picos (ápice, curva ascendente e descendente), obtidos através do detector de fluorescência, com $\lambda_{\text {excitação }}=254 \mathrm{~nm}$ e $\lambda_{\text {emissão }}=425 \mathrm{~nm}$ para a harmana e $\lambda_{\text {excitação }}=254 \mathrm{~nm}$ e $\lambda_{\text {emissão }}=410 \mathrm{~nm}$ para a harmina.

Para atestar a pureza destes picos na amostra, os respectivos espectros de fluorescência foram comparados com os obtidos a partir das soluções padrão de harmana e de harmina. Os picos foram considerados puros quando as secções espectrais entre os pontos coincidiram. 


\subsubsection{Linearidade}

A linearidade foi avaliada por meio do coeficiente de correlação linear da curva analítica construída em triplicata, pelo método de adição de padrão, através da análise das amostras fortificadas em cinco níveis de concentração (ICH, 2010).

Alíquotas da solução padrão de harmana e de harmina na concentração de $100,0 \mu \mathrm{g} \mathrm{L}^{-1}$ foram adicionadas aos extratos no início das extrações, de forma a obter cinco concentrações finais $\left(0,1 ; 5,0 ; 10,0 ; 15,0\right.$ e $\left.20,0 \mu \mathrm{g} \mathrm{L}^{-1}\right)$, cada uma analisada em triplicata. Os dados foram processados por meio do programa Microsoft Office Excel 2007.

\subsubsection{Exatidão}

A exatidão foi obtida por ensaios de recuperação, com a adição de uma quantidade conhecida do padrão na amostra de sementes no início da extração por SBSE/CLAE-Flu dual, em três níveis diferentes de concentração $(0,1 ; 10,0$ e $\left.20,0 \mu \mathrm{g} \mathrm{L}^{-1}\right)$. O valor experimental foi determinado para cada nível de concentração por extrações em triplicatas, totalizando 9 determinações.

A exatidão foi expressa como a percentagem de desvio entre a quantidade de padrão encontrado pela análise por SBSE/CLAE-Flu dual (valor experimental) e a quantidade adicionada nos três níveis de concentração examinados (valor teórico), sendo calculada por meio da Equação 3.

$$
\text { Exatidão }(\%)=\frac{\text { valor experimental } x 100}{\text { valor teórico }}
$$

\subsubsection{Precisão}

A repetibilidade (precisão intra-análises) foi avaliada em um mesmo dia. Para isso, foram feitas extrações pelo método SBSE/CLAE-Flu dual, com análises em triplicata de três amostras fortificadas $(n=9)$, em três níveis diferentes de concentração $\left(0,1 ; 10,0\right.$ e 20,0 $\left.\mathrm{g} \mathrm{L} \mathrm{L}^{-1}\right)$ usando soluções padrão de harmana e de harmina (100,0 $\mathrm{gg} \mathrm{L}^{-1}$ em metanol) adicionadas antes da extração por SBSE, aos $10,0 \mathrm{~mL}$ (volume final) de água Milli-Q, contendo a alíquota de 1,0 grama de 
sementes e os demais reagentes necessários para o ajuste das condições de extração para cada alcaloide.

A precisão intermediária (precisão inter-análises) foi avaliada em três dias diferentes. As análises foram feitas por extrações por SBSE/CLAE-Flu dual, em triplicatas de três amostras fortificadas $(n=3)$, em três níveis diferentes de concentração $\left(0,1 ; 10,0\right.$ e 20,0 $\left.\mathrm{Mg} \mathrm{L}^{-1}\right)$ usando soluções padrão de harmana e de harmina $\left(100,0 \mu \mathrm{g} \mathrm{L}^{-1}\right.$ em metanol) adicionadas antes da extração por SBSE, aos 10,0 mL (volume final) de água Milli-Q, contendo a alíquota de 1,0 grama de sementes e os demais reagentes necessários para o ajuste das condições de extração para cada alcaloide.

A precisão foi expressa pelos cálculos de desvio padrão relativo (DPR\%) por meio da Equação 4, entre as áreas dos picos cromatográficos obtidos para cada concentração em triplicata.

$$
\operatorname{DPR}(\%)=\frac{\text { desvio padrão } \times 100}{\text { área média determinada }}
$$

\subsubsection{Limite de Detecção e Limite de Quantificação}

O Limite de Detecção (LOD) e o Limite de Quantificação (LOQ) foram determinados experimentalmente a partir da análise de uma solução padrão estoque de harmana na concentração de $100,0 \mu \mathrm{g} \mathrm{L}^{-1}$ e outra de harmina na concentração de $100,0 \mu \mathrm{g} \mathrm{L}^{-1}$ (ambas em metanol), diluídas sucessivamente obtendo-se outras soluções de concentração conhecidas, até alcançar os valores para LOD e LOQ para ambos os alcaloides.

A menor concentração que pode ser detectada (LOD) foi determinada analisando soluções diluídas em concentrações conhecidas e estabelecendo a relação de 3:1 entre a área do sinal e do ruído da linha de base $(\mathrm{ICH}, 2010)$.

A menor concentração que pode ser quantificada (LOQ) foi determinada analisando soluções diluídas em concentrações conhecidas e estabelecendo a relação de 10:1 entre a área do sinal e do ruído da linha e base (ICH, 2010). 


\section{RESULTADOS E DISCUSSÃO}

O suco caseiro de maracujá geralmente é preparado utilizando a polpa junto com as sementes do fruto, batidas em um liquidificador doméstico. A trituração das sementes juntamente com a polpa pode contribuir com o aumento na quantidade de alcaloides harmânicos no suco (PEREIRA; SANTOS; YARIWAKE, 2011), por isso os estudos analíticos para a qualificação e a quantificação destes alcaloides nas sementes de maracujá são importantes.

Para a análise quantitativa dos alcaloides harmana e harmina em sementes de maracujá azedo por SBSE/CLAE-Flu dual, foi necessário realizar a adaptação e a validação do método para amostras de sementes, considerando a diferença física e química entre as amostras: a polpa é uma amostra viscosa e de maior acidez em relação às sementes, que possui uma parte dura de coloração marrom escura (parte externa da semente) e outra parte mole e mais clara (parte interna da semente) além da presença de óleos vegetais em ambas as partes (Figura 13).

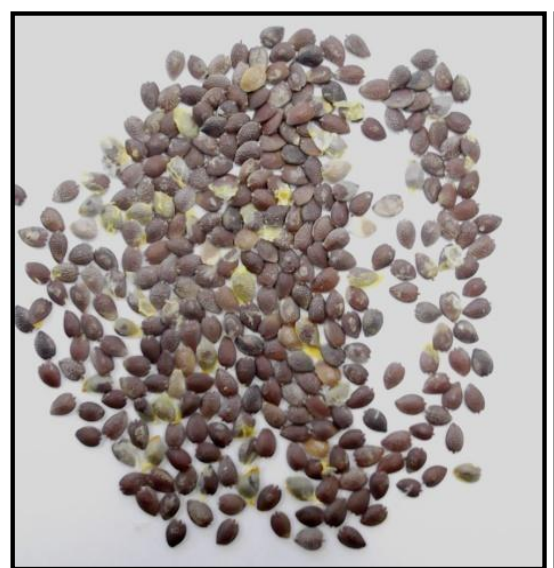

(A)

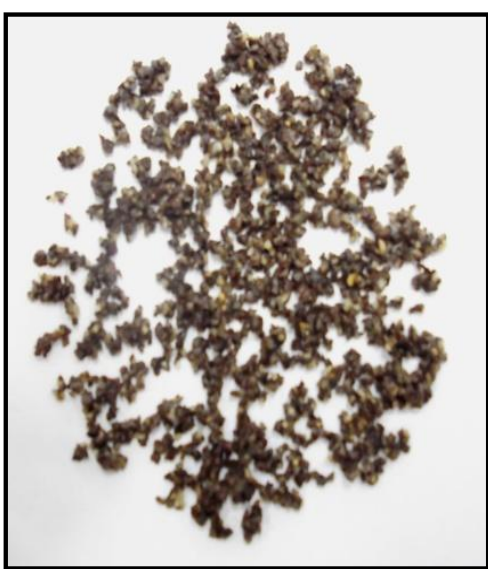

(B)

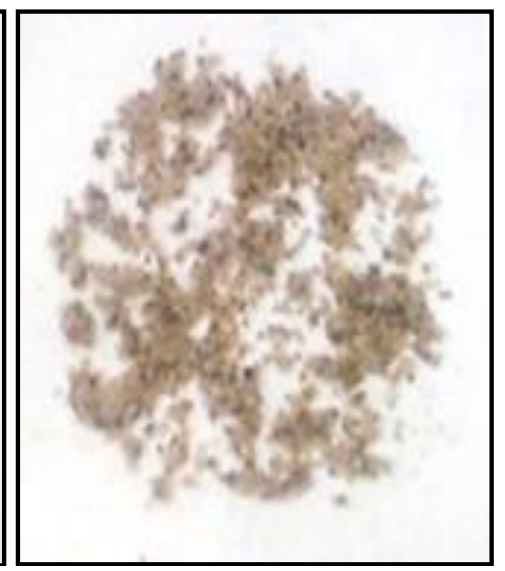

(C)

Figura 13 - Sementes inteiras de maracujá azedo $(A)$, parte externa $(B)$ e parte interna $(C)$.

\subsection{PREPARAÇÃO DA AMOSTRA VEGETAL}

Para o preparo da amostra, a polpa com as sementes foram retiradas do fruto de maracujá e separadas por peneiração. Após a separação da polpa e das sementes, a polpa foi armazenada em frascos plásticos e estocada sob resfriamento $\left(-20^{\circ} \mathrm{C}\right)$ (Figura 14). 


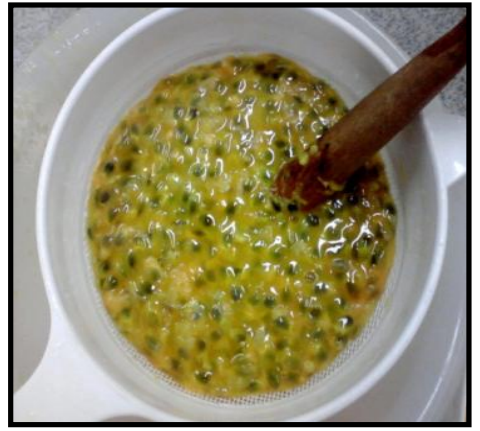

(A)

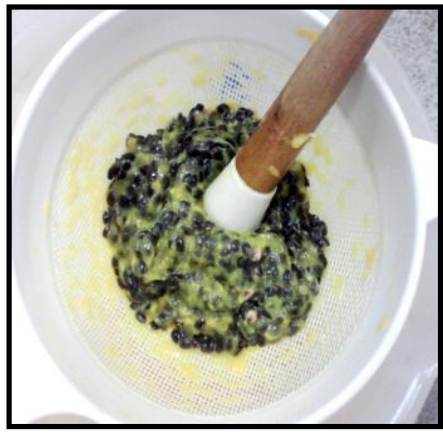

(B)

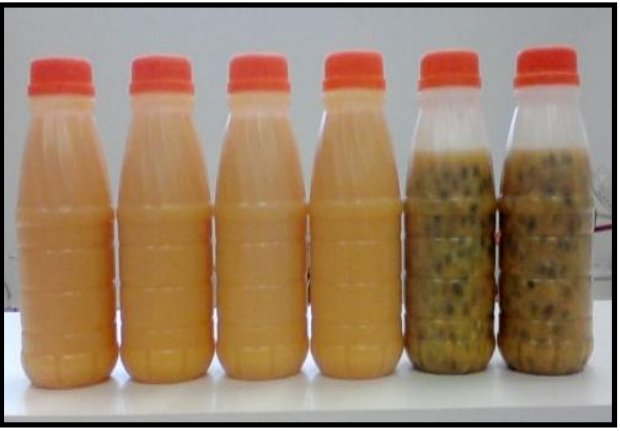

(C)

Figura 14 - Etapas do preparo da amostra vegetal: (A) e (B) processo de separação das sementes por peneiração; (C) armazenagem da polpa em frascos plásticos $\left(-20^{\circ} \mathrm{C}\right)$.

Depois de secas em estufa $\left(35-40^{\circ} \mathrm{C}\right.$ por 72 horas), as sementes foram trituradas e separadas em três granulometrias diferentes: o material com o menor tamanho de partículas (a parte mais interna das sementes) com granulometria entre 32 a 65 mesh $(0,25$ a 0,59 $\mathrm{mm})$; as outras duas, que correspondem às cascas das sementes, foram classificadas como material de granulometria entre 16 a 32 mesh $(1,0 \mathrm{~mm})$ e granulometria inferior a 16 mesh (> 1,0 mm) (Figura 15).

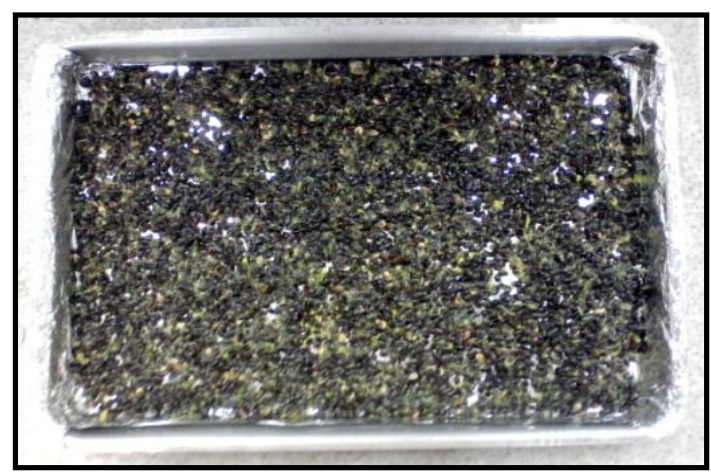

(A)

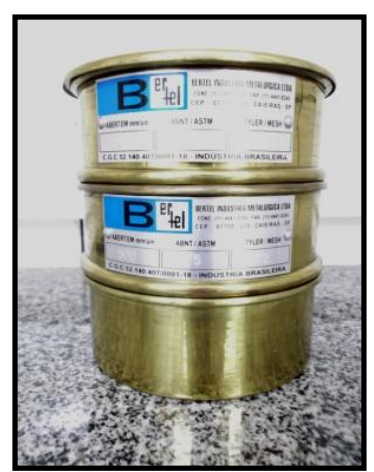

(B)

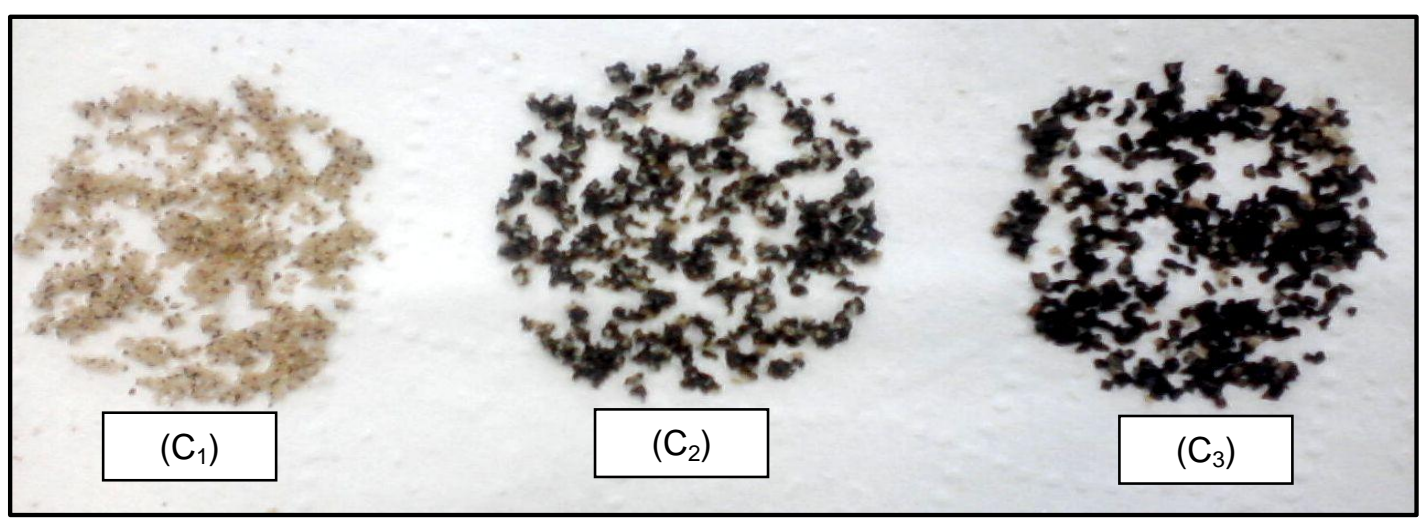

(C)

Figura 15 - Secagem e determinação da granulometria das sementes de maracujá azedo: (A) sementes depositadas em uma forma metálica para secagem em estufa $35-40 \stackrel{\circ}{\circ}$ por 72 horas; (B) peneiras para determinação da granulometria e sementes trituradas de maracujá azedo $(C)$ : $\left(C_{1}\right)$ material com granulometria entre 32 a 65 mesh; $\left(C_{2}\right)$ com granulometria entre 16 a 32 mesh; e $\left(C_{3}\right)$ com granulometria inferior a 16 mesh. 
Para os estudos preliminares e analíticos dos alcaloides harmânicos (harmana e harmina) com as sementes de maracujá azedo, foi utilizada como amostra vegetal as sementes trituradas com granulometria entre 16 a 32 mesh por conter partículas tanto da parte externa como da parte interna das sementes, possibilitando o estudo dos alcaloides com todas as partes da semente.

\subsection{ANÁLISE CROMATOGRÁFICA POR CCD}

A etapa preliminar utilizando a CCD consistiu na verificação da presença de compostos fluorescentes, para avaliar a presença dos alcaloides harmânicos em amostras de sementes. Análises realizadas por cromatografia em camada delgada (CCD) com revelação sob luz UV nos $\lambda=254 \mathrm{~nm}$ e $366 \mathrm{~nm}$ possibilitaram a verificação da presença de alcaloides por meio da emissão de fluorescência (FARAH et al., 2008).

Os ensaios por CCD incluíram a comparação direta dos extratos de sementes de maracujá azedo obtidos por ELL, com um padrão comercial autêntico do alcaloide harmana ( $98 \%$ de pureza), através dos fatores de retenção $\left(R_{F}\right)$ das substâncias fluorescentes presentes nas amostras de sementes de maracujá azedo. A Figura 16 mostra a comparação entre os extratos das amostras de sementes de maracujá azedo com a solução padrão de harmana $20,0 \mathrm{mg} \mathrm{L}^{-1}$.

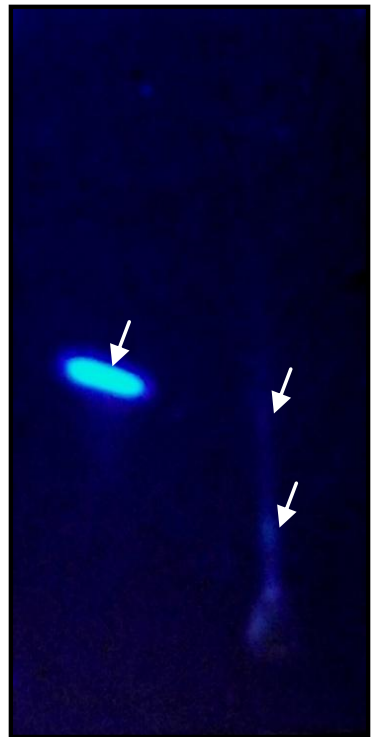

(A)

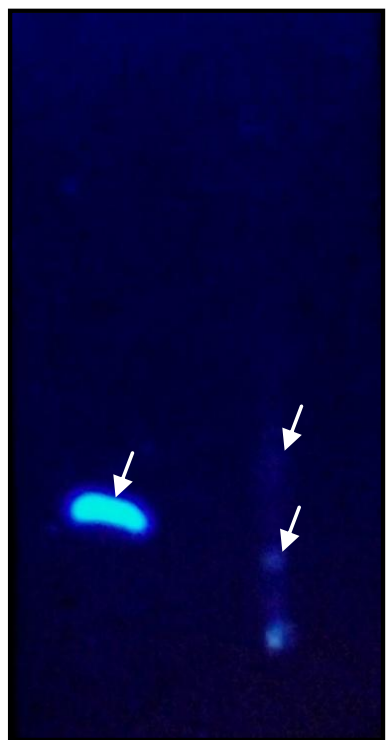

(A)

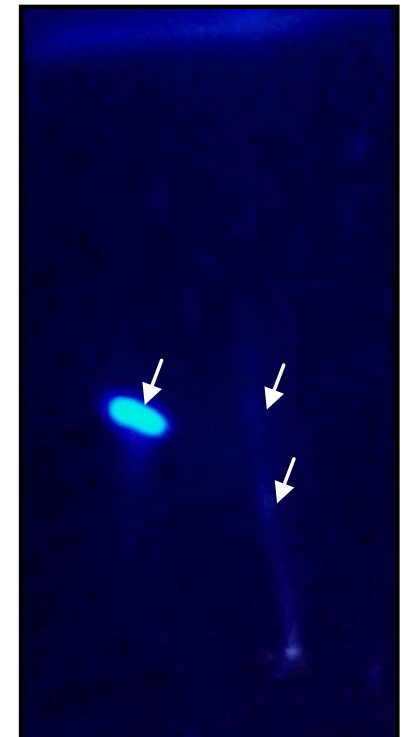

(A)
(B)

Figura 16 - Fotos das CCD do padrão de harmana $20,0 \mathrm{mg} \mathrm{L}^{-1}\left(R_{F}=0,56\right)(A)$ e de extratos de sementes de maracujá por ELL (B). Visualização sob luz UV em $\lambda=366 \mathrm{~nm}$. As setas brancas indicam as manchas fluorescentes características de alcaloides $\left(R_{F}=0,54\right.$ e 0,56$)$. 
Os alcaloides harmânicos apresentam forte fluorescência sob luz UV (THE MERCK INDEX, 1989) e segundo Taveira e Cruz, (2008) os alcaloides são detectados pela emissão de fluorescência azul arroxeada na região do visível. $A$ solução padrão da harmana $20,0 \mathrm{mg} \mathrm{L}^{-1}$ apresentou uma mancha fluorescente de cor azul arroxeada com $R_{F}=0,56$. A amostra de sementes apresentou manchas fluorescentes de cor azul arroxeada com $R_{F}=0,54$ e 0,56 próximos aos obtidos para o padrão. Com isso, a análise preliminar por CCD indicou a presença de compostos fluorescentes nas amostras de sementes de maracujá azedo, sendo um indicativo da presença de alcaloides harmânicos, por serem compostos que emitem fluorescência, tanto pela emissão e coloração da fluorescência como pela semelhança com o $\mathrm{R}_{\mathrm{F}}$ da mancha do padrão.

\subsection{ANÁLISE CROMATOGRÁFICA POR CLAE}

O estudo analítico das sementes de maracujá azedo para a quantificação de alcaloides harmânicos foi realizado pelo método SBSE/CLAE-Flu dual. Os alcaloides harmana e harmina foram encontrados em amostras de polpa e polpa com sementes de maracujá azedo (PEREIRA; SANTOS; YARIWAKE, 2013); por esse motivo, foram utilizados padrões analíticos destes alcaloides na análise das sementes por SBSE/CLAE-Flu.

As proporções dos reagentes utilizados a fim de manter as condições ideais para a extração da harmana e da harmina pelo método SBSE/CLAE-Flu dual precisaram ser ajustadas para a análise das sementes de maracujá (Tabela 3).

Tabela 3 - Reagentes utilizados para o estudo de alcaloides harmânicos em sementes de maracujá azedo pelo método SBSE/CLAE-Flu dual

\begin{tabular}{|c|c|c|c|c|}
\hline \multirow{3}{*}{$\begin{array}{c}\text { Condições } \\
\text { estabelecidas }\end{array}$} & \multicolumn{4}{|c|}{ Método SBSE/CLAE-Flu dual } \\
\hline & \multicolumn{2}{|c|}{ Polpa e polpa com sementes ${ }^{*}$} & \multicolumn{2}{|c|}{ Sementes** } \\
\hline & harmana & harmina & harmana & harmina \\
\hline Material vegetal & $1,0 \mathrm{~mL}$ & $1,0 \mathrm{~mL}$ & $1,0 \mathrm{~g}$ & $1,0 \mathrm{~g}$ \\
\hline $\mathrm{NaCl}$ & $5,0 \mathrm{~g}$ & $5,0 \mathrm{~g}$ & $5,0 \mathrm{~g}$ & $5,0 \mathrm{~g}$ \\
\hline $\mathrm{pH}$ & 2,0 mL NaOH & $1,0 \mathrm{~mL} \mathrm{NH}_{4} \mathrm{OH}$ & $1,0 \mathrm{~mL} \mathrm{NaOH}$ & $0,3 \mathrm{~mL} \mathrm{NH}_{4} \mathrm{OH}$ \\
\hline Água Milli-Q & $7,0 \mathrm{~mL}$ & $8,0 \mathrm{~mL}$ & $9,0 \mathrm{~mL}$ & $9,7 \mathrm{~mL}$ \\
\hline Solvente de dessorção & $100 \%$ metanol & $100 \%$ metanol & $100 \%$ metanol & $100 \%$ metanol \\
\hline Tempo de extração & $120 \mathrm{~min}$ & $120 \mathrm{~min}$ & $120 \mathrm{~min}$ & $120 \mathrm{~min}$ \\
\hline Tempo de dessorção & $60 \mathrm{~min}$ & $60 \min$ & $60 \mathrm{~min}$ & $60 \mathrm{~min}$ \\
\hline
\end{tabular}


Após o processo de extração utilizando as sementes de maracujá azedo, a fase extratora de PDMS da barra de SBSE, que é translúcida, não apresentou alterações de coloração, evidenciando que não ocorreu a extração de pigmentos que poderiam interferir na análise por CLAE-Flu.

Para a análise cromatográfica dos extratos de polpa com sementes de maracujá azedo por SBSE/CLAE-Flu dual utilizando uma coluna cromatográfica de fase reversa $\left(X-\right.$ Terra $\left.^{\circledR}\right)$, conseguiu-se uma boa separação dos picos dos compostos desta amostra (PEREIRA, SANTOS E YARIWAKE, 2013); estas colunas, além de melhorar a eficiência da separação dos picos de compostos básicos (como os alcaloides), devido à menor quantidade de grupos silanóis, suportam altas temperaturas e baixos valores de pH (TONHI et al., 2002). A acidificação da fase móvel (água e acetonitrila) com adição de 0,5\% de ácido fórmico $(\mathrm{pH}=3,5)$ e a eluição no modo em gradiente resultaram em uma boa separação dos picos na análise simultânea dos alcaloides do maracujá azedo em um curto tempo de análise (18 minutos) para a quantificação destes compostos (PEREIRA, SANTOS E YARIWAKE, 2011).

O detector de fluorescência foi adequado para a detecção dos alcaloides, mesmo que em baixas quantidades $\left(\mu \mathrm{g} \mathrm{L}^{-1}\right)$, e possibilita a escolha do $\lambda_{\text {excitação }} \mathrm{e}$

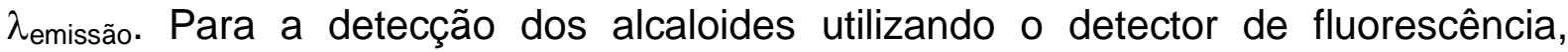
Pereira, Santos e Yariwake, (2013) obtiveram melhor sensibilidade com o $\lambda_{\text {excitação }}=254 \mathrm{~nm}$ e $\lambda_{\text {emissão }}=425 \mathrm{~nm}$ para harmana e $\lambda_{\text {excitação }}=254 \mathrm{~nm}$ e $\lambda_{\text {emissão }}=410 \mathrm{~nm}$ para harmina; portanto, para a detecção destes compostos nas

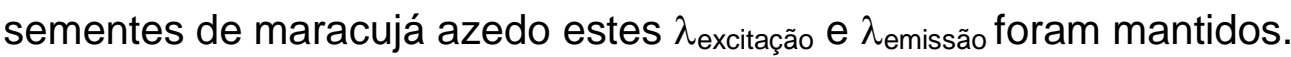

A Figura 17 mostra o cromatograma obtido com o extrato da amostra de sementes de maracujá azedo, nas condições cromatográficas específicas para a análise dos alcaloides harmânicos usando o método SBSE/CLAE-Flu dual.

O cromatograma da Figura 17 mostrou uma boa separação dos picos para os compostos presentes nas sementes, e também a possibilidade da análise simultânea de harmana e harmina em um mesmo cromatograma, confirmando a aplicabilidade deste método para a amostra de sementes de maracujá azedo. 

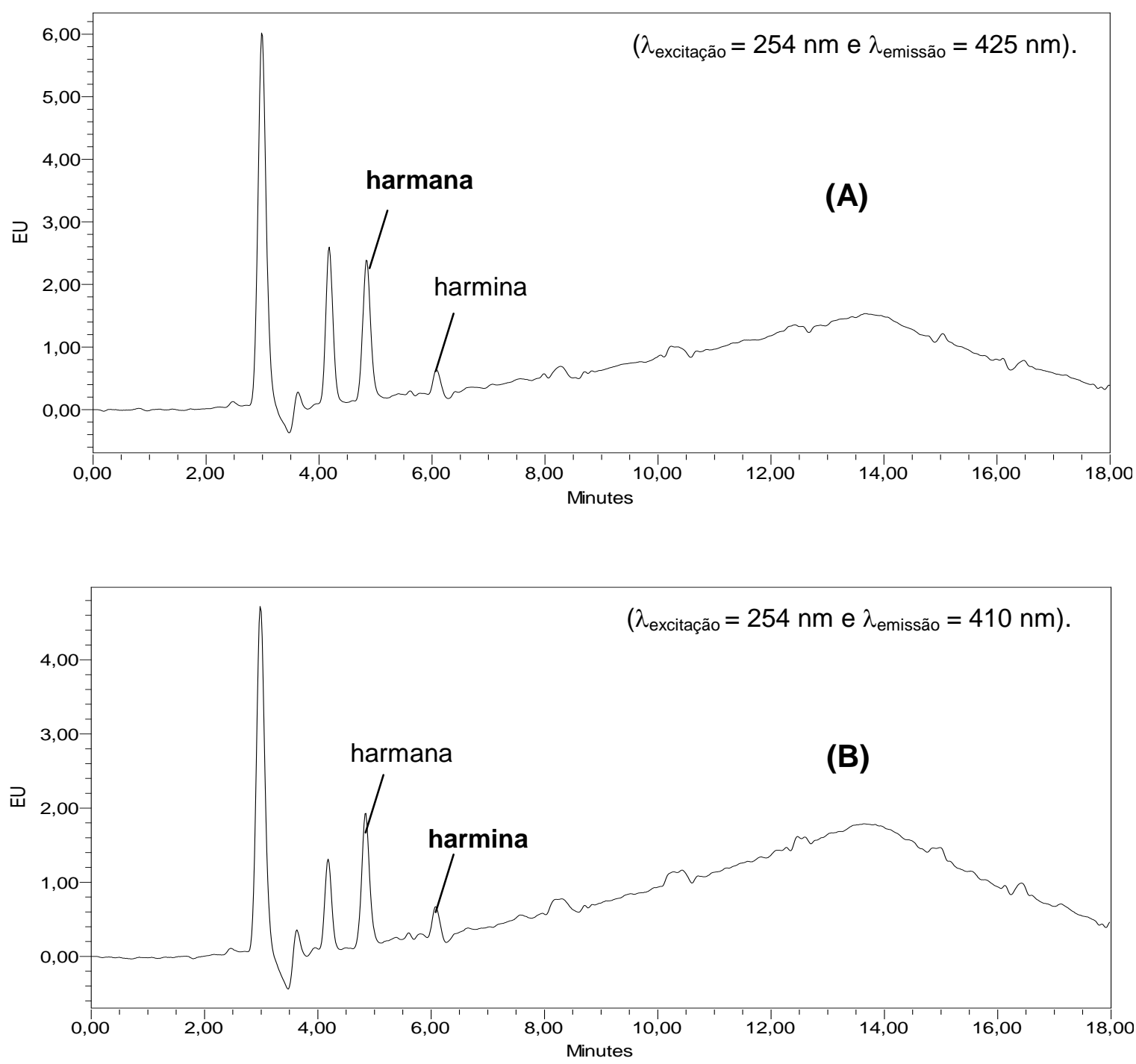

Figura 17 - Cromatograma do extrato de sementes de maracujá azedo obtido por SBSE/CLAE-Flu dual: detecção no comprimento de onda específico para harmana $(A)$ e detecção no comprimento de onda específico para harmina (B). (Condições cromatográficas de acordo com a Tabela 1).

O cromatograma do extrato de sementes, obtido por SBSE/CLAE-Flu dual, foi comparado com os cromatogramas de soluções padrão de harmana e de harmina $\left(10,0 \mu \mathrm{g} \mathrm{L}^{-1}\right)$ e do solvente de dessorção (metanol), nas mesmas condições cromatográficas (Figura 18).

A comparação com o metanol foi realizada para verificar a interferência deste solvente (ensaio em branco) nos picos do cromatograma da amostra, e mostrou que esse solvente não interfere com os picos de interesse da amostra (harmana e harmina) e por esse motivo foi utilizado como solvente na dessorção líquida. 

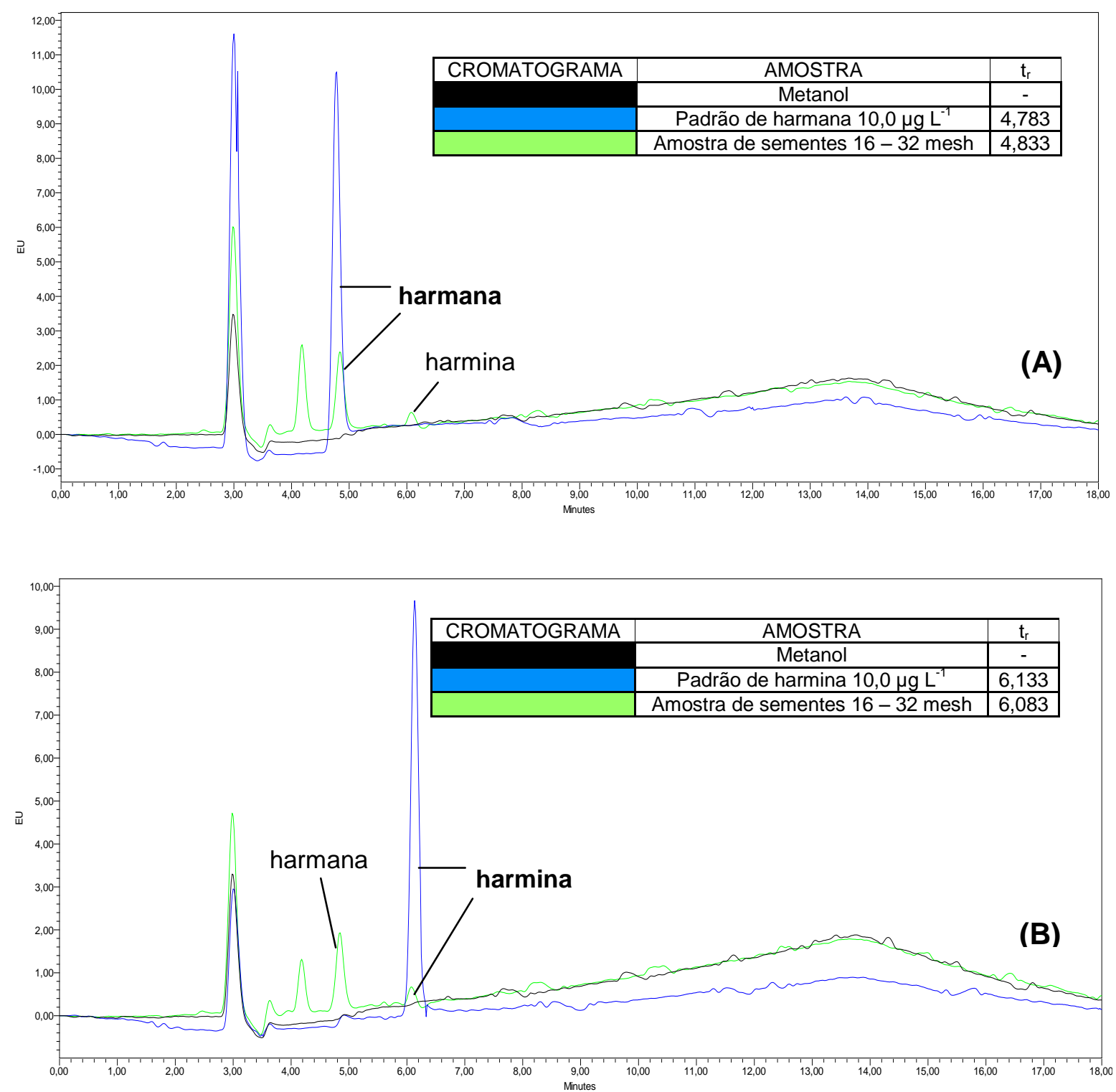

Figura 18 - Comparação dos cromatogramas do extrato de sementes de maracujá azedo com o padrão de harmana $10,0 \mu \mathrm{g} \mathrm{L}^{-1}$ e metanol (A) e de harmina $10,0 \mu \mathrm{g} \mathrm{L}^{-1}$ e metanol (B) obtidos por CLAE/Flu $\left(\lambda_{\text {excitação }}=254 \mathrm{~nm}\right.$ e $\lambda_{\text {emissão }} 425 \mathrm{~nm}$ para harmana $\mathrm{e}$ $\lambda_{\text {excitação }}=254 \mathrm{~nm}$ e $\lambda_{\text {emissão }}=410 \mathrm{~nm}$ para harmina). (Condições cromatográficas de acordo com a Tabela 1).

Os $t_{r}$ dos picos cromatográficos dos padrões de harmana e de harmina $\left(10,0 \mathrm{ug} \mathrm{L}^{-1}\right)$ foram de $t_{r}=4,783$ e $t_{r}=6,133$ respectivamente, que coincidem com os $t_{r}$ para os picos presentes nos extratos de sementes de maracujá azedo, sendo o $\mathrm{t}_{\mathrm{r}}=4,833$ para o pico da harmana e $\mathrm{t}_{\mathrm{r}}=6,083$ para a harmina.

A semelhança dos espectros de fluorescência dos picos cromatográficos da amostra, com $t_{r}$ semelhantes aos dos picos cromatográficos de padrões de harmana e de harmina, confirmou que os picos no cromatograma da amostra de sementes são os alcaloides harmânicos estudados (harmana e harmina) (Figura 19). 


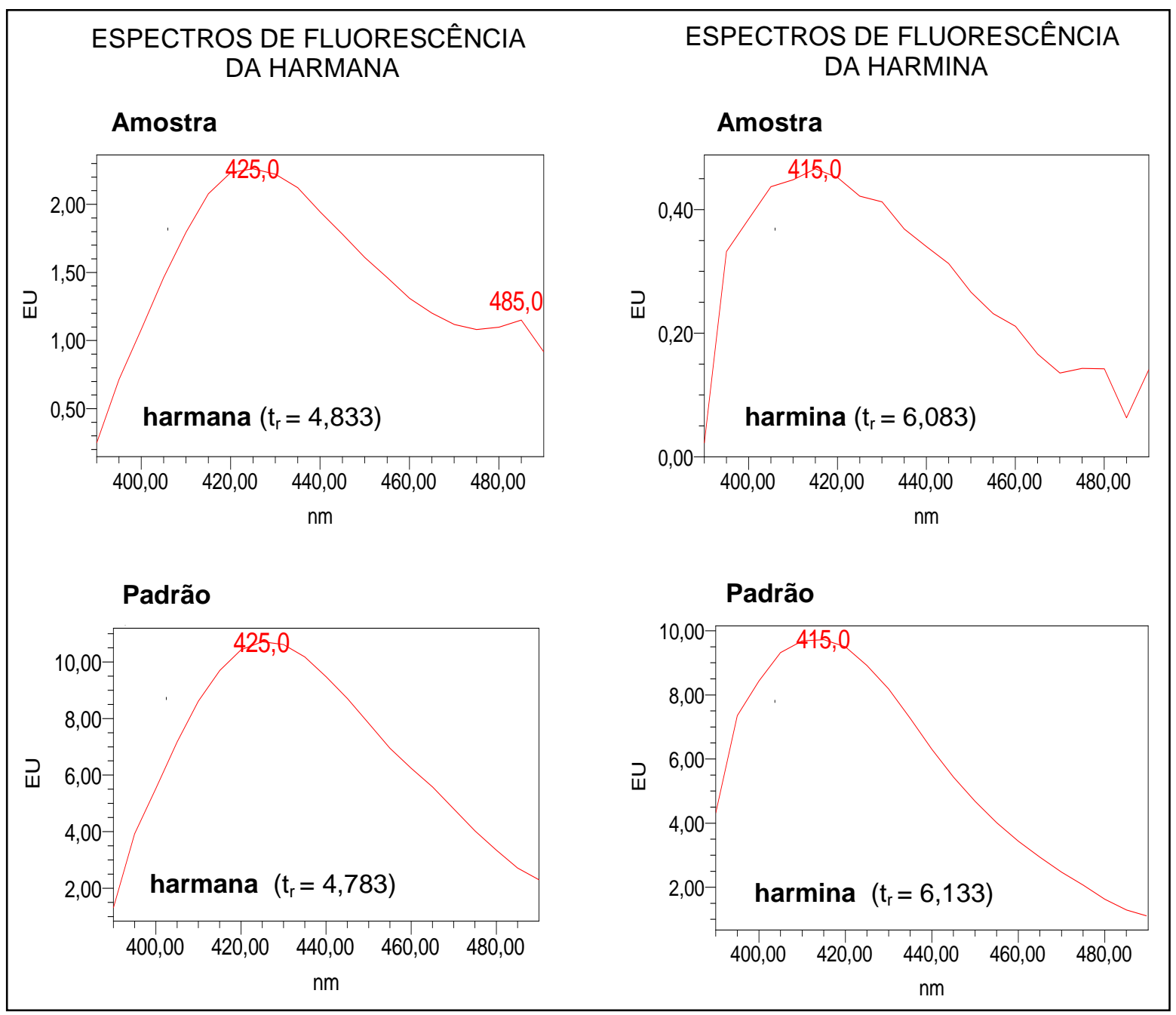

Figura 19 - Comparação dos espectros de fluorescência dos picos da harmana e da harmina na amostra de sementes de maracujá azedo por SBSE/CLAE-Flu dual, referentes ao cromatograma da Figura 18, com os obtidos de soluções padrão de harmana e de harmina $\left(10,0 \mu \mathrm{g} \mathrm{L}^{-1}\right)$ obtidos por CLAE/Flu $\left(\lambda_{\text {excitação }}=254 \mathrm{~nm}\right.$ e $\lambda_{\text {emissão }}=425 \mathrm{~nm}$ para a harmana e $\lambda_{\text {excitação }}=254 \mathrm{~nm}$ e $\lambda_{\text {emissão }}=410 \mathrm{~nm}$ para a harmina) .

\subsection{QUANTIFICAÇÃO DE HARMANA E HARMINA POR SBSE/CLAE-Flu dual}

Em amostras complexas, assim como as sementes de maracujá, com a possibilidade de ocorrer o efeito de matriz, a eficiência da extração por SBSE pode ser afetada; por isso, para a quantificação de harmana e de harmina em sementes de maracujá azedo, foi utilizado o método de adição de padrão por meio da construção de curvas analíticas, sendo este método o mais indicado por corrigir a influência dos componentes da matriz (efeito de matriz) na quantificação exata dos analitos (CUADROS-RODRÍGUEZ et al., 2003; RIBANI et al., 2004; QUINTANA; RODRIGUEZ, 2006; PINHO et al., 2009). 
A Figura 20 mostra as curvas analíticas obtidas pelo método SBSE/CLAE-Flu dual por adição de padrão para obtenção da concentração dos alcaloides harmana e harmina nas sementes de maracujá azedo. A concentração de cada ponto da curva $\left(0,1 ; 5,0 ; 10,0 ; 15,0\right.$ e 20,0 $\left.\mathrm{g} \mathrm{L} \mathrm{L}^{-1}\right)$ foi corrigida levando em consideração o grau de pureza dos padrões analíticos utilizados (98\%) e a pré-concentração dos analitos pela barra de SBSE.
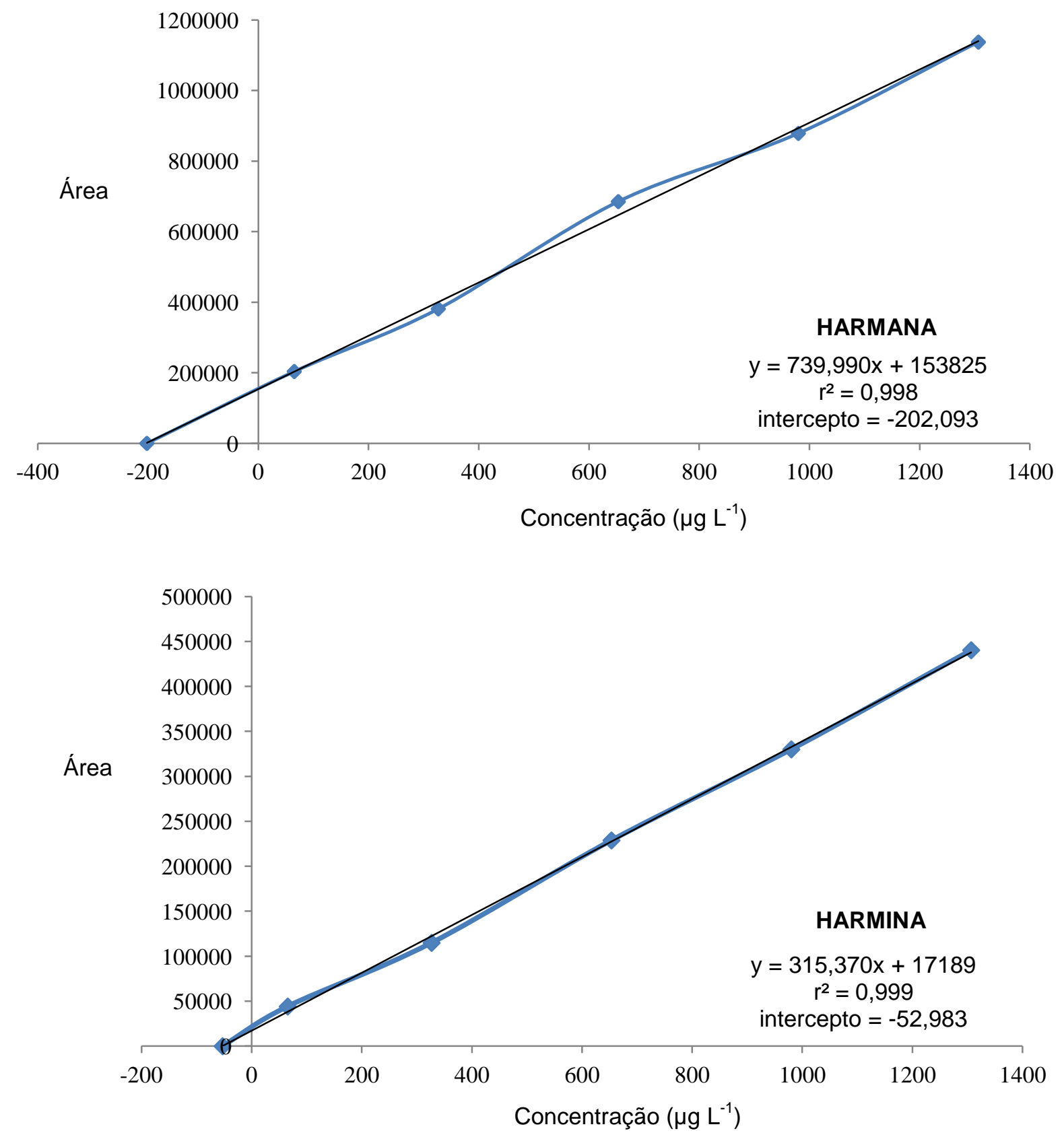

Figura 20 - Curvas analíticas obtidas pelo método SBSE/CLAE-Flu dual por adição de padrão para obtenção da concentração da harmana e da harmina nas sementes de maracujá azedo. 
Considerando o ponto aonde a reta corta o eixo das ordenadas como sendo correspondente à área do pico do alcaloide e que a extrapolação da reta define no eixo das abscissas a concentração do alcaloide na amostra sem nenhuma adição de padrão (RIBANI et al., 2004), obteve-se as concentrações de harmana e de harmina nas amostras de sementes de maracujá azedo quantificadas pelo método SBSE/CLAE-Flu dual.

O valor da concentração $\left(\mu \mathrm{g} \mathrm{L}^{-1}\right)$ dos alcaloides encontrada através das curvas de adição de padrão refere-se à quantidade de harmana e de harmina contidas em 150,0 $\mu \mathrm{L}$ de metanol (volume usado para dessorção). Para chegar-se à quantidade destes alcaloides em 1,0 grama de sementes secas, os cálculos foram feitos conforme a seguir:

Intercepto (obtido pela curva de adição de padrão) ( $\mu \mathrm{g})$ $1000 \mathrm{~mL}$ x ( $\mu \mathrm{g})$------- 0,150 mL (metanol)

Sendo $\times(\mu \mathrm{g})=$ massa do alcaloide em 1,0 grama de sementes secas.

Considerando a concentração encontrada através do intercepto das curvas de adição de padrão para a harmana $=202,093 \mu \mathrm{g} \mathrm{L}^{-1}$ e para a harmina $=52,983 \mu \mathrm{g} \mathrm{L}^{-1}$ temos na Tabela 4 os valores obtidos para as massas de harmana e de harmina em 1,0 grama de sementes secas.

Tabela 4 - Dados obtidos para a quantificação de harmana e harmina nas sementes secas de maracujá azedo por SBSE/CLAE-Flu dual.

Amostra

Sementes de maracujá azedo
Substância

harmana

harmina
Massa de alcaloides / grama de sementes secas $\left(\mu g^{-1}\right) \pm D P^{*}$

$8,108 \times 10^{-3} \pm 7,599 \times 10^{-4}$

${ }^{{ }^{*} \mathrm{DP}}=$ desvio padrão.

\subsection{VALIDAÇÃO DO MÉTODO ANALÍTICO}

Antes do processo da validação, a eficiência da coluna cromatográfica foi avaliada através da determinação do número de pratos teóricos $(\mathrm{N})$, e quanto maior o valor obtido para N, maior será a eficiência da coluna (RIBANI et al., 2004). 
O ICH (2010) não exige a determinação do N, porém, Ribani et al., 2004 sugerem que a eficiência da coluna de separação utilizada na etapa da validação pode ser avaliada para assegurar o sucesso dos ensaios no processo de validação e sugerem ainda que o valor de $\mathrm{N}$ esteja acima de 2.000 para CLAE.

Para a determinação de $\mathrm{N}$, conforme o procedimento sugerido pelo fabricante $\left(\right.$ Waters $\left.^{\circledR}\right)$, foi feita por CLAE e detecção por UV $(\lambda=254 \mathrm{~nm})$ a análise de 3,0 $\mu \mathrm{L}$ de uma solução de acenafteno $1,0 \mathrm{mg} \mathrm{mL}^{-1} /$ acetona $10 \mu \mathrm{L} \mathrm{mL}^{-1} 80 \%$, com fase móvel acetonitrila/água Milli-Q (50/50 v/v) em modo isocrático com fluxo de 1,0 mL min ${ }^{-1}$ e a temperatura do forno, onde a coluna é acoplada, era de $25^{\circ} \mathrm{C}$. O valor obtido de $\mathrm{N}=$ 16.972,9 mostrou que a coluna utilizada na validação deste trabalho foi eficiente para a separação dos compostos da amostra considerando apenas o valor de $\mathrm{N}$.

Após a determinação de N, o método SBSE/CLAE-Flu dual foi validado para a análise quantitativa dos alcaloides harmana e harmina em sementes de maracujá azedo. A validação foi conduzida segundo os protocolos do ICH (2010), através de ensaios da especificidade, linearidade, exatidão e precisão, além dos ensaios para definição dos limites de detecção (LOD) e quantificação (LOQ).

Devido às características da amostra, foram feitas análises preliminares para determinar a faixa de concentração mais adequada para os ensaios da validação (linearidade, exatidão e precisão). A faixa de concentração foi determinada por meio da análise de amostras fortificadas com soluções padrão (harmana e harmina) em diferentes concentrações, utilizando CLAE/Flu, até obter-se uma faixa de concentração na qual a quantidade real destes alcaloides na amostra estivesse compreendida dentro da faixa escolhida, a fim de manter a proporção entre os picos.

Conforme o ICH (2010) são estabelecidos cinco níveis de concentração para os ensaios de linearidade e três níveis para os ensaios de precisão e exatidão, sendo a faixa de concentração, para as sementes de maracujá, estabelecida entre $0,1-20,0 \mu \mathrm{L} \mathrm{L}^{-1}$.

\subsubsection{Especificidade}

A especificidade ou seletividade é o parâmetro que garante a resposta do método para um determinado analito, mesmo na presença de outros compostos contidos na amostra, e garante que a quantificação deste não será afetada pelo efeito de matriz (CASSIANO et al., 2009; MELO, 2012). Se a especificidade do 
método não for assegurada, as outras etapas da validação estarão comprometidas (RIBANI et al. 2004).

Para comprovar a especificidade do método SBSE/CLAE-Flu dual, foi realizado o teste de pureza para os picos cromatográficos da harmana e da harmina presentes nos extratos de sementes de maracujá azedo, através da comparação dos espectros de fluorescência dos picos da amostra com os obtidos de soluções padrão de harmana e de harmina 10,0 $\mathrm{g} \mathrm{L}^{-1}$ (Figuras 21 e 22).
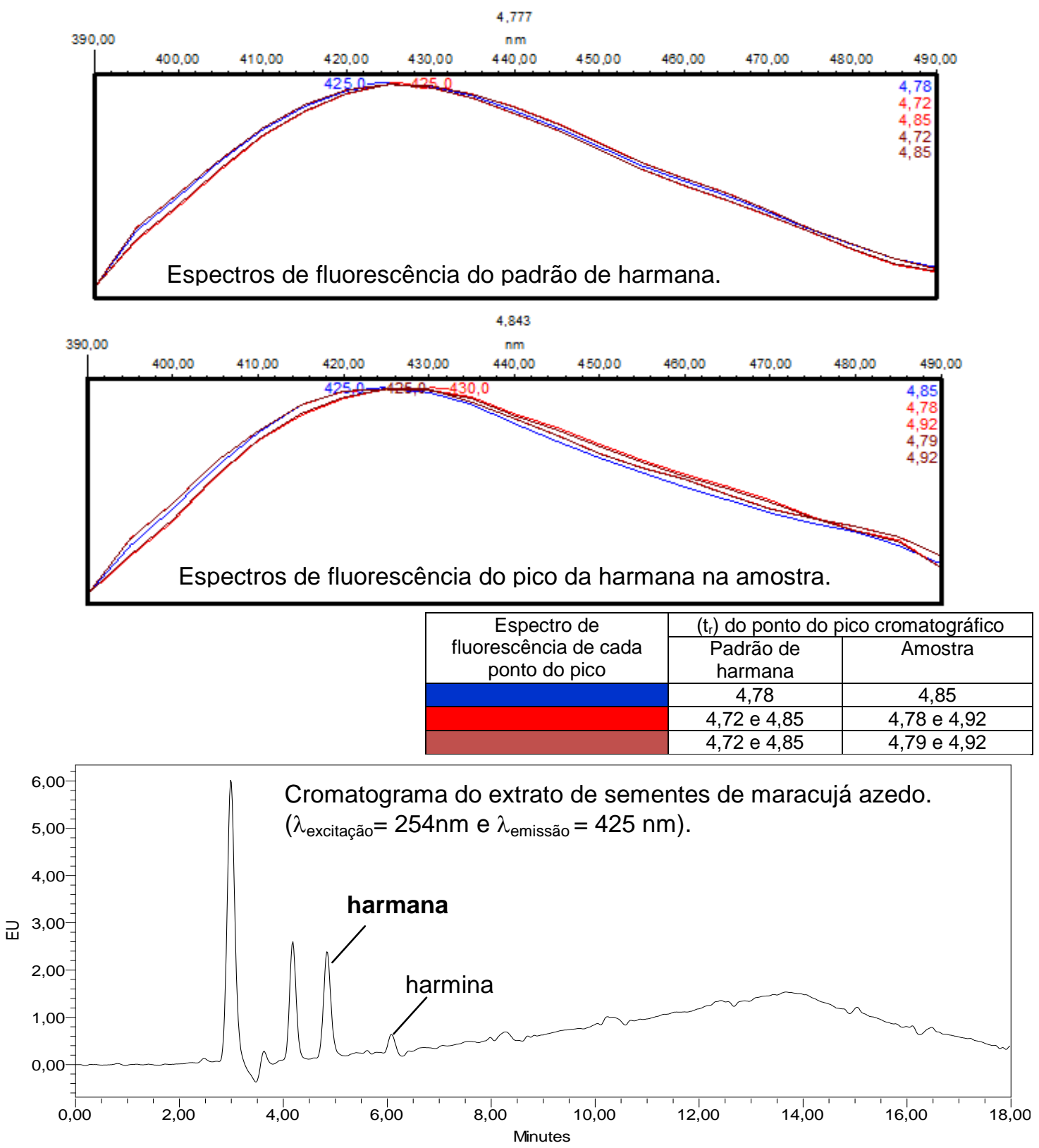

Figura 21 - Espectros de fluorescência em diferentes regiões do pico do padrão de harmana $\left(10,0 \mu \mathrm{g} \mathrm{L}^{-1}\right)$, do pico da harmana na amostra e cromatograma do extrato de sementes de maracujá obtido pelo método SBSE/CLAE-Flu dual. 


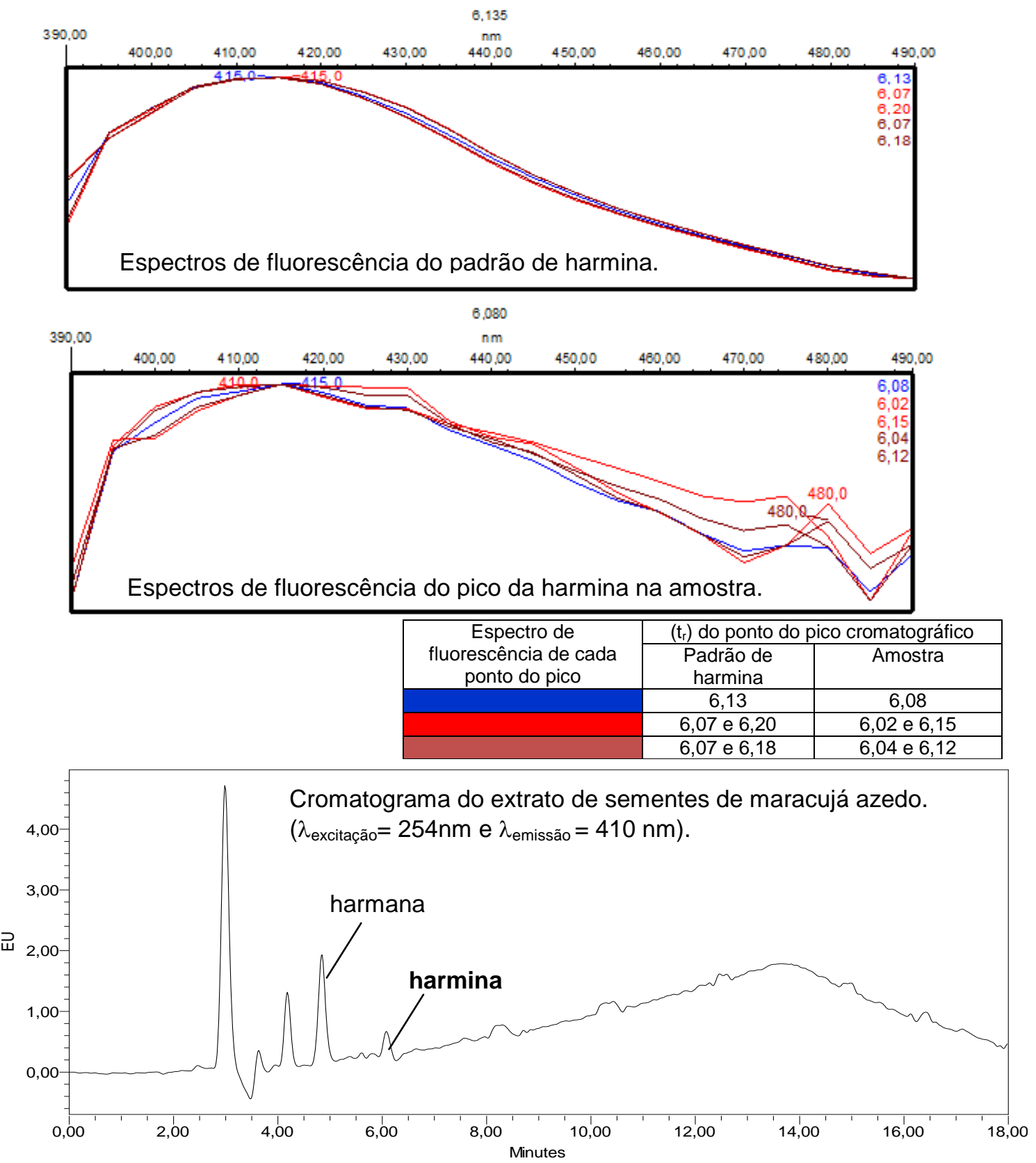

Figura 22 - Espectros de fluorescência em diferentes regiões do pico do padrão de harmina $\left(10,0 \mathrm{~g} \mathrm{~L} \mathrm{~L}^{-1}\right)$, do pico da harmina na amostra e cromatograma do extrato de sementes de maracujá obtido pelo método SBSE/CLAE-Flu dual.

Os picos foram considerados puros, pois na sobreposição dos espectros de fluorescência dos diferentes pontos dos picos do cromatograma da amostra e na comparação com os espectros obtidos de soluções padrão, foi observada grande coincidência entre os espectros. Essa similaridade sugere não haver a co-eluição de compostos interferentes com mesmo tempo de retenção dos picos de harmana e de 
harmina, comprovando que estes picos são exclusivamente destes compostos, garantindo a especificidade do método SBSE/CLAE-Flu dual para a amostra de sementes de maracujá azedo.

\subsubsection{Linearidade}

A linearidade está relacionada com a capacidade do método de extrair os analitos de interesse, proporcionalmente à sua concentração na amostra (MELO, 2012). A linearidade do método SBSE/CLAE-Flu dual foi confirmada através da regressão linear das curvas analíticas de harmana e de harmina, com cinco níveis de concentração $\left(0,1 ; 5,0 ; 10,0 ; 15,0\right.$ e 20,0 ug L $\left.{ }^{-1}\right)$, construídas em triplicata, pelo método de adição de padrão. A Tabela 5 mostra os valores das áreas médias dos picos de harmana e de harmina e o DPR(\%), e os coeficientes de correlação $\left(r^{2}\right)$ e as equações das curvas analíticas $(y=a x+b)$ obtidas para a harmana e a harmina, calculadas pelo método matemático de regressão linear com o Software Microsoft Excel 2007.

Tabela 5 - Área média e DPR(\%), $\mathrm{r}^{2}$ e equação da curva analítica dos alcaloides harmana e harmina presentes nas sementes de maracujá azedo.

\begin{tabular}{|c|c|c|c|c|c|}
\hline Padrão & $\begin{array}{c}\text { Concentração } \\
\left(\mu g L^{-1}\right)\end{array}$ & $\begin{array}{c}\text { Área média } \\
\left(\mu \mathrm{V}^{*} \mathrm{sec}\right)\end{array}$ & $\begin{array}{l}\text { DPR } \\
(\%)\end{array}$ & $r^{2}$ & $\begin{array}{c}\text { Equação } \\
(y=a x+b)\end{array}$ \\
\hline harmana & $\begin{array}{c}0,1(65,33)^{\star *} \\
5,0(326,67)^{\star *} \\
10,0(653,33)^{\star *} \\
15,0(980,00)^{\star *} \\
20,0(1306,67)^{\star *}\end{array}$ & $\begin{array}{c}203749,67 \\
381289,33 \\
685272,67 \\
878585,67 \\
1137420,00\end{array}$ & $\begin{array}{l}0,49 \\
0,52 \\
0,05 \\
0,20 \\
0,08\end{array}$ & 0,996 & $\begin{array}{c}y=7,3893 \cdot 10^{2} x+ \\
1,54791 \cdot 10^{5}\end{array}$ \\
\hline harmina & $\begin{array}{c}0,1(65,33)^{\star *} \\
5,0(326,67)^{\star *} \\
10,0(653,33)^{\star *} \\
15,0(980,00)^{\star *} \\
20,0(1306,67)^{\star *}\end{array}$ & $\begin{array}{c}44128,00 \\
114889,33 \\
228844,67 \\
330111,67 \\
440369,00\end{array}$ & $\begin{array}{l}2,90 \\
0,33 \\
0,69 \\
0,82 \\
0,16\end{array}$ & 0,999 & $\begin{array}{c}y=3,1527.10^{2} x+ \\
1,72840 \cdot 10^{4}\end{array}$ \\
\hline
\end{tabular}

$\mathrm{r}^{2}=$ coeficiente de correlação linear.

$\left(^{* *}\right)$ = valores das concentrações corrigidos levando em consideração a pré-concentração pelo PDMS da barra de SBSE e a pureza de $98 \%$ dos padrões de alcaloides de harmana e de harmina)

Os valores de $r^{2}=0,996$ para harmana e $r^{2}=0,999$ para harmina, obtidos para o ensaio de linearidade, mostraram uma ótima correlação entre a concentração do composto na amostra fortificada e a área dos picos obtidos comprovando a 
linearidade do método nas faixas de concentração escolhidas para ambos os alcaloides estudados.

Os parâmetros analíticos de exatidão, precisão e recuperação estão associados à linearidade do método (RIBANI et al. 2004), pois a quantidade dos alcaloides extraída pelo PDMS da barra da SBSE deve acontecer de forma proporcional à quantidade de padrão adicionado nos três níveis de concentração. $O$ ICH (2010) estabelece como ideais, para o parâmetro da linearidade, os valores mais próximos possíveis de 1,0. Dessa forma, a obtenção de uma ótima linearidade (> 0,996), para o método SBSE/CLAE-Flu dual, assegura que a extração dos compostos foi diretamente relacionada com a quantidade dos alcaloides presentes na amostra, indicando que os resultados para os ensaios de precisão e exatidão, que também dependem da quantidade do composto na amostra, possivelmente irão apresentar resultados em conformidade com os parâmetros estabelecidos pelo ICH (2010).

\subsubsection{Precisão}

A precisão avalia a proximidade dos resultados obtidos para uma mesma amostra, utilizando a mesma metodologia e a mesma instrumentação (ANVISA, 2003). A repetibilidade (intradias) avalia a proximidade dos resultados obtidos em um mesmo dia $(n=9)$ para diferentes níveis de concentração $(0,1 ; 10,0$ e 20,0 $\left.\mathrm{g} \mathrm{L} \mathrm{L}^{-1}\right)$, por meio do DPR(\%) entre as áreas dos picos referentes à harmana e à harmina.

A precisão intermediária (interdias) avalia a proximidade dos resultados, por meio do DPR(\%) entre áreas dos picos da harmana e da harmina, obtidos em 3 dias diferentes. As análises foram feitas em triplicata, para três diferentes níveis de concentração $\left(0,1 ; 10,0\right.$ e $\left.20,0 \mu \mathrm{g} \mathrm{L}^{-1}\right)$.

Considerando os critérios estabelecidos pela ICH (2010) para os valores do DPR(\%), são aceitáveis os valores inferiores ou iguais a $5 \%$. Todos os ensaios para a repetibilidade e precisão intermediária, apresentados na Tabela 6, apresentaram valores de $\mathrm{DPR}(\%)$ abaixo de $5 \%$, sendo assim o método considerado preciso pelos protocolos do ICH (2010). 
Tabela 6 - Resultados para os ensaios de precisão para a amostra de sementes de maracujá azedo fortificadas com soluções padrão de harmana e harmina.

\begin{tabular}{cccc}
\hline Padrão & $\begin{array}{c}\text { Concentração } \\
\left(\mathrm{ug} \mathrm{L}^{-1}\right)\end{array}$ & $\begin{array}{c}\text { Repetibilidade } \\
(\text { mesmo dia, } \mathrm{n}=9) \\
\text { DPR(\%) }\end{array}$ & $\begin{array}{c}\text { Precisão intermediária } \\
(3 \text { dias diferentes, } \mathrm{n}=3) \\
\text { DPR(\%) }\end{array}$ \\
\hline harmana & 0,1 & 0,41 & 0,76 \\
& 10,0 & 0,35 & 0,16 \\
harmina & 20,0 & 0,22 & 0,07 \\
& 0,1 & 3,69 & 2,56 \\
& 10,0 & 0,68 & 0,17 \\
\hline \hline
\end{tabular}

$\overline{\mathrm{DPR}(\%)=\text { Desvio Padrão Relativo. }}$

Para a harmina foram obtidos valores de $\mathrm{DPR}(\%)$ superiores aos valores do DPR $(\%)$ obtidos para a harmana. A baixa quantidade de harmina contida nas sementes pode refletir-se nos valores de DPR(\%) mais elevados.

\subsubsection{Exatidão}

A exatidão avalia a proximidade entre o valor experimental obtido e o valor verdadeiro esperado (sem a necessidade que este valor seja de $100 \%$ ), ou seja, avalia a confiabilidade do método. Sugere-se que a sua investigação seja feita após a determinação da seletividade, da linearidade e da precisão do método (US-FDA, 2001). Para isso foram adicionadas quantidades conhecidas de uma solução padrão de harmana e de harmina, de modo a obter três diferentes níveis de concentração $\left(0,1 ; 10,0\right.$ e 20,0 $\left.\mu \mathrm{g} \mathrm{L}^{-1}\right)$ para cada alcaloide.

A exatidão foi calculada através da porcentagem de recuperação do padrão, com a determinação do valor experimental, obtido para cada nível de concentração, com ensaios realizados em triplicata. Os valores apresentados na Tabela 7, para os ensaios de exatidão para a harmana e a harmina pelo método SBSE/CLAE-Flu dual, foram considerados adequados com os parâmetros da ICH (2010), que estabelece como aceitáveis os valores compreendidos entre o intervalo de 70 a $120 \%$. 
Tabela 7 - Valores obtidos para os ensaios de exatidão para a harmana e a harmina, em diferentes níveis de concentração, pelo método SBSE/CLAE-Flu dual.

\begin{tabular}{cccc}
\hline \hline Padrão & $\begin{array}{c}\text { Concentração } \\
\left(\mu \mathrm{g} \mathrm{L}^{-1}\right)\end{array}$ & $\begin{array}{c}\text { Exatidão } \\
(\mathrm{n}=3) \\
(\%)\end{array}$ & $\begin{array}{c}\text { Desvio Padrão Relativo } \\
(\%)\end{array}$ \\
\hline \multirow{5}{*}{ harmana } & 0,1 & 105,90 & 0,49 \\
& 10,0 & 99,34 & 0,36 \\
harmina & 20,0 & 92,34 & 1,45 \\
& 0,1 & 117,76 & 1,29 \\
& 10,0 & 95,45 & 0,57 \\
\hline \hline
\end{tabular}

Os valores obtidos para os ensaios de exatidão estão compreendidos entre $92,34 \%$ a $105,90 \%$ para a harmana e $83,61 \%$ a $117,76 \%$ para a harmina, mostrando a exatidão do método SBSE/CLAE-Flu dual para a amostra de sementes de maracujá azedo.

Para verificar a possibilidade da extração dos compostos de interesse pela SBSE, os valores teóricos aproximados para a recuperação foram calculados usando o software Twister Recovery Calculator $\left(\right.$ Gerstel $\left.^{\circledR}\right)$, considerando os valores teóricos de $\mathrm{K}_{\mathrm{O} / \mathrm{w}}$ para os alcaloides harmana $\left(\mathrm{K}_{\mathrm{O} / \mathrm{w}}=3,1\right)$ e harmina $\left(\mathrm{K}_{\mathrm{O}} \mathrm{w}=3,56\right)$, e a proporção entre a fase aquosa e a fase de PDMS. Uma vez que o volume da amostra foi de $10 \mathrm{~mL}$ e o volume de PDMS da SBSE foi de $55 \mu \mathrm{L}$, o valor teórico calculado para a recuperação da harmana é $85,5 \%$ e para a harmina de $94,5 \%$. Assim, os resultados para os ensaios de recuperação obtidos experimentalmente com o método SBSE/CLAE-Flu dual, foram condizentes com os valores de recuperação teóricos.

As diferenças nos valores de recuperação obtidos para os compostos (harmana e harmina) podem ser explicados pelos seus valores de $\mathrm{K}_{\mathrm{PDMS}} \mathrm{W}$ (MELO, 2012) e considerando que os valores de $K_{\text {PDMS }}$ são semelhantes aos valores de $\mathrm{K}_{\mathrm{O} / \mathrm{w}}$. Considerando o valor de $\mathrm{K}_{\mathrm{O} / \mathrm{w}}=3,5$ como característico de compostos polares, a proximidade dos valores de $\mathrm{K}_{\text {PDMS }}$ destes alcaloides (K $\mathrm{K}_{\mathrm{PDMS}} \mathrm{W}$ para a harmana $=3,1$ e para a harmina $=3,56$ ) com o valor de $K_{\text {PDMSN }}$ do PDMS $(<3,5)$ permite a extração destes alcaloides, no entanto espera-se que as taxas de recuperação para a harmina teoricamente sejam maiores do que os valores obtidos para a harmana, considerando a maior proximidade do seu $\mathrm{K}_{\mathrm{PDMS} / \mathrm{W}}$ (maior polaridade, maior afinidade) com o $K_{\text {PDMS }}$ do PDMS da SBSE. 
Pode-se observar que a harmina apresentou uma taxa de recuperação maior em relação à harmana apenas para o nível de concentração de $0,1 \mu \mathrm{g} \mathrm{L}^{-1}$. No entanto, quanto maior a massa de alcaloides (harmana e harmina) contidos e/ou adicionados na amostra, menor será a taxa de recuperação devido à saturação da fase extratora (PDMS).

Essa questão, além dos valores de $\mathrm{K}_{\mathrm{PDMS} / \mathrm{w}}$, pode ser explicada pelo efeito de matriz da amostra e da saturação da fase de PDMS da barra de SBSE, que se refere ao equilíbrio de partição dos analitos entre a fase de PDMS e a fase aquosa, ou seja, foram obtidas menores taxas de recuperação pelo método SBSE/CLAE-Flu dual conforme o aumento da concentração destes alcaloides na amostra. Os valores de recuperação abaixo de $100 \%$ para as faixas de concentração de 10,0 e $20,0 \mu \mathrm{g} \mathrm{L}^{-1}$ para ambos os alcaloides, e a relação decrescente destes valores entre o menor e o maior nível de concentração, também refletem a questão da saturação do PDMS da barra de SBSE.

O efeito da matriz pode refletir-se na obtenção de taxas de recuperação acima de 100\% (PINHO et al., 2009), pois além do padrão adicionado, quantidades dos alcaloides já presentes na amostra contribuem com a saturação da fase extratora de PDMS da barra de SBSE que reflete-se no aumento dos valores de recuperação obtidos. Para as amostras na faixa de concentração de $0,1 \mu \mathrm{g} \mathrm{L}^{-1}$ a recuperação foi de $105,90 \%$ para a harmana e $117,76 \%$ para a harmina.

\subsubsection{Limite de Detecção (LOD) e Limite de Quantificação (LOQ)}

Os testes para a determinação do LOD e do LOQ são realizados para verificar a capacidade do método para a detecção dos analitos de interesse em baixas quantidades (CASSIANO et al., 2009).

Para soluções padrão de harmana $10,0 \mu \mathrm{g} \mathrm{L}^{-1}$ (Figura 23) e de harmina $10,0 \mu \mathrm{g} \mathrm{L} \mathrm{L}^{-1}$ (Figura 24), as áreas dos picos foram 1.045.619 $\mu \mathrm{V}^{*}$ sec e 883.112 $\mu \mathrm{V}^{*}$ sec respectivamente. A comparação entre a emissão de fluorescência destes picos (da harmana e da harmina), obtidos de soluções padrão de mesma concentração mostrou diferenças de valores entre as áreas obtidas. 


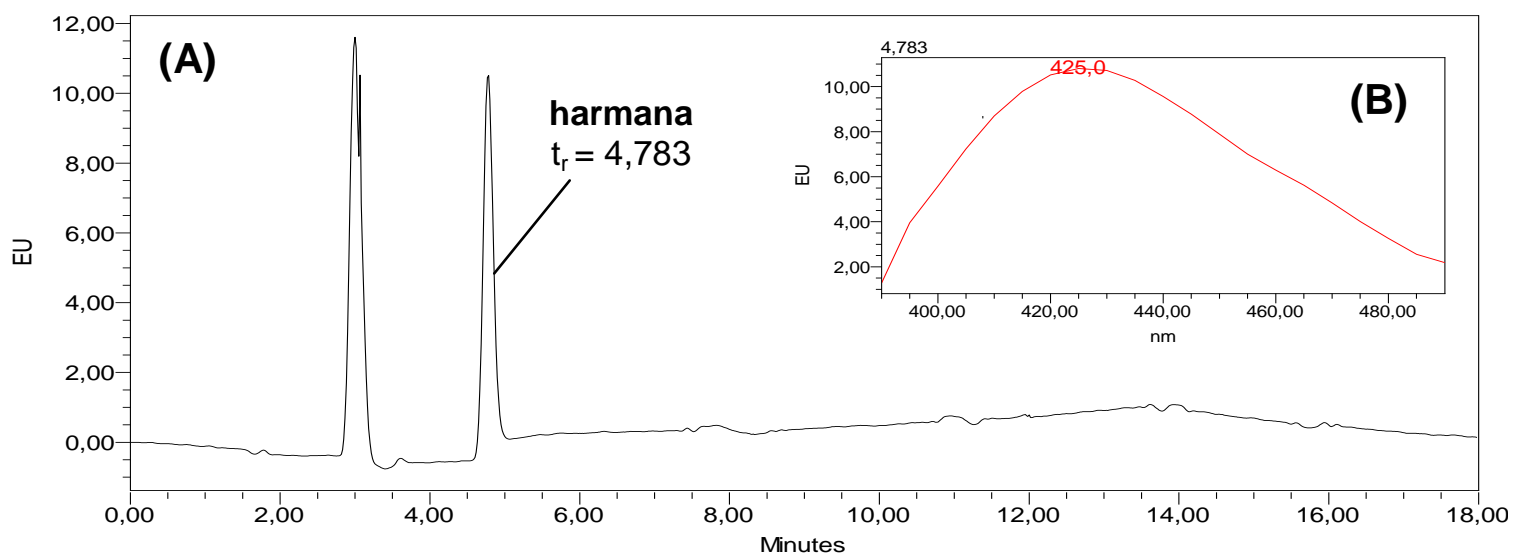

Figura 23 - Cromatograma (A) e espectro de fluorescência (B) de uma solução padrão de harmana $10,0 \mu \mathrm{g} \mathrm{L}^{-1}\left(\lambda_{\text {excitação }}=254 \mathrm{~nm}\right.$ e $\left.\lambda_{\text {emissão }}=425 \mathrm{~nm}\right)$ obtidos por CLAE-Flu.

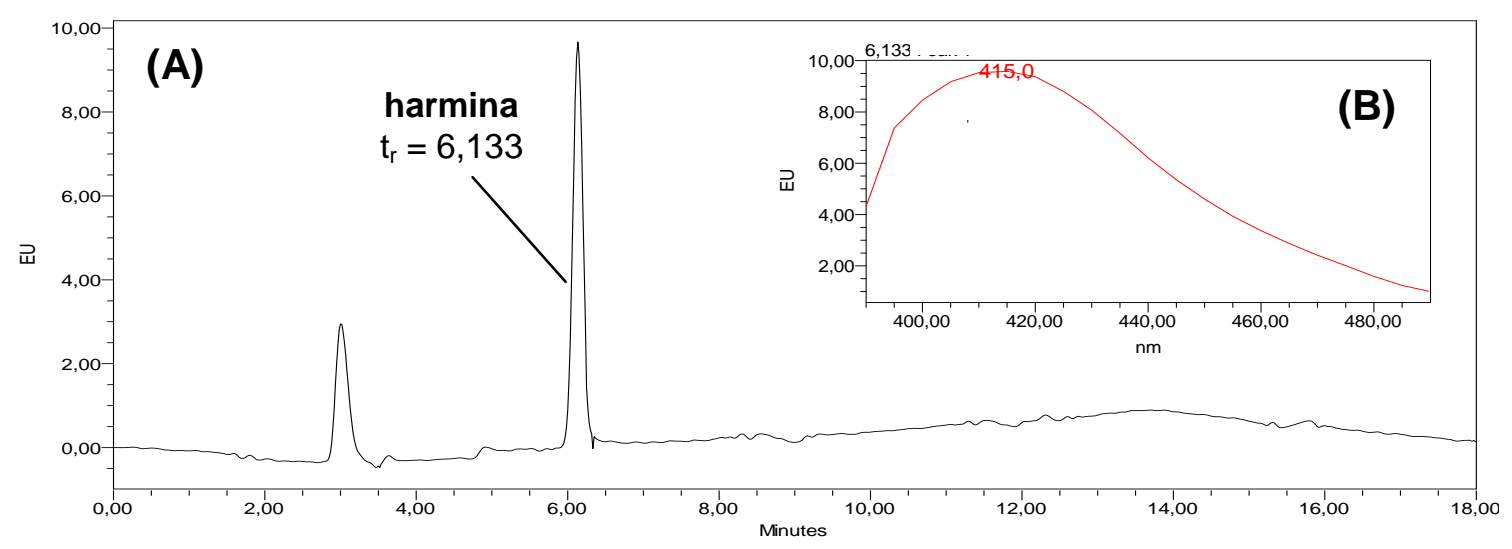

Figura 24 - Cromatograma $(A)$ e espectro de fluorescência $(B)$ de uma solução padrão de harmina $10,0 \mu \mathrm{g} \mathrm{L}^{-1}\left(\lambda_{\text {excitação }}=254 \mathrm{~nm}\right.$ e $\lambda_{\text {emissão }}=410 \mathrm{~nm}$ ) obtidos por CLAE-Flu.

Em solução aquosa a harmana e a harmina podem co-existir em espécies diferentemente carregadas (catiônica, neutra e aniônica) que se encontram no estado fundamental de excitação $\left(S_{0}\right)$, porém a fotoexcitação destes compostos resulta em uma quarta espécie, a espécie anfotérica, que se encontra no estado excitado $\left(S_{1}\right)$ e que é detectada pelo detector de fluorescência (REYMON et al., 1999). Com isso, essa diferença na emissão da fluorescência pode ser explicada através do equilíbrio de dissociação química destes alcaloides, através dos diferentes valores de pKa entre os compostos (DOUGLAS et al., 1983), pois a harmana e a harmina possuem dois sítios de dissociação (e, por isso, dois valores de pKa): o grupo $\mathrm{NH}$ do anel indol ( $\left.\mathrm{pKa}_{1}\right)$ e o nitrogênio do anel piridínico $\left(\mathrm{pKa}_{2}\right)$ (Figura 25) (WOLFBEIS; FURLINGER, 1982). 
(A)

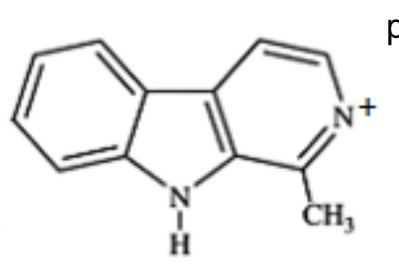

espécie catiônica<smiles>Cc1nccc2c1[nH]c1ccccc12</smiles>

espécie neutra<smiles>Cc1nccc2c1[nH]c1ccccc12</smiles>

espécie aniônica<smiles>COc1ccc2c(c1)[nH]c1c(C)[nH+]ccc12</smiles>

espécie catiônica<smiles>COc1ccc2c(c1)[nH]c1c(C)nccc12</smiles>

espécie neutra<smiles>CCCCCOC(C)(C)C</smiles>

espécie aniônica

Figura 25 - Equilíbrio de dissociação química dos alcaloides harmana (A) e harmina (B). Fonte: Adaptado de (PICADA et al., 1997).

A diferença entre os valores das áreas dos picos da harmana e da harmina interfere no LOD e LOQ; considerando que a harmina possui uma resposta inferior para o valor da área do pico, são esperados, para este alcaloide, valores maiores para o LOD e o LOQ em relação aos obtidos para a harmana. Devido à diferença no equilíbrio químico destes compostos (diferentes valores de pKa), a fluorescência emitida por estes compostos é diferenciada, e a detecção (emissão) por fluorescência é mais sensível para a harmana (WOLFBEIS; FURLINGER, 1982).

O critério adotado para a determinação do LOD e do LOQ foi a relação entre a área do sinal e do ruído da linha de base, sendo adotadas as relações de 3:1 para o LOD e 10:1 para o LOQ conforme estabelecido pelo ICH (2010). Os valores para o LOD e o LOQ obtidos para a harmana e a harmina são apresentados na Tabela 8.

Tabela 8 - Limites de detecção (LOD) e de quantificação (LOQ) estabelecidos para soluções padrão de harmana e de harmina.
Padrão
$\operatorname{LOD}\left(\mathrm{ng} \mathrm{L}^{-1}\right)$
LOQ (ng L $\left.{ }^{-1}\right)$

harmana

30,0

200,0

harmina

100,0

400,0 
Os valores obtidos para os ensaios de determinação do LOD e do LOQ para a detecção de alcaloides harmânicos apresentam diferenças conforme o método empregado e/ou os equipamentos utilizados: para a quantificação de harmana, Marques (2009) utilizando CLAE com detecção por fluorescência para a análise de harmana em amostras de chá de camomila, erva-doce e capim-cidreira, determinou valores de $\mathrm{LOD}=3,1 \mathrm{ng} \mathrm{L^{-1 }}$ e $\mathrm{LOQ}=10,3 \mathrm{ng} \mathrm{L}^{-1}$ para o alcaloide harmana e Zheng et al., (2000) utilizando CLAE com fase reversa e detector de fluorescência para determinação de alcaloides em amostras de sangue humano, determinou valores de $\mathrm{LOD}=206,0 \mathrm{pg} \mathrm{mL}{ }^{-1}$ para a harmana e $\mathrm{LOD}=81,0 \mathrm{pg} \mathrm{mL}^{-1}$ para a harmina. Ambos os trabalhos concluíram que o método usado foi sensível para os alcaloides estudados (harmana e harmina).

Os valores do LOD e do LOQ obtidos neste trabalho para a quantificação dos alcaloides harmana e harmina mostram que a detecção por fluorescência foi um método sensível para a detecção destes alcaloides presentes em amostra de sementes secas de maracujá azedo. 


\section{CONCLUSÕES}

O método SBSE/CLAE-Flu dual, desenvolvido e validado para análise de alcaloides na polpa e polpa com sementes de maracujá azedo (PEREIRA et al. 2013), mostrou-se adequado para o estudo analítico quantitativo de amostras de sementes de maracujá azedo, possibilitando a quantificação dos alcaloides harmana e harmina nesta matriz.

A validação do método para a amostra de sementes mostrou resultados para os parâmetros analíticos avaliados que confirmam uma ótima especificidade, linearidade na faixa de concentração escolhida, exatidão e precisão em conformidade com os parâmetros preconizados pelo ICH (2010).

O método SBSE/CLAE-Flu dual poderá ser empregado, dentre outras aplicações, para analisar amostras de frutos de lotes diferentes para verificar a questão da sazonalidade (épocas diferentes do ano) nos frutos do maracujá.

O método SBSE/CLAE-Flu dual está sendo usado para estudos adicionais da composição química dos frutos do maracujá, em combinação com a cromatografia líquida acoplada ao espectrômetro de massas. 


\section{REFERÊNCIAS}

ABOURASHED, E. A.; VANDERPLANK, J.; KHAN, I. A. High-speed extraction and HPLC fingerprinting of medicinal plants - II. Application to harman alkaloids of genus Passiflora. Pharmaceutical Biology, v. 41, p. 100-106, 2003.

AGÊNCIA NACIONAL DE VIGILÂNCIA SANITÁRIA (ANVISA). Formulário de fitoterápicos da farmacopeia brasileira. Brasília: Anvisa, 2011. 126 p.

Disponível em: <http://www.anvisa.gov.br/hotsite/farmacopeiabrasileira/conteudo/ Formulario_de_Fitoterapicos_da_Farmacopeia_Brasileira.pdf $>$. Acesso em: 25 set. 2013.

ALMEIDA, C.; ROSÁRIO, P.; SERÔDIO, P.; NOGUEIRA, J. M. F. Novas perspectivas na preparação de amostras para análise cromatográfica. Química, v. 95, p. 69-77, 2004. Disponível em:

<http://www.yumpu.com/pt/document/view/9507662/novas-perspectivas-napreparacao-de-amostras-para-analise>. Acesso em: 27 nov. 2013.

BALÓN, M.; MUNOZ, M. A.; HIDALGO, J.; CARMONA, M. C.; SANCHEZ, M. Fluorescence charactersitics of $\beta$-carboline alkaloids in highly concentrated hydroxide solutions. Journal of Photochemistry. v. 36, p. 193-204, 1987.

BARLETTA, J.; GOMES, P. C. F. L.; SANTOS NETO, A. J.; LANÇAS, F. M. Development of a new stir bar sorptive extraction coating and its application for the determination of six pesticides in sugarcane juice. Journal of Separation Science. v. 34, p. 1317-1325, 2011.

BARRACA, S. A. Manejo e produção de plantas medicinais e aromáticas.

Piracicaba: ESALQ, 1999. (Relatório do estágio supervisionado produção vegetal II). Disponível em: <http://www.esalq.usp.br/siesalq/pm/p02.pdf>. Acesso em: 19 set. 2011.

BERALDO, J.; KATO, E. T. M. Morfoanatomia de folhas e caules de Passiflora edulis Sims, Passifloraceae. Revista Brasileira de Farmacognosia, v. 20, p. 233-239, 2010.

BRASIL. Ministério da Saúde. Agência Nacional de Vigilância Sanitária (ANVISA). Guia para validação de métodos analíticos e bioanalíticos. Resolução-RE $n^{\circ} .899$ de 29 de maio de 2003. Diário Oficial da União, Brasília, 02 de junho de 2003.

Disponível em: <http://www.diariodasleis.com.br/busca/exibelink.php?numlink=1-934-2003-05-29-899>. Acesso em: 10 ago. 2013. 
BRASIL. Ministério da Saúde. Agência Nacional de Vigilância Sanitária (ANVISA). Farmacopeia Brasileira. Resolução RDC nํ. 49 de 23 de novembro de 2010. Diário Oficial da União, Brasília, 24 de novembro de 2010. Disponível em: <http://www.anvisa.gov.br/hotsite/cd_farmacopeia/pdf/volume1\%2020110216.pdf>. Acesso em: 10 ago. 2013.

CASSIANO, N. M.; BARREIRO, J. C.; MARTINS, L. R. R.; OLIVEIRA, R. V.; CASS, Q. B. Validação em métodos cromatográficos para análises de pequenas moléculas em matrizes biológicas. Química Nova, v. 32, p. 1021-1030, 2009.

CHAVES, A. R.; QUEIROZ, M. E. C. Extração sortiva em barra de agitação para análise de fármacos em fluidos biológicos. Química Nova, v. 31, p. 1814-1819, 2008.

COLLINS, C. H.; BRAGA, G. L.; BONATTO, P. S. Introdução a métodos cromatográficos. 6ª ed. Campinas: Editora Unicamp, 1995. 300 p.

COSTA, S. P. Aplicação de ferramentas da qualidade no desenvolvimento de métodos multivariados. 2012. 137 f. Dissertação (Mestrado) - Instituto de Química de São Carlos - Universidade de São Paulo, São Carlos, 2012.

CUADROS-RODRÍGUEZ, L.; GARCIA-CAMPAÑA, A. M.; ALMANSA-LÓPEZ, E. M.; EGEA-GONZÁLEZ, F. J.; CANO, M. L. C.; FRENICH, A. G.; MARTINEZ-VIDAL, J. L.; Correction function on biased results due to matrix effects application to the routine analysis of pesticide residues. Analytica Chimica Acta. v. 478, p. 281-301, 2003.

DAVID, F.; SANDRA, P. Stir bar sorptive extraction for trace analysis. Journal of Chromatography A, v. 1152, p. 54-69, 2007.

DEGANI, A. L. G.; CASS, Q. B.; VIEIRA, P. C. Cromatografia: um breve ensaio. Química Nova na Escola, v. 7, p. 21-25, 1998.

DE SOUZA, P. A. Alcaloides e o chá de Ayahuasca: uma correlação dos "estados alterados da consciência" induzido por alucinógenos. Revista Brasileira de Plantas Medicinais, v. 13, p. 349-358, 2011.

DHAWAN, K.; DHAWAN, S.; SHARMA, A. Passiflora: a review update. Journal of Ethnopharmacology, v. 94, p. 1-23, 2004. 
DOUGLAS, K. T.; SHARMA, R. K.; WALMSLEY, J. F.; HIDER, R. C. Ionization processes of some harmala alkaloids. Molecular Pharmacology, v. 23, p. 614-618, 1983.

FARAH, S.; VARELLA, A. D.; YOUNES, R. N.; SUFFREDINI, I. B. Análise da presença de alcaloides e compostos fenólicos em frações do extrato orgânico de Palicourea guianensis Aubl. com atividade biológica e antioxidante. In: REUNIÃO ANUAL DA SOCIEDADE BRASILEIRA DE QUÍMICA, 31., 2008, Águas de Lindóia. Anais... São Paulo: Sociedade Brasileira de Química, 2008. Disponível em: <http://sec.sbq.org.br/cdrom/31ra/resumos/T0638-1.pdf>. Acesso em: 19 set. 2013.

FIGUEIREDO, F. S.; GONÇALVES, T. F. M. Determinação seletiva de derivados da $\beta$-carbolina através da fosforimetria na temperatura ambiente e substrato sólido (FTASS) e eletrocromatografia capilar micelar (ECCM). PUC-Rio. Departamento de Química, 2006 / 2007. (Relatório Anual CNPQ / PIBIC ). Disponível em: <http://www.pucrio.br/pibic/relatorio_resumo2007/relatorios/qui/qui flavia_silva_figueiredo_thiago_fernando_mota_goncalves.pdf $>$. Acesso em: 19 set. 2011.

FIGUEROA, A. R. M. Avaliação dos efeitos neurotóxicos do chá Ayahuasca. 2012. 119 f. Tese (Doutorado) - Faculdade de Ciências Farmacêuticas de Ribeirão Preto, Universidade de São Paulo, Ribeirão Preto, 2012.

FILHO, G. C. N.; RONCATTO, G.; RUGGIERO, C.; OLIVEIRA, J. C.; MALHEIROS, E. B. Produção de mudas de maracujazeiro-amarelo por enxertia hipocotiledonar sobre sete espécies de Passiflora. Revista Brasileira de Fruticultura, v. 33, p. 237-245, 2011.

FRYE, A.; HAUSTEIN, C. Extraction, identification, and quantification of harmala alkaloids in three species of Passiflora. American Journal of Undergraduate Research, v. 6, p. 19-26, 2007.

GIORDANO, A.; FERNANDEZ-FRANZON, M.; RUIZ, M. J.; FONT, G.; PICO, Y. Pesticide residue determination in surface waters by stir bar sorptive extraction and liquid chromatography/tandem mass spectrometry. Analytical and Bioanalytical Chemistry, v. 393, p.1733-1743, 2009.

HUANG, X.; QIU, N.; YUAN, D. Direct enrichment of phenols in lake and sea water by stir bar sorptive extraction based on poly (vinylpyridine-ethylene dimethacrylate) monolithic material and liquid chromatographic analysis. Journal of

Chromatography A, v. 1194, p.134-138, 2008. 
HUANG, X.; YUAN, D.; HUANG, B. Determination of steroid sex hormones in urine matrix by stir bar sorptive extraction based on monolithic material and liquid chromatography with diode array detection. Talanta, v. 75, p.172-177, 2008.

HUANG, X.; QIU, N.; YUAN, D. Development and validation of stir bar sorptive extraction of polar phenols in water followed by HPLC separation in poly(vinylpyrrolididonedivinylbenzene) monolith. Journal of Separation Science, v. 32, p. 1407-1414, 2009a.

HUANG, X.; QIU, N.; YUAN, D.; LIN, Q. Sensitive determination of strongly polar aromatic amines in water samples by stir bar sorptive extraction based on poly(vinylimidazole-divinylbenzene) monolithic material and liquid chromatographic analysis. Journal of Chromatography A, v. 1216, p. 4354-4360, $2009 \mathrm{~b}$.

INSTITUTO BRASILEIRO DE GEOGRAFIA E ESTATÍSTICA (IBGE). Produção agrícola municipal: Culturas temporárias e permanentes. Rio de Janeiro, 2006. v. 33.

INSTITUTO BRASILEIRO DE GEOGRAFIA E ESTATÍSTICA (IBGE). Produção agrícola municipal: Culturas temporárias e permanentes. Rio de Janeiro, 2010. v. 37.

INTERNATIONAL CONFERENCE ON HARMONISATION (ICH). Validation of analitical procedures: Text and Methodology, Q2(R1) 2010.

Disponível em: <http://www.ich.org/fileadmin/Public_Web_Site/News_room/C Publications/ICH_20_anniversary_Value_Benefits_of_ICH_for_Regulators.pdf $>$. Acesso em: 12 ago. 2013.

IPARRAGUIRRE, A.; PRIETO, A.; NAVARRO, P.; OLIVARES, M.; FERNÁNDEZ, L. A.; ZULOAGA, O. Optimisation of stir bar sorptive extraction and in-tube derivatisation-thermal desorption-gas chromatography-mass spectrometry for the determination of several endocrine disruptor compounds in environmental water samples. Analytical and Bioanalitical Chemistry, n. 401, p. 339-352, 2011.

JIN, Y.; XUE, X.; SHI, H.; XIAO, Y.; ZHANG, F.; LIANG, X. HPLC and UPLC switch for TCM analysis. Word Science and Technology, v. 10, p. 80-84, 2008.

KAWAGUCHI, M.; ITO, R.; NAKAZAWA, H.; TAKATSU, A. Applications of stir bar sorptive extraction to food analysis. Trends in Analytical Chemistry, v. 45, p. 280- 293, 2013. 
LANÇAS, F. M.; QUEIROZ, M. E. C.; GROSSI, P.; OLIVARES, I. B. Recent developments and applications of stir bar sorptive extraction. Journal of Separation Science, v. 32, p. 813-824, 2009.

LIANG, Y. Z.; XIEP, P. E.; CHAN, K. Quality control of herbal medicines. Journal of Chromatography B, v. 802, p. 53-70, 2004.

LUTOMSKI, J. Pharmacochemical investigation of the raw materials from Passiflora genus. 2. The pharmacochemical estimation of juices from the fruits of Passiflora edulis and Passiflora edulis forma flavicarpa. Planta Médica, v. 27, p. 112-121, 1975.

MACHADO, M. W.; STERN NETO, C.; SALGADO, J.; ZAFFARI, G.; BARISON, A.; CAMPOS, F. R.; CORILO, Y. E.; EBERLIM, M. N.; BIAVATTI, M. W. Search for alkaloids on callus culture of Passiflora alata. Brazilian Archives of Biology and Technology, v. 53, p. 901-910, 2010.

MALDANER, L.; JARDIM, I. C. S. F. O estado da arte da cromatografia líquida de ultra eficiência. Química Nova, v. 32, p. 214-222, 2009.

MALDANER, L.; COLLINS, C. H.; JARDIM, I. C. S. F. Fases estacionárias modernas para cromatografia líquida de alta eficiência em fase reversa. Química Nova, v. 33, p. 1559-1568, 2010.

MARQUES, F. F. C. Desenvolvimento de métodos analíticos espectroluminescentes e eletroforéticos para determinação de alcaloides (beta - carbolínicos, camptotecina e derivados) de interesse farmacológico. 2009. 237 f. Tese (Doutorado em Química) - Pontifícia Universidade Católica do Rio de Janeiro (PUC-Rio), Rio de Janeiro, 2009.

MARTINS, C. M.; VASCONCELlOS, M. A. S.; ROSSETTO, C. A. V.; CARVALHO, M. G. Prospecção fitoquímica do arilo de sementes de maracujá amarelo e influência em germinação de sementes. Ciência Rural, v. 40, p. 1934-1940, 2010.

MATSUI, Y.; SUGIYAMA, K.; KAMEI, M.; TAKAHASHI, T.; SUZUKI, T.; KATAGATA, Y.; ITO, T. Extract of passion fruit (Passiflora edulis) seed containing high amounts of piceatannol inhibits melanogenesis and promotes collagen synthesis. Journal of Agricultural and Food Chemistry, v. 58, p. 11112-11118, 2010. 
MELO, L. P.; NOGUEIRA, A. M.; LANÇAS, F. M.; QUEIROZ, M. E. Polydimethylsiloxane/polypyrrole stir bar sorptive extraction and liquid chromatography (SBSE/LC-UV) analysis of antidepressants in plasma samples. Analytica Chimica Acta, v. 633, p. 57-64, 2009.

MELO, L. P. Desenvolvimento de métodos cromatográficos para análises de antimicrobianos em amostras complexas. 2012. $189 \mathrm{f}$. Tese (Doutorado) Faculdade de Filosofia, Ciências e Letras de Ribeirão Preto, Departamento de Química - Universidade de São Paulo, Ribeirão Preto, 2012.

MONSEF-ESFAHANI, H. R.; FARAMARZI, M. A.; MORTEZAEE, V.; AMINI, M. Determination of harmine and harmaline in Peganum harmala seeds by highperformance liquid chromatography. Journal of Applied Science, v. 8, p. 1761-1765, 2008.

MOURA, D. J. Estudos dos alcaloides $\beta$-carbolínicos em diferentes modelos biológicos. 2006. 132 f. Dissertação (Mestrado) - Universidade Federal do Rio Grande do Sul, Porto Alegre, 2006.

MÜHLEN, C; LANÇAS, F. M. Cromatografia unificada. Química Nova, v. 27, p. 747-753, 2004.

MÜLLER, S. D. Determinação de alcaloides e flavonóides através de CLAE e UV de extratos de Passiflora alata Curtis, Passifloraceae - Maracujá-doce. 2006. 91 f. Dissertação (Mestrado) - Universidade do Vale do Itajaí, Itajaí, Santa Catarina, 2006.

NERY, A. L. P.; FERNANDES, C. Fluorescência e estrutura atômica: experimentos simples para abordar o tema. Química Nova na Escola, v. 19, p. 39-42, 2004.

NOGUEIRA, A. M. Desenvolvimento, avaliação e aplicações de novas fases para extração por sorção em barra de agitação (SBSE). 2007. 118 f. Dissertação (Mestrado). - Instituto de Química de São Carlos, Universidade de São Paulo, São Carlos, 2007.

NOGUEIRA, N. M.; SOARES, B. T. M.; ANDRADE, A. B. N.; SINGH, A. K. Méritos comparativos da cromatografia em fase líquida de alta eficiência em escala convencional e miniaturizada. Revista Brasileira de Farmácia, v. 92, p. 44-50, 2011. 
OKUMURA, F.; SOARES, M. H. F. B.; CAVALHEIRO, E. T. G. Identificação de pigmentos naturais de espécies vegetais utilizando-se cromatografia em papel. Química Nova, v. 25, p. 680-683, 2002.

PEREIRA, C. A.; YARIWAKE, J. H. Quantification of harman alkaloids in passion fruit samples by dual SBSE-LC/Flu. In: INTERNATIONAL SYMPOSIUM ON CAPILLARY CHROMATOGRAPHY, 36; AND GCxGC SYMPOSIUM, 9., 2012, Riva del Garda Itália. Abstract book...Messina: Chromaleont S. r. L., 2012. P. 493.

PEREIRA, C. A. M.; SANTOS, B. M.; YARIWAKE, J. H.; Otimização multivariada da extração de alcaloides harmânicos do maracujá por SBSE e análise por SBSE/LCFlu "off line". In: REUNIÃO ANUAL DA SOCIEDADE BRASILEIRA DE QUÍMICA, 34., 2011, Florianópolis. Anais... Santa Catarina: Sociedade Brasileira de Química, 2011. Disponível em: <http://sec.sbq.org.br/cdrom/34ra/resumos/T2453-1.pdf>. Acesso em: 24 set. 2013.

PEREIRA, C. A. M.; SANTOS, B. M.; YARIWAKE, J. H.; Análise de alcaloides harmânicos em suco de maracujá por um novo método SBSE-LC/Flu. In: REUNIÃO ANUAL DA SOCIEDADE BRASILEIRA DE QUÍMICA, 36., 2013, Águas de Lindóia. Anais... São Paulo: Sociedade Brasileira de Química, 2013.

Disponível em: <http://www.eventoexpress.com.br/cd-36rasbq/resumos/T01231.pdf>. Acesso em: 24 set. 2013.

PEREIRA, C. A. M.; VILEGAS, J. H. Y. Constituintes químicos e farmacologia do gênero Passiflora com ênfase a P.alata Dryander., P. edulis Sims e P. incarnata L. Revista Brasileira de Plantas Medicinais, v. 3, p. 1-12, 2000.

PEREIRA, C. A. M. Estudo cromatográfico (HPLC, HPTLC, LC-MS) e análise microscópica das folhas de espécies de Passiflora L. 2002. $260 \mathrm{f}$. Tese (Doutorado em Química Analítica) - Instituto de Química de São Carlos, Universidade de São Paulo, São Carlos, 2002.

PICADA, J. N.; SILVA, K. V. C. L.; ERDTMANN, B.; HENRIQUES, A. T.; HENRIQUES, J. A. P. Genotoxic effects of structurally related $\beta$-carboline alkaloids. Mutation Research, v. 379, p. 135 - 149, 1997.

PINHO, G. P.; NEVES, A. A.; QUEIROZ, M. E. L. R.; SILVÉRIO, F. O. Efeito de matriz na quantificação de agrotóxicos por cromatografia gasosa. Química Nova, v. 32, p. 987-995, 2009. 
PRESTES, O. D.; PRESTA, M. A.; KOLBERG, D. I. S.; ZANELLA, R.; ROSSATO, S. B.; PENNA, N. G.; HECKTHEUER, L. H. R. Desenvolvimento e validação de um método analítico para a determinação de histamina em vinhos utilizando cromatografia líquida de alta eficiência com detecção por fluorescência. Química Nova, v. 30, p. 18-21, 2007.

PRIETO, A.; BASAURI, O.; RODIL, R.; USOBIAGA, A.; FERNANDEZ, L. A.; ETXEBARRIA, N.; ZULOAGA, O. Stir bar sorptive extraction: a view on method optimisation, novel applications, limitations and potential solutions. Journal of Chromatography A, v. 1217, p. 2642-2666, 2010.

QUINTANA, J. B.; RODRIGUEZ, I. Strategies for the microextration of polar organic contaminants in water samples. Analitical Bioanalitical Chemistry, v. 384, p.1447-1461, 2006.

REHWALD, A.; STICHER, O.; MEIER, B. Trace analysis of harman alkaloids in Passiflora incarnata by reversed-phase high performance liquid chromatography. Phytochemical Analysis, v. 6, p. 96-100, 1995.

REYMON, D.; VIÑAS, M. H.; CAMACHO, J. J. Steady state and time resolved study of the proton transfer fluorescence of harmine and 2-methyl-harmine in organic solvents. Journal Photobiology Chemistry, n. 120, p. 85 - 91, 1999.

RIBANI, M.; BOTTOLI, C. B. G.; COLLINS, C. H.; JARDIM, I. C. S. F.; MELO, L. F. C.; Validação em métodos cromatográficos e eletroforéticos. Química Nova, v. 27, p. 771-780, 2004.

SANTOS NETO, A. J. Como obter maior eficiência com partículas superficialmente porosas em HPLC. Scientia Chromatographica, v. 3, p. 65-87, 2011.

SALARI, E.; AHMADI, K.; DEHYAGHOBI, R. Z.; PURHEMATY, A.;

TAKALLOOZADEH, H. M. Toxic and repellent effect of harmal (Peganum harmala L.) acetonic extract on several aphids and Tribolium castaneum (Herbst). Chilean Journal of Agricultural Research, v. 72, p. 147-151, 2012.

SCOTT, R. P. W. Liquid chromatography for the analyst. New York: Marcel Dekker, 1994. v. 67, p. 180-183 (Chromatographic Science Series).

SECRETARIA DE AGRICULTURA, IRRIGAÇÃO E REFORMA AGRÁRIA (SEAGRI). Cultura - Maracujá. Governo da Bahia. 2013.

Disponível em: <http://www.seagri.ba.gov.br/Maracuja.htm> Acesso em 30 jul. 2013. 
SEQUEIROS, R. C. P. Aplicação de novas metodologias analíticas no estudo de compostos fenólicos em matrizes alimentares. 2009. 70 f. Dissertação

(Mestrado) - Instituto de Química, Universidade de Lisboa, Portugal, 2009.

SÉRPICO, R. L.; CAMURÇA, D. M. Ayahuasca: revisão teórica e considerações botânicas sobre as espécies Banisteriopsis caapi (Griseb. In Mart.) C. V. Morton e Psychotria viridis Ruíz \& Pavón. 2006. 43 f. Monografia (Licenciatura plena em ciências biológicas) - Universidade de Guarulhos, Guarulhos, 2006.

SILVA, C. R.; JARDIM, I. C. F. S.; COLLINS, C. H.; AIROLDI, C. Novas fases estacionárias à base de sílica para cromatografia líquida de alta eficiência. Química Nova, v. 27, p. 270-276, 2004.

SILVA, A. R. M.; PORTUGAL, F. C. M.; NOGUEIRA, J. M. F. Advances in stir bar sorptive extraction for the determination of acidic in environmental water matrices comparison between polyurethane and polydimethylsiloxane polymeric phases. Journal of Chromatography A, v. 1209, p. 10-16, 2008.

SILVA, C. G. A.; COLLINS, C. H. Aplicações de cromatografia líquida de alta eficiência para o estudo de poluentes orgânicos emergentes. Química Nova, v. 34, p. 665-676, 2011.

SILVA, S. M. Padronização e validação do método extração sortiva em barra de agitação e cromatografia líquida de alta eficiência (SBSE/HPLC) para a determinação de antidepressivos em amostras de plasma. 2007. $103 \mathrm{f}$. Dissertação (Mestrado) - Faculdade de Ciências Farmacêuticas de Ribeirão Preto, Universidade de São Paulo, Ribeirão Preto, 2007.

SIMPSON, C. F. Practical high performance liquid chromatography. Brighton: Editora Heyden \& Son, 1976. 288 p.

SKOOG, D. A.; WEST, D. M.; HOLLER, F. J. Fundamentals of analytical Chemistry. 5ee․ New York: Saunders College, 1996. p. 644-651.

TAVEIRA, M.; CRUZ, S. Alcaloides da cravagem do centeio. 2008. Disponível em: <http://www.ff.up.pt/toxicologia/monografias/ano0708/g25_centeio/cut.html>. Acesso em: 19 set. 2013.

THE MERCK INDEX. An encyclopedia of chemicals drugs and biologicals. 11aㅡ edição. Rahway: Merck. 1989. p. 727-728. 
TONHI, E.; COLLINS, K. E.; JARDIM, I. C. S. F.; COLLINS, C. H. Fases estacionárias para cromatografia líquida de alta eficiência em fase reversa (CLAE-FR) baseadas em superfícies de óxidos inorgânicos funcionalizados. Química Nova, v. 25, p. 616-623, 2002.

TSUCHIYA, H.; HAYASHI, H.; SATO, M.; SHIMIZU, H.; LINUMA, M. Quantitative analysis of all types of $\beta$-carboline alkaloids in medicinal plants and dried edible plants by high performance liquid chromatography with selective fluorometric detection. Phytochemical Analysis, v. 10, p. 247-253, 1999.

UNCETA, N.; UGARTE, A.; SÁMCHEZ, A.; GÓMEZ-CABALLERO, A.; GOICOLEA, M. A.; BARRIO, R. J. Development of a stir bar sorptive extraction based HPLC-FLD method for the quantification of serotonin reuptake inhibitors in plasma, urine and brain tissue samples. Journal of Pharmaceutical and Biomedical Analysis, v. 51, p. 178-185, 2010.

UNITED STATES FOOD AND DRUG ADMINISTRATION (US-FDA). Guidance for Industry: bioanalytical method validation, 2001. 25 f. Dispovível em:

<http://www.fda.gov/downloads/Drugs/Guidances/ucm070107.pdf>. Acesso em: 28 ago. 2013.

VALENZUELA, A. I.; POPA, D. S.; REDONDO, M. J.; MAÑES, J. Comparison of various liquid chromatographic methods for the analysis of avermectin residues in citrus fruits. Journal of Chromatography, v. 918, p. 59-65, 2001.

VILA, F. C. Identificação dos flavonoides com atividade antioxidante da canade-açúcar. 2006. 68 f. Dissertação (Mestrado em Química Analítica) - Instituto de Química de São Carlos, Universidade de São Paulo, São Carlos, 2006.

VIÑAS, P.; CAMPILLO, N.; HERNÁNDEZ-PÉREZ, M.; HERNÁNDEZ CÓRDOBA, M. A comparison of solid-phase microextraction and stir bar sorptive extraction coupled to liquid chromatography for the rapid analysis of resveratrol isomers in wines, musts and fruit juices. Analytica Chimica Acta, v. 611, p. 119-125, 2008.

WATERS QUALITY PARTS ${ }^{\circledR}$. Cromatography columns and supplies catalog: catálogo. Milford: Waters Corporation, 2013. p. 114.

WOLFBEIS, O. S.; FURLINGER, E. The pH-dependence of the absorption and fluorescence spectra of harmine and harmol: drastic differences in the tautomeric WOLFBEIS, O. S.; FURLINGER, E equilibria of ground and first excited singlet state. Zeitschrift Fur Physikalische Chemie-Wiesbaden, v. 129, p. 171-183, 1982. 
WOLFBEIS, O. S.; FURLINGER, E.; WINTERSTEIGER, R. Solvent and pHdependence of the absorption and fluorescence spectra of harman: Detection of three ground state and four excited state species. Monatshefte Fur Chemie, v. 113, p. 509-517, 1982.

ZHENG, W.; WANG, S.; BARNES, L. F.; GUAN, Y.; LOUIS, E. D. Determination of harmane and harmine in human blood using reversed-phased high-performance liquid chromatography and fluorescence detection. Analytical Biochemistry, v. 15, p. 125-129, 2000.

\section{ZERAIK, M. L. Estudo analítico dos flavonoides dos frutos de maracujá} (Passiflora edulis Sims f. flavicarpa Degener). 2010. $191 \mathrm{f}$. Tese (Doutorado em Química Analítica) - Instituto de Química de São Carlos, Universidade de São Paulo, São Carlos, 2010.

ZERAIK, M. L.; PEREIRA, C. A. M.; ZUIN, V. G.; YARIWAKE, J. H. Maracujá: um alimento funcional? Revista Brasileira de Farmacognosia, v. 20, p. 459-471, 2010.

ZERAIK, M. L.; SERTEYN, D.; DEBY-DUPONT, G.; WAUTERS, J. N.; TITS, M.; YARIWAKE, J. H.; ANGENOT, L.; FRANCK, T. Evaluation of the antioxidant activity of passion fruit (Passiflora edulis and Passiflora alata) extracts on stimulated neutrophils and myeloperoxidase activity assays. Food Chemistry, v. 128, p. 259-265, 2011.

ZERAIK, M. L.; YARIWAKE, J. H. Quantification of isoorientin and total flavonoids in Passiflora edulis fruit pulp by HPLC-UV/DAD. Microchemical Journal, v. 96, p. 86-91, 2010.

ZUCOLOTTO, S. M. Estudo fitoquímico das folhas, frutos e raízes de Passiflora edulis. 2005. 129 f. Dissertação (Mestrado) - Centro de Ciências da Saúde, Universidade Federal de Santa Catarina, Florianópolis, 2005. 
"Tudo o que é seu, encontrará uma maneira de chegar até você." 